\title{
La poule et le coq dans les collections du Musée de l'Homme
}

\author{
Pauline Rameau, Delphine Brabant et Serge Bahuchet
}

\section{(2) OpenEdition}

1 Journals

\section{Édition électronique}

URL : http://journals.openedition.org/ethnoecologie/3388

DOI : $10.4000 /$ ethnoecologie.3388

ISSN : 2267-2419

\section{Éditeur}

Laboratoire Eco-anthropologie et Ethnobiologie

\section{Référence électronique}

Pauline Rameau, Delphine Brabant et Serge Bahuchet, « La poule et le coq dans les collections du Musée de l'Homme », Revue d'ethnoécologie [En ligne], 12 | 2017, mis en ligne le 18 décembre 2017, consulté le 19 avril 2019. URL : http://journals.openedition.org/ethnoecologie/3388 ; DOI : 10.4000/ ethnoecologie.3388

\section{Ce document a été généré automatiquement le 19 avril 2019}

Revue d'ethnoécologie est mis à disposition selon les termes de la licence Creative Commons Attribution - Pas d'Utilisation Commerciale - Pas de Modification 4.0 International. 


\title{
La poule et le coq dans les collections du Musée de l'Homme
}

\author{
Pauline Rameau, Delphine Brabant et Serge Bahuchet
}

\section{Introduction}

1 La parution du numéro collectif consacré à la poule (Revue d'Ethnoécologie 12 | 2017) est pour nous l'occasion de faire connaître les objets concernant cet oiseau dans les collections du Musée de l'Homme.

2 Les collections d'anthropologie culturelle du Muséum national d'Histoire naturelle, conservées au Musée de l'Homme, résultent de l'histoire des laboratoires et équipes de recherche successives. Ces collections sont actuellement divisées en trois entités, avec chacune leur catalogage propre : l'ethnologie, l'ethnobiologie et l'anthropologie médicale. Notre programme de travail consiste à harmoniser ces ensembles pour in fine, les réunir, et ce premier catalogue commun est une étape en ce sens.

3 L'ensemble d'ethnologie est issu de l'ancien laboratoire d'ethnologie ${ }^{1}$. Les objets sont inventoriés sous le " préfixe » MNHN-E. ; une partie d'entre eux est inscrite au patrimoine au terme de la loi relative aux musées de France. Il comporte environ 4000 objets.

4 L'ensemble d'ethnobiologie résulte des recherches de l'ancien laboratoire d'ethnobiologie-biogéographie, puis de celles de l'Unité mixte de recherche écoanthropologie et ethnobiologie. L'inventaire est indexé ETB. Les origines de cette collection remontent aux activités de Raymond Pujol, professeur d'ethnozoologie dans ce laboratoire, dès les années 60 , poursuivies sous l'impulsion de Serge Bahuchet, professeur d'ethnobiologie du MNHN à partir de 1999. Il s'agit d'une "collection d'étude ", au sens du règlement des collections du $\mathrm{MNHN}$, d'environ 3800 objets.

5 L'ensemble d'anthropologie médicale a été entrepris dans les mêmes laboratoires, par Alain Epelboin, chargé de recherche au CNRS. Les objets sont enregistrés sous le sigle ALEP. Il s'agit là aussi d'une collection d'étude, comptant plus de 5000 objets. 


\section{La collection}

6 Notre modeste collection d'objets contemporains concernant la poule et le coq s'étale dans le temps, puisque l'objet le plus anciennement collecté l'a été au milieu du $\mathrm{xx}^{\mathrm{e}}$ siècle et les plus récents au mois d'octobre 2017, et dans l'espace en couvrant 25 pays sur cinq continents, Afrique, Amérique, Asie, Europe et Océanie.

7 La diversité de ces 87 objets nous permet d'illustrer l'ensemble des manières qu'a l'humanité d'utiliser Gallus gallus, couvrant ainsi les aspects zootechniques, alimentaires, décoratifs, ludiques, rituels, religieux et esthétiques.

8 L'ordre choisi pour cataloguer les objets est celui des techniques, des plus matérielles aux plus spirituelles : élevage ; utilisation alimentaire, utilisation des œufs (œufs de Pâques), des plumes (accessoires domestiques, ornements corporels, décors d'objets); jeux (les combats de coqs); usages rituels (offrandes, amulettes d'Afrique occidentale, amulettes du zodiaque asiatique) ; représentations esthétiques (motifs zoomorphes).

Chaque objet est présenté sous forme d'une fiche, accompagnée d'une photographie, comportant les éléments suivants :

Nom de l'objet

Nom de l'ethnie. Localisation : pays, village, région (département). Lieu d'achat.

Description, usage, matières.

Date de collecte ; nom du collecteur.

Dimensions : hauteur $\mathrm{x}$ longueur $\mathrm{x}$ largeur, diamètre, profondeur, en centimètres.

Numéro d'inventaire : dans la collection d'ethnobiologie (ETB-code Iso pays-initiales du collecteur-année- $n^{\circ}$ objet); dans la collection d'ethnologie (MNHN-E-année-collection-n objet) ; dans la collection d'anthropologie médicale (ALEP- $n^{\circ}$ objet).

\section{Élevage}

10 1- Cillères, lunette aveuglante pour poule pondeuse 


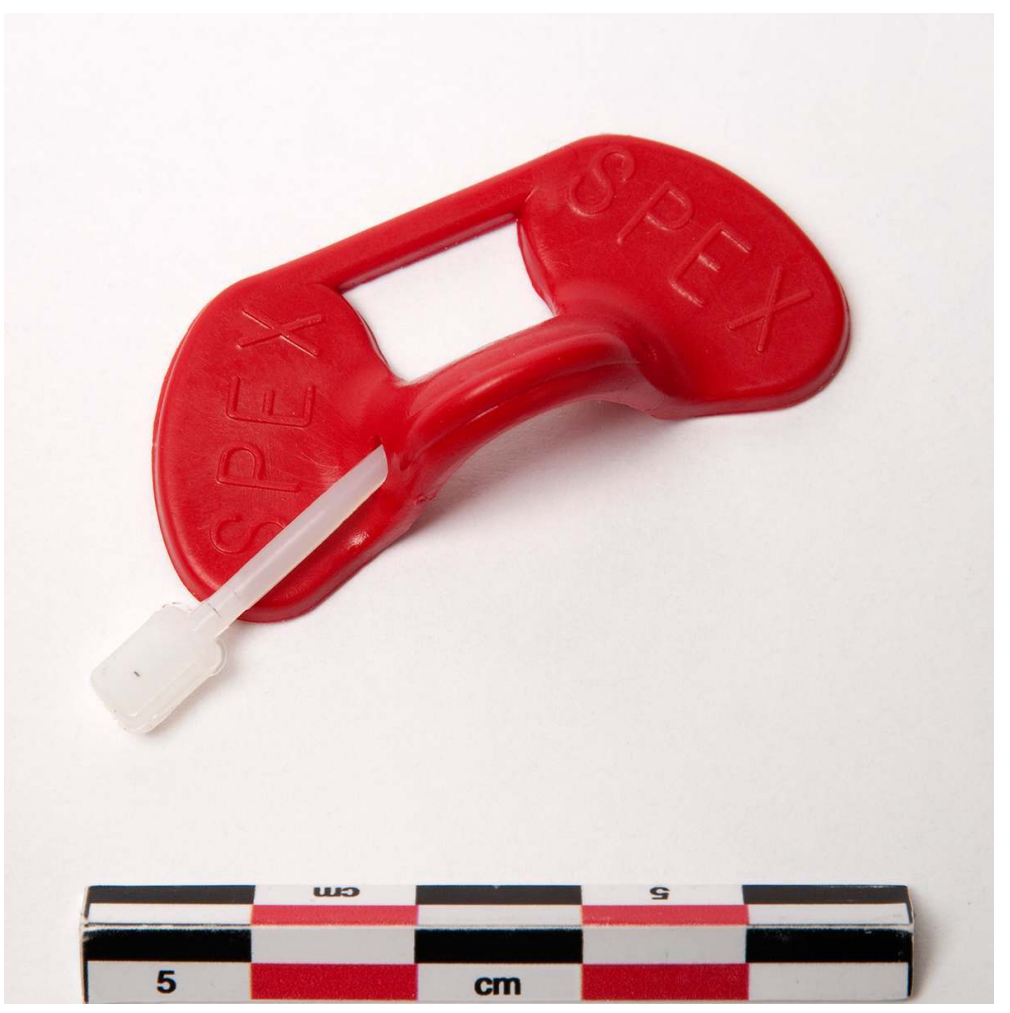

(C) J.-C. Domenech

11 Mexique. Autlán (Jalisco).

Outil en plastique qui se place sur le bec de la poule; il est maintenu en place par une tige de plastique blanc passant au travers des narines. Il diminue son champ de vision pour éviter que la poule ne perce ses propres œufs et ne blesse ses congénères. Marque SPEX. 20 avril 2010 ; collecteur Serge Bahuchet longueur $2 \mathrm{~cm}$ x largeur $4,5 \mathrm{~cm}$ ETB-MX-SB-2010A-032

\section{Transport, gardiennage et reproduction}

12 Pour la plupart, ces paniers servent à enfermer les poules la nuit pour les protéger des prédateurs (chiens, chats, mangoustes, voire cobras), soit en les rentrant dans la maison, soit en les plaçant en hauteur. Ils serviront de pondoir un jour ou l'autre, et également pour transporter les volailles lorsqu'on veut les vendre au marché.

2- Panier à poule, cage à volaille 


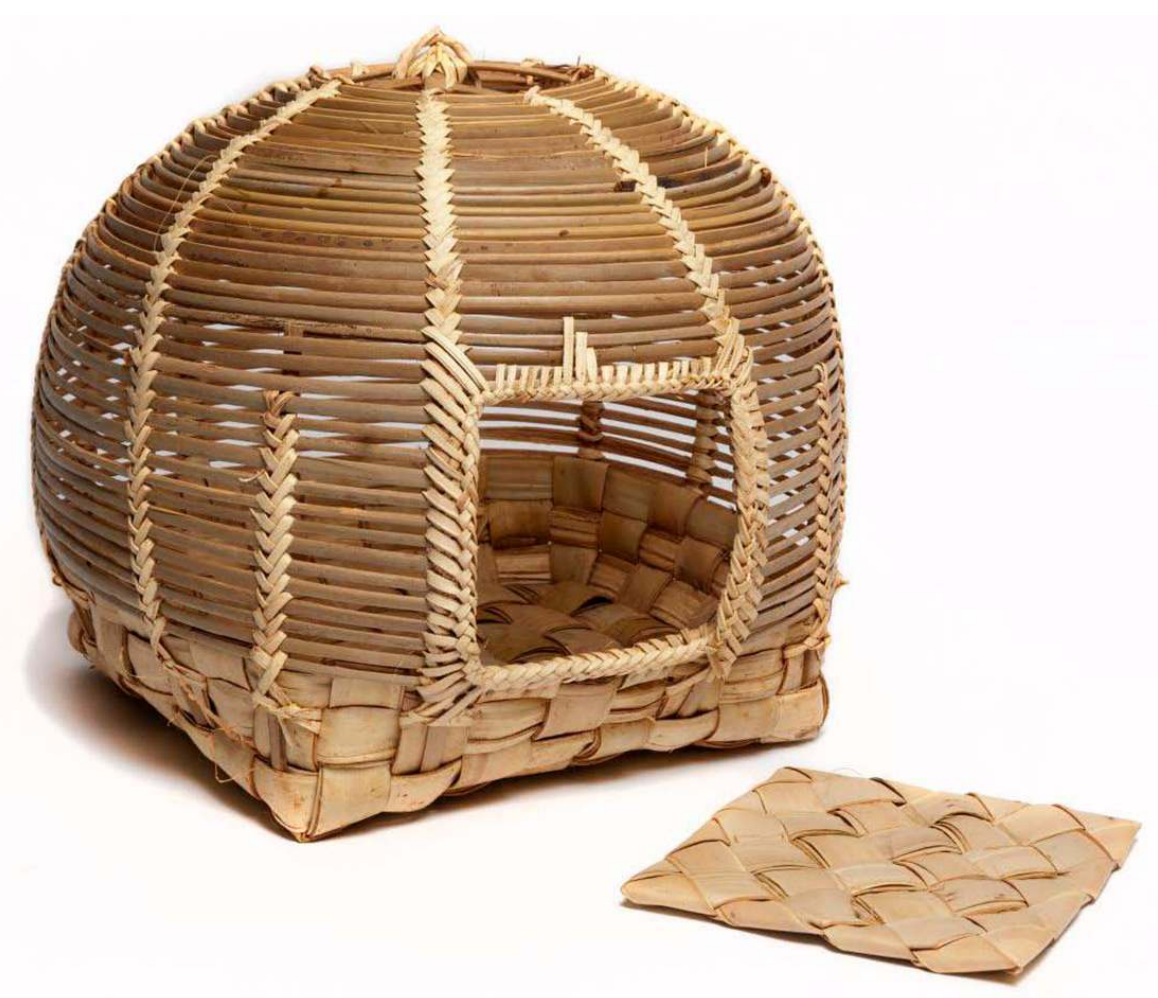

() J.-C. Domenech

Ethnie sème (siamou). Burkina Faso. Village de Bandougou (région de la ville d'Orodara, province de Kenedougou)

Cage à volaille neuve avec cloison de fermeture. Conçue pour transporter des volailles ou abriter les plus fragiles. La base de la cage, à fond carré, de type natte, est tressée en feuilles de rônier Borassus flabellifer. La cage est une vannerie spiralée en rachis de feuilles de Raphia sudanica, nouée par des liens en feuilles de rônier. Au sommet, un nœud en feuilles de Borassus relie les quatre arcs et comporte un anneau de préhension. La porte de fermeture amovible est faite en feuilles de rônier Borassus flabellifer; sur la figure 2 elle est posée devant la cage.

2011 ; collectrice Anne Fournier, offert à celle-ci par son guide-interprète M. Souleymane Traoré.

hauteur $33 \mathrm{~cm}$, base $26 \times 26 \mathrm{~cm}$, diamètre $38 \mathrm{~cm}$

MNHN-E-2011.12.2(1, 2) 
Figure 3 : Les paniers à poule dans un village de la région d'Orodara, 2011 (Burkina Faso)

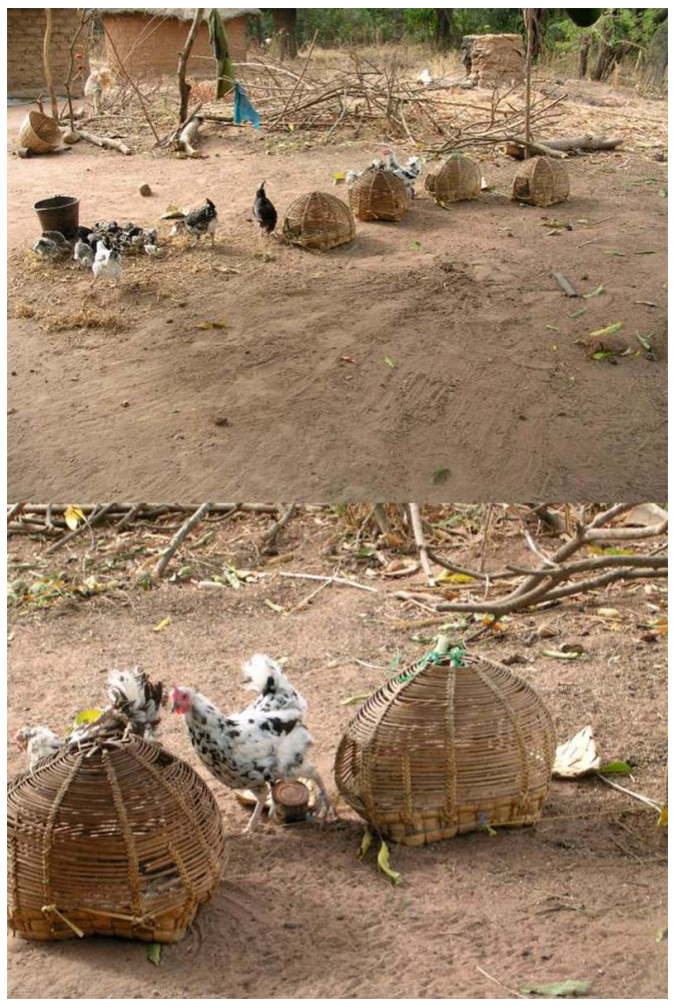

Les volailles sont gardées la nuit dans ces paniers qui sont rentrés dans une maison. Le matin la grand-mère les sort et les nourrit

(c) A. Fournier

15 3- Panier à poule, cage à volaille 
Figure 4 : Panier à poule MNHN-E-2013.1.43

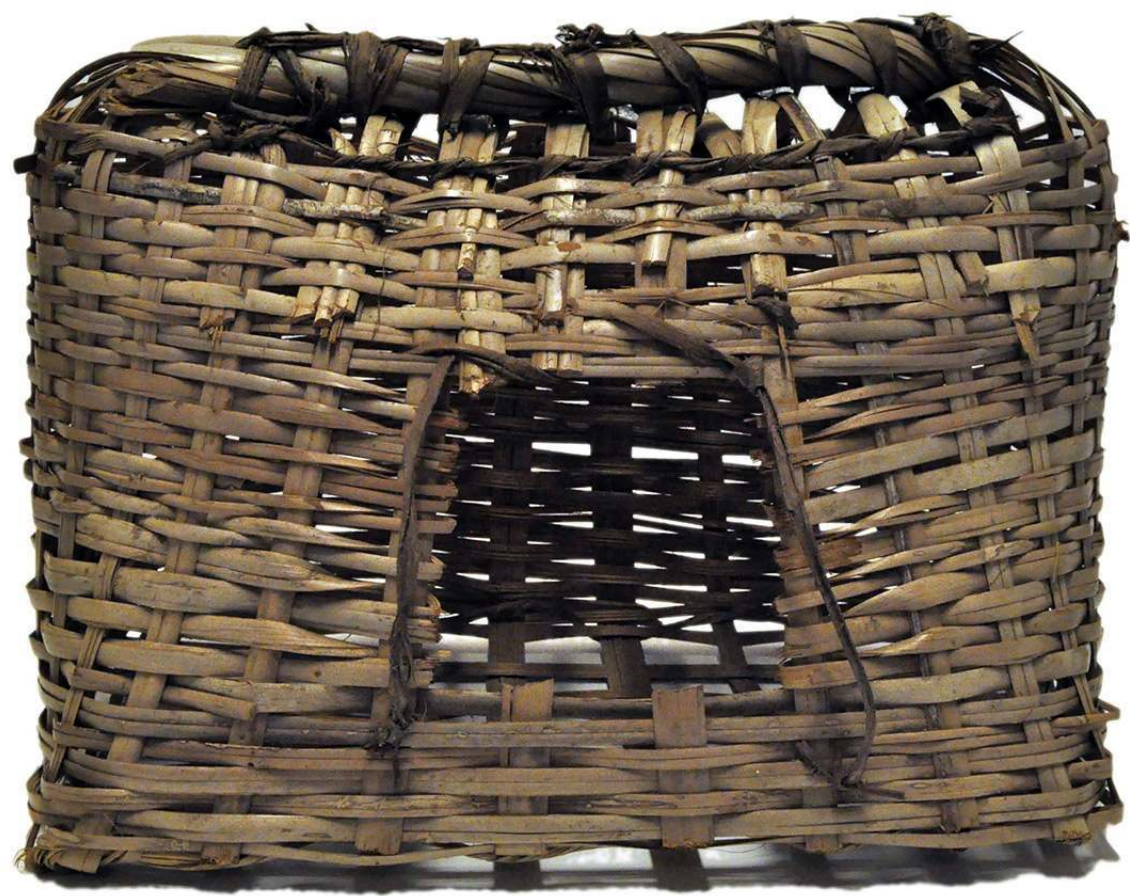

(c) D. Brabant

16

Libéria.

Cage à poule en tiges tressées de Marantacées, pour le transport de la volaille vivante destinée au marché.

2013 ; collecteur Carlo de' Reguardati

longueur $46 \mathrm{~cm}$ x largeur $35 \mathrm{~cm}$ x hauteur $32 \mathrm{~cm}$

MNHN-E-2013.1.43 
Figure 5 : Panier à poule au village. On distingue la poule qui couve, au fond du panier

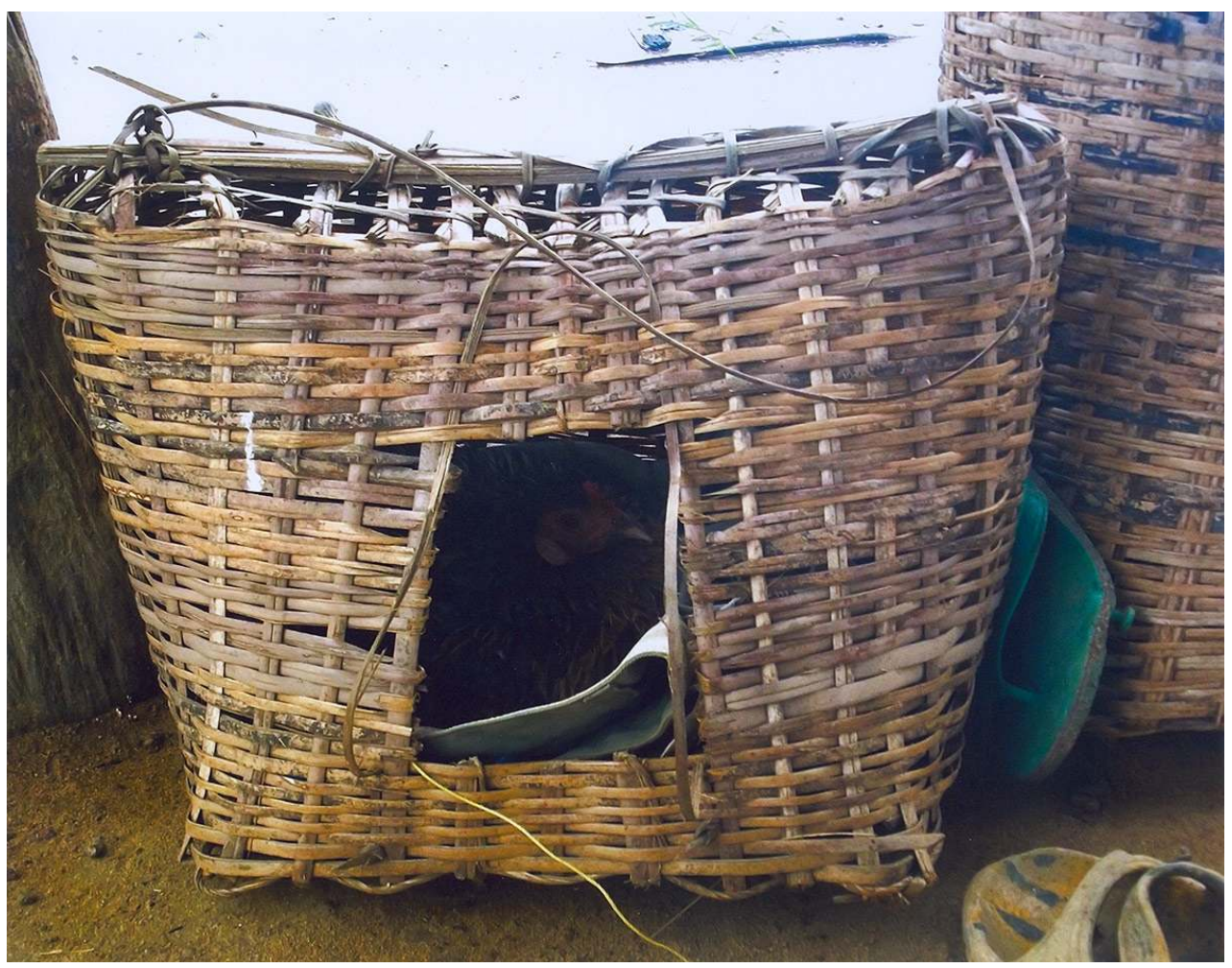

(C) C. de' Reguardati

4- Panier à poule, cage à volaille

Figure 6 : Panier à poule MNHN-E-2014.9.6 


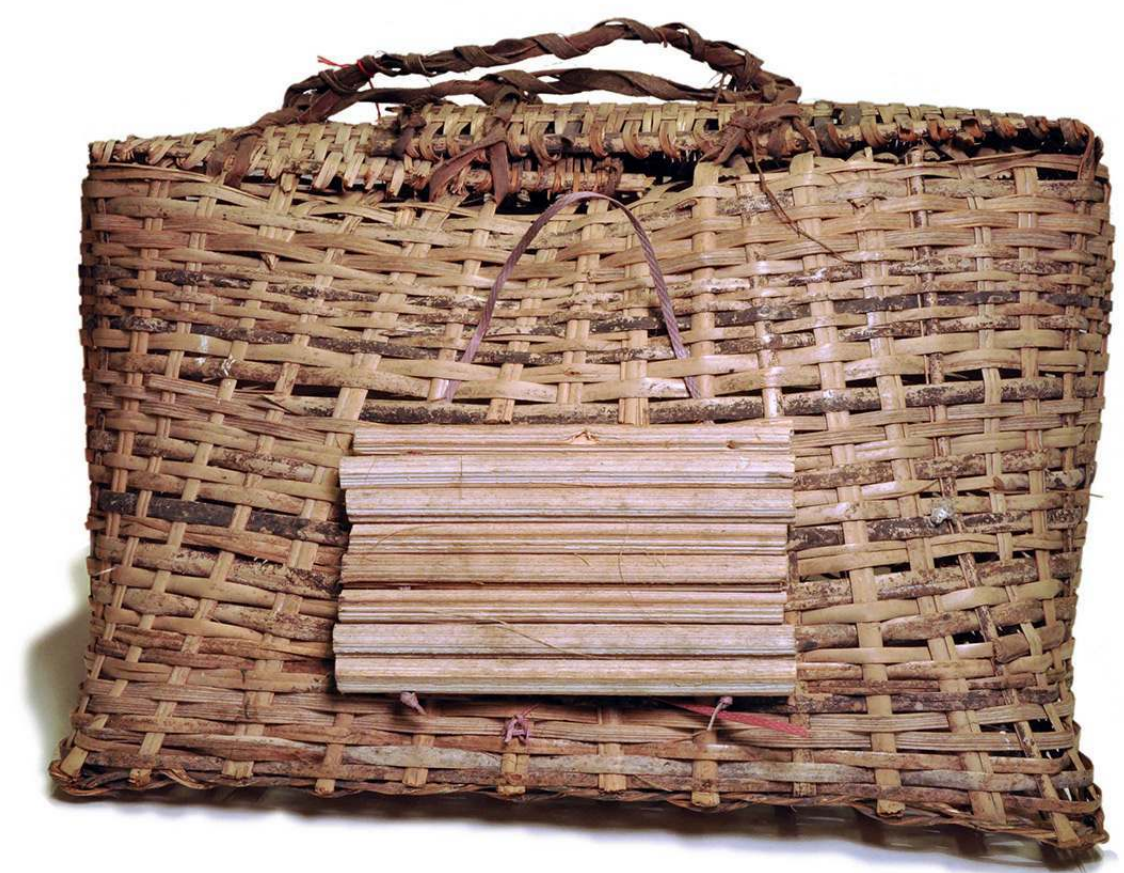

(C) D. Brabant

18 Libéria. Marché de Salala.

Cage à poule en tiges tressées de Marantacées, pour le transport de la volaille vivante destinée au marché. Elle est surmontée d'une poignée en écorces de liane torsadées, et fermée par une portière en moelle de Raphia.

Novembre 2013 ; collecteur Carlo de' Reguardati

hauteur $32 \mathrm{~cm}$ x largeur $46 \mathrm{~cm}$, profondeur $36 \mathrm{~cm}$

MNHN-E-2014.9.6

19 5- Panier à poule, cage à volaille 
Figure 7 : Panier à poule ETB-GN-RP-2017-001

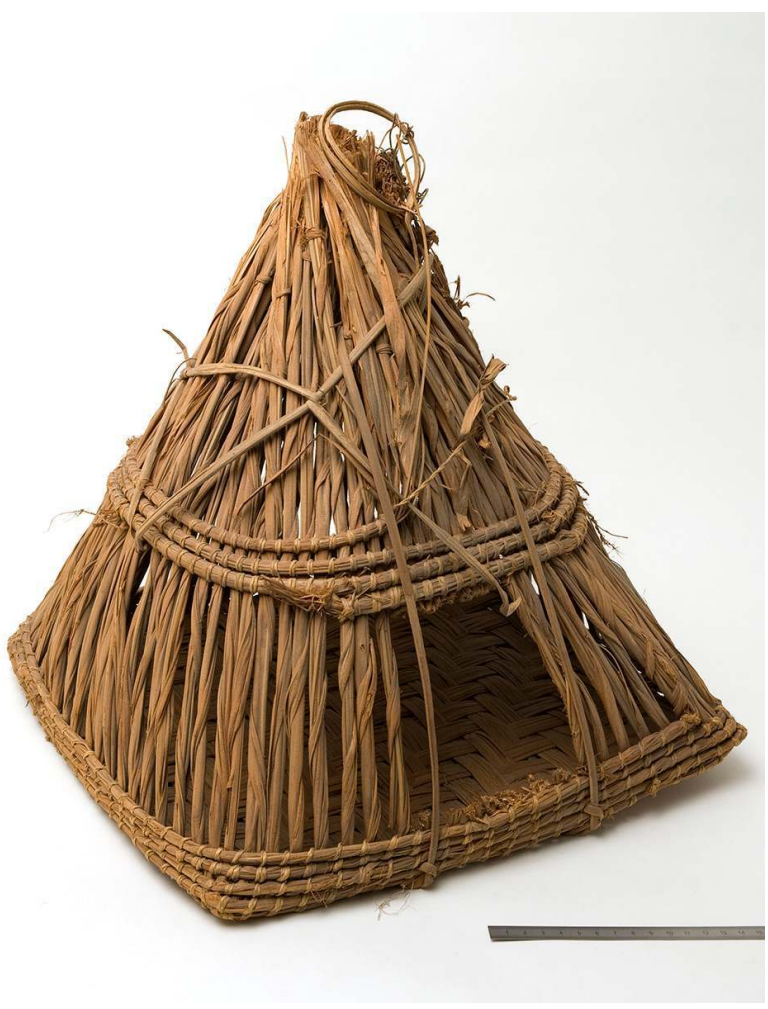

(c) J.-C. Domenech

arestière. Régions de Kissidougou, Guéckédou, Nzérékoré

Cage à poule en fibres de Raphia torsadées. Le fond est une natte en tiges de Marantacées (deux brins pris, deux sautés). On y entre les poules le soir, pour les protéger, et pour qu'elles y pondent. La porte manque.

1949-1953 ; collecteur Raymond Pujol

hauteur $28 \mathrm{~cm}$, diamètre $25 \mathrm{~cm}$; base parallélépipédique $23 \times 21 \mathrm{~cm}$.

ETB-GN-RP-2017-001 


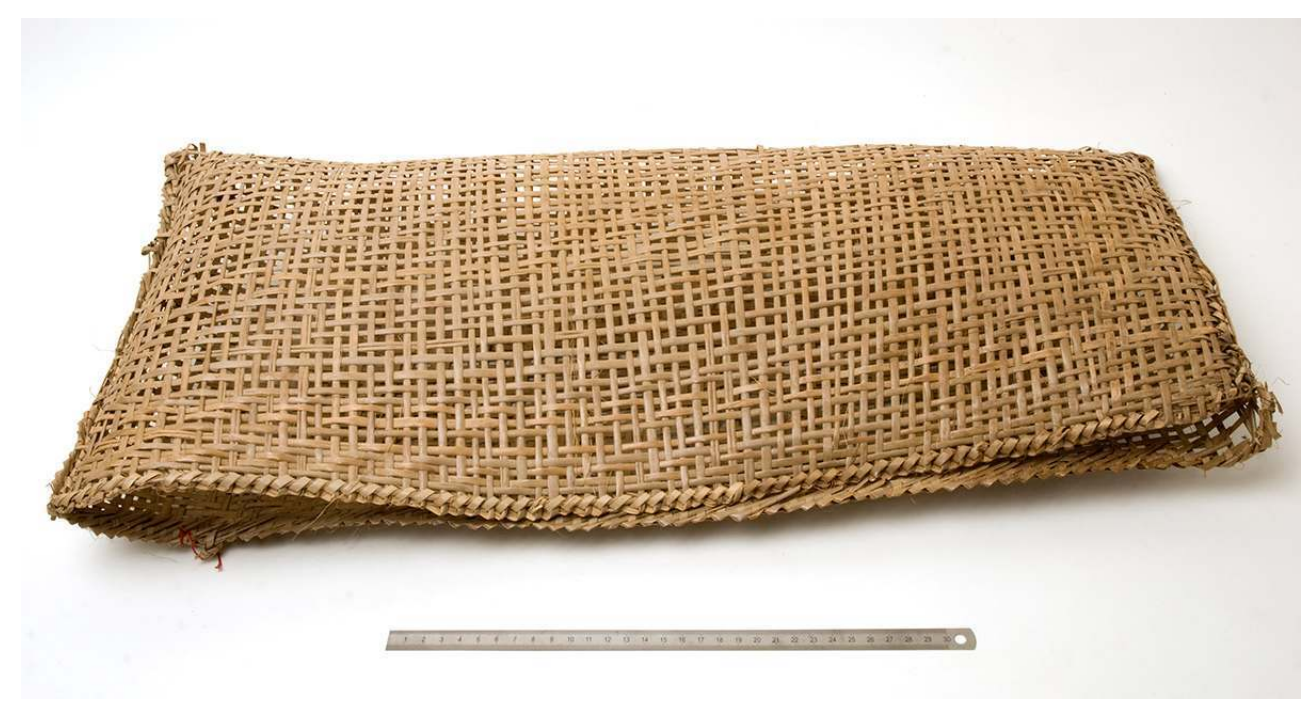

(C) J.-C. Domenech

Ethnie bongo. Gabon, village Makoula (Ogooué-Lolo).

Pour transporter les marchandises. Cette forme, simple natte lâche repliée et cousue sur les côtés, est d'usage général dans toutes les communautés du Gabon, pour toutes sortes de transports de marchandises, y compris pour les poules vivantes destinées au marché. Il sert également à filtrer l'eau dans les barrages sur les rivières, puis à transporter les petits poissons. En lamelles de Marantacées.

Février 2007 ; collectrice Marine Robillard

longueur $31 \mathrm{~cm}$ x largeur $67 \mathrm{~cm}$

ETB-GA-MR-2007-001

(Bahuchet et Rameau 2016 : § 37 catalogue pêche : « n 17 panier filtrant simple ».)

23 7- Pondoir-nichoir du Cambodge 


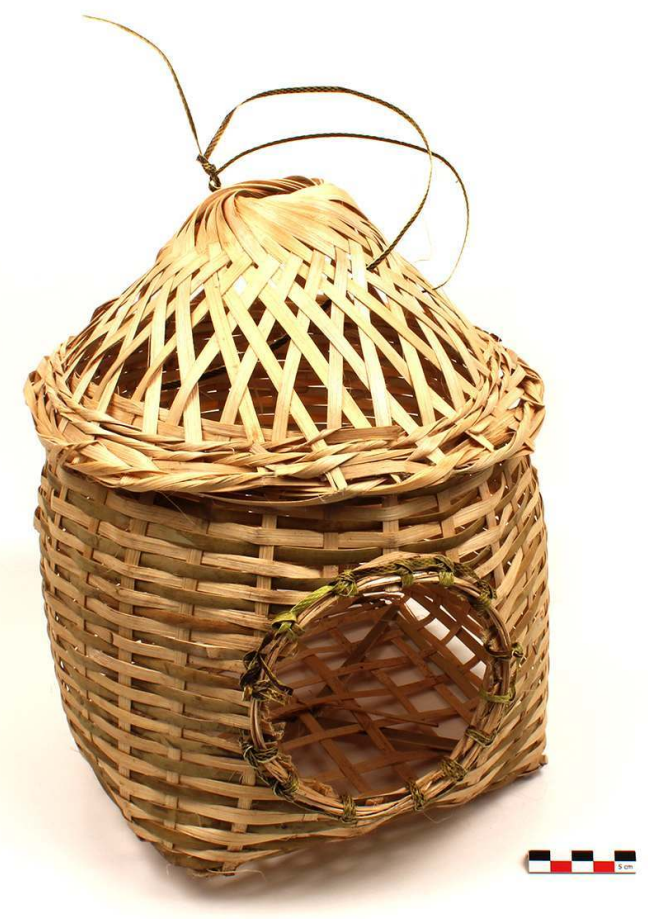

(c) P. Rameau

Ethnie brou. Cambodge. Province du Ratanakiri.

Cage à poule, en bambou. Un brin de plastique entoure l'ouverture. Elle sert de pondoir. La cage peut être simplement posée, ou mise en hauteur au bout d'un bâton en bois, enfoncé dans le trou au sommet de la cage, la partie plate de la cage étant ainsi le toit de la cage. Dans les villages avec des maisons sur pilotis, « les volailles ont leur place sous la maison, où des cages en vannerie, soigneusement tressées, sont suspendues. » (MatrasTroubetzkoy 1983 : 395)

17 décembre 2015 ; collectrice Bérénice Alard

hauteur $28 \mathrm{~cm}$, diamètre $25 \mathrm{~cm}$, base carrée $23 \mathrm{~cm} \times 21 \mathrm{~cm}$.

ETB-KH-BA-2015-001 
Figure 10 : Les pondoirs au village, décembre 2015

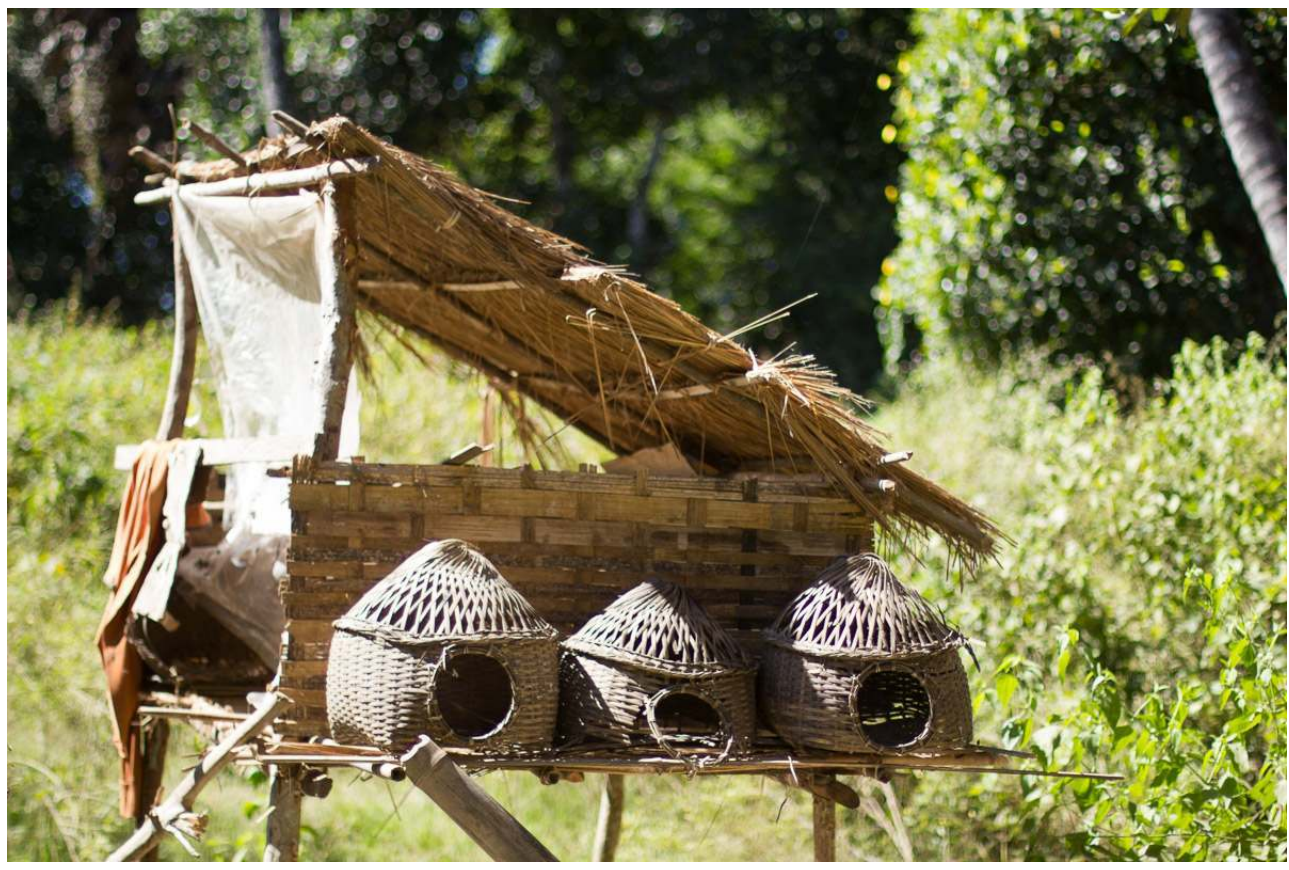

(c) B. Alard

Figure 11 : Schéma d'une maison brou montrant un panier à poule

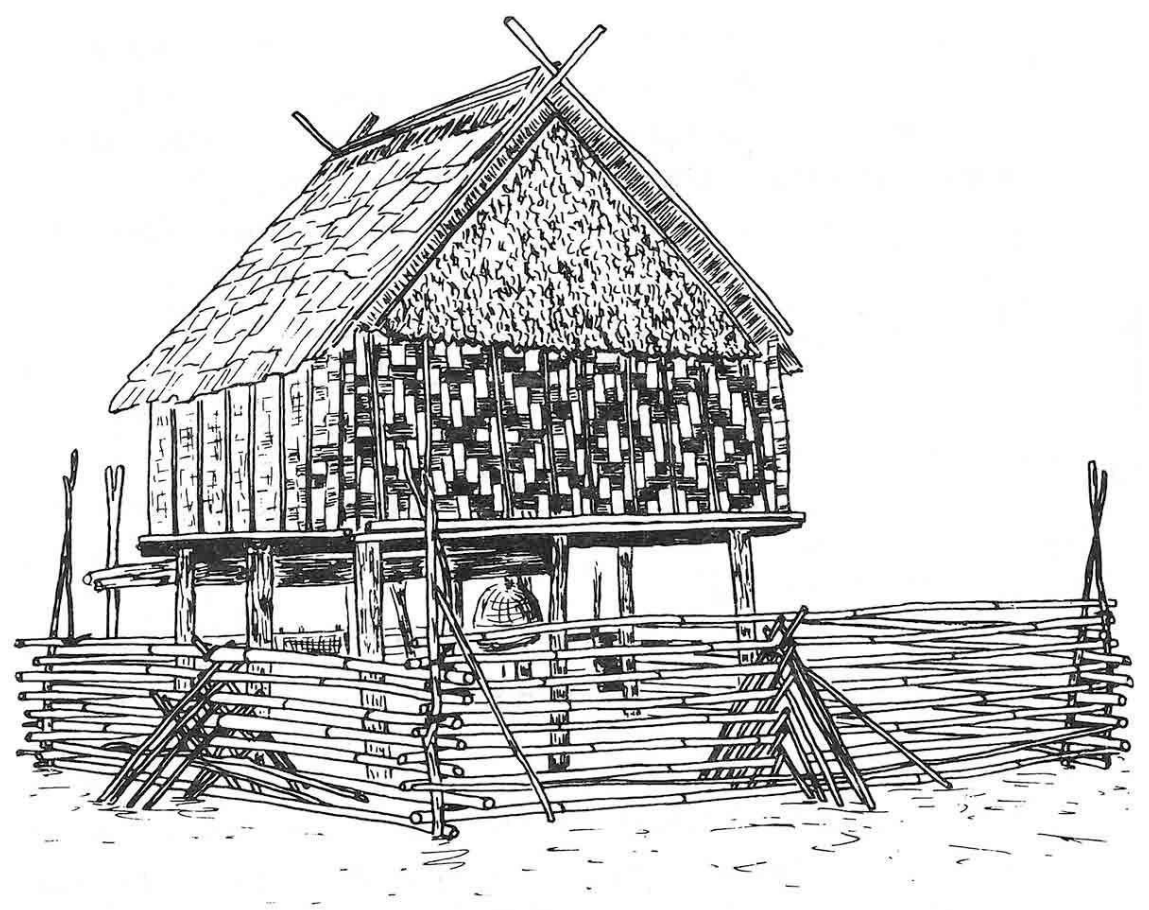

Fig. 55. Sous une petite maison, l'enclos des porcs.

D'après Matras-Troubetzkoy 1983 : 394, fig. 55 


\section{Utilisations}

\section{L'alimentation}

8- Pince à épiler les poulets

Figure 12 : Pince ETB-FR-SB-2007-001

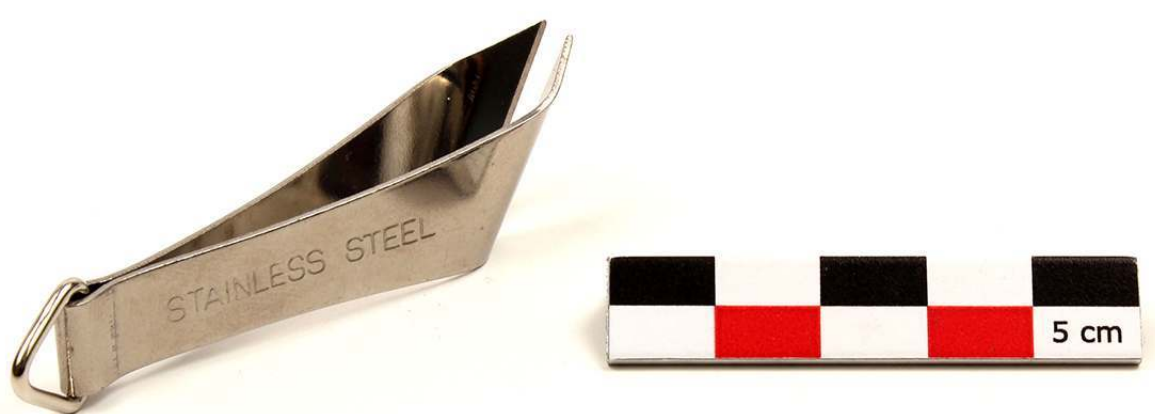

(c) P. Rameau

Japon. Achat à Paris.

Pour épiler les poulets avant rôtissage, une fois qu'ils ont été plumés. Acier inoxydable. 25 décembre 2007 ; collecteur Serge Bahuchet longueur $7 \mathrm{~cm}$ x largeur $2,5 \mathrm{~cm}$ ETB-FR-SB-2007-001

9- Fouet à œuf roumain 


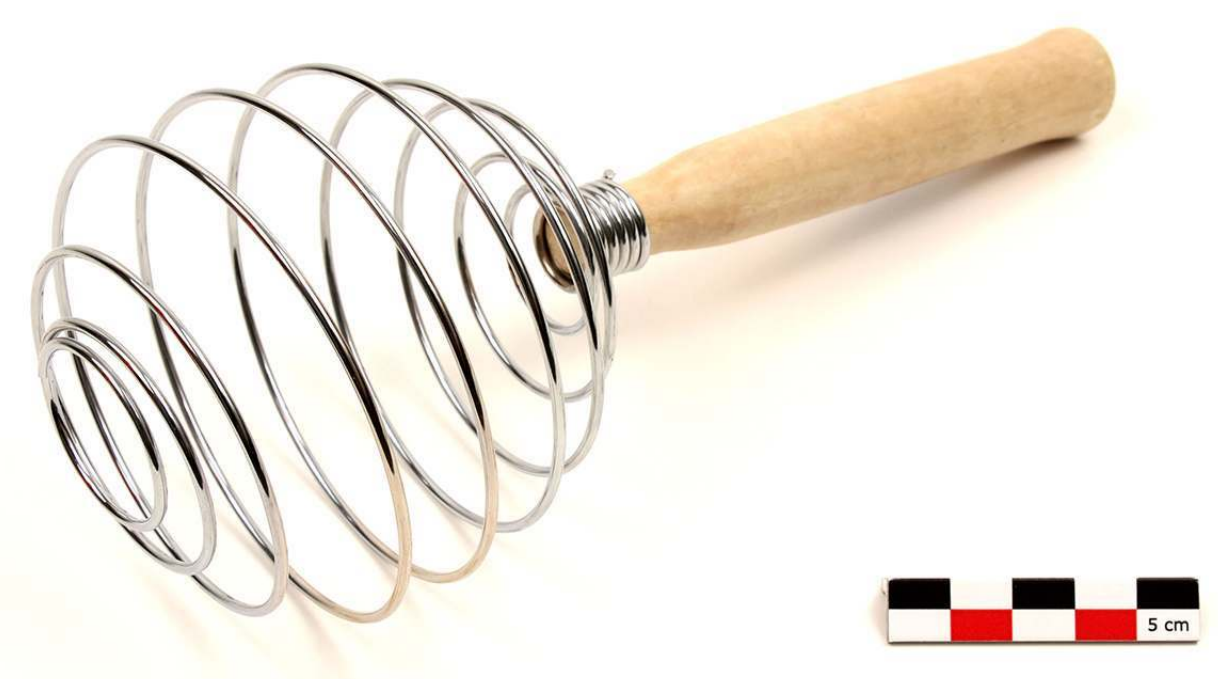

(c) P. Rameau

Roumanie. Miercurea Ciuc (Transylvanie). Achat en supermarché.

Fouet pour battre les œufs en neige, pour la pâtisserie. S'utilise verticalement, par un mouvement de haut en bas, en bénéficiant de l'effet de ressort. Batador para mare «batteur (en forme de) grande poire».

Janvier 2015 ; collectrice Pauline Laval

longueur $23 \mathrm{~cm}$, diamètre $9 \mathrm{~cm}$

ETB-RO-PL-2015-001

Trois représentations de plats pour les offrandes de la fête des morts (Mexique) : voir §

37.

\section{L'œuf}

Par sa forme et sa fonction biologique, l'œuf de poule est un symbole quasi-universel de la naissance du monde et du renouvellement cyclique de la nature. Il s'est ainsi inscrit dans les rites accompagnant la fête de Pâques dans le monde chrétien. "Dans les pays orthodoxes, les souhaits au sortir de la messe de Pâques et les échanges d'œufs bénits sont chaleureux : " Christ est ressuscité ! ", " Il est vraiment ressuscité! " (Cretin 1999: 35)».

31 En Europe de l'Est, tout particulièrement en Russie, Ukraine, Roumanie, Hongrie..., les œufs de Pâques sont de délicates œuvres finement teintes à la réserve de cire, que l'on offre et que l'on garde. Les motifs sont tracés à la cire d'abeille fondue, à l'aide d'un stylet ou d'un petit cône percé, puis, une fois la cire sèche, la coquille est plongée pendant une demi-heure dans un bain de colorant. Une fois sortie et séchée, on la chauffe doucement 
pour essuyer la cire fondante avec un chiffon. Ensuite, on passe une deuxième couche de cire sur les parties teintes que l'on veut garder, et on plonge l'œuf dans un second bain coloré. Et ainsi de suite selon le nombre de couleurs que l'on souhaite superposer (Newall 1965).

10- Sept œufs de Pâques

Figure 14 : Fufs de Pâques

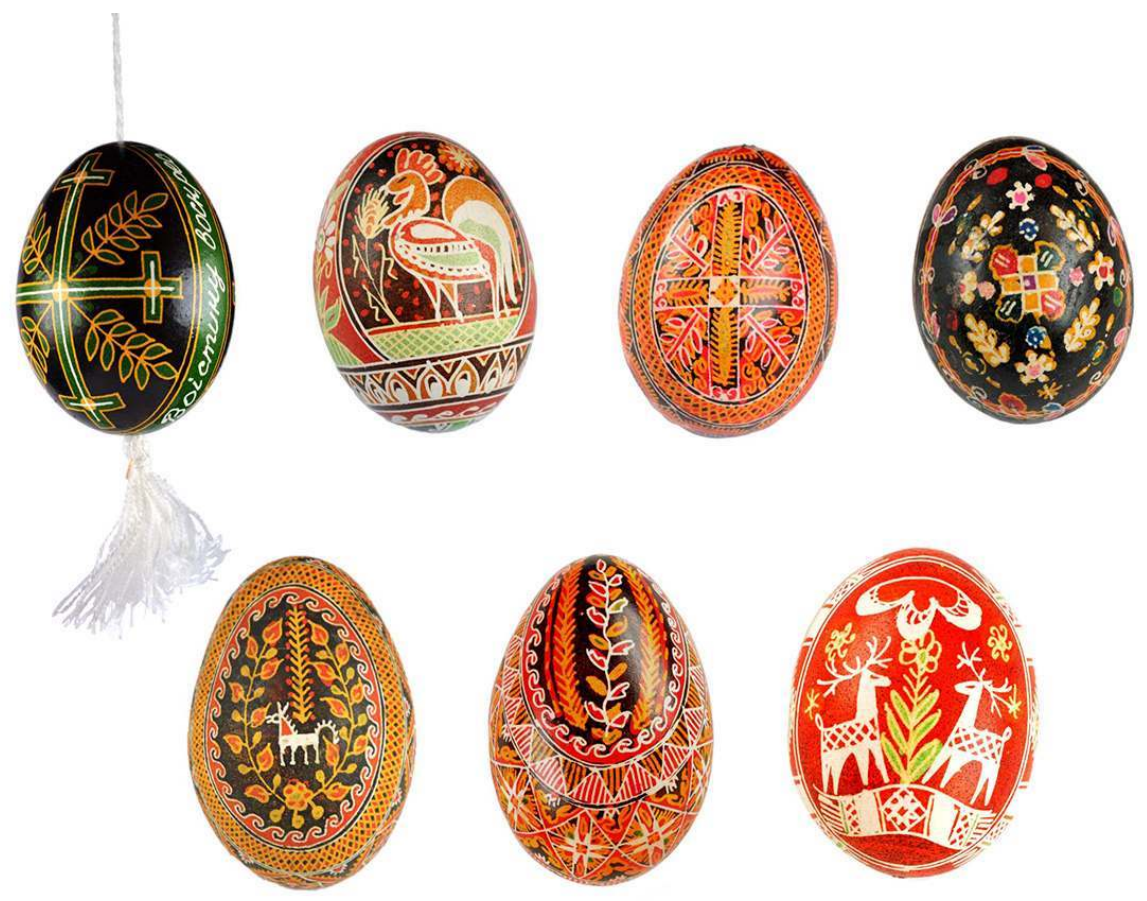

(C) D. Brabant

Ukraine. Kiev, marché artisanal.

CEufs de poule évidés et peints pysanka (dérivé du verbe signifiant «écrire »). Cuufs de Pâques, cadeau démontrant un véritable geste d'amitié et d'amour. Traditionnellement l'œuf offert apportait le bonheur, la santé, la prospérité et la protection.

1980, 2000, 2013, 2014 ; collectrice Tatiana Fougal

Longueur $5 \mathrm{~cm}$ x largeur $4 \mathrm{~cm}$

MNHN-E-2013.15.7 (exposé dans la galerie permanente du Musée de l'Homme) [5 couleurs superposées]

MNHN-E-2013.15.8 (exposé dans la galerie permanente du Musée de l'Homme) [4 couleurs superposées]

MNHN-E-2013.15.9 (exposé dans la galerie permanente du Musée de l'Homme) [5 couleurs superposées]

MNHN-E-2013.15.10 [3 couleurs superposées]

MNHN-E-2013.15.11 [4 couleurs superposées]

MNHN-E-2013.15.12 [4 couleurs superposées]

MNHN-E-2014.8.13 (exposé dans la galerie permanente du Musée de l'Homme) [3 couleurs superposées]

11- CEuf de Pâques 


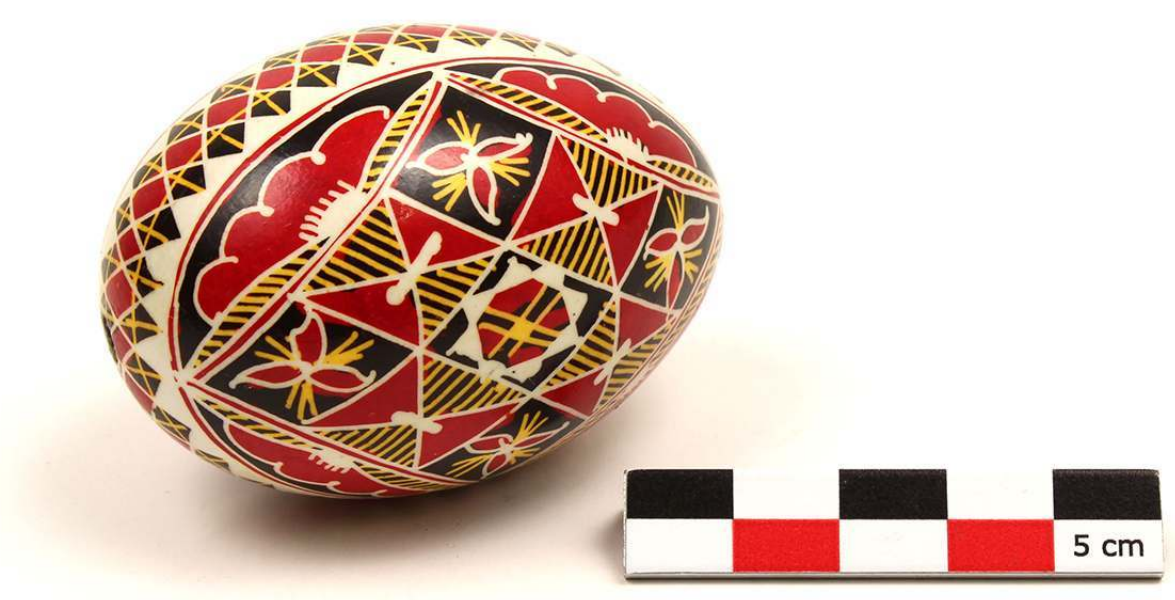

(c) P. Rameau

\section{Cuf évidé, teint de trois couches superposées. Ouă roșü de Paști}

Janvier 2015 ; collectrice Pauline Laval

longueur $7 \mathrm{~cm}$ x largeur $4,5 \mathrm{~cm}$

ETB-RO-PL-2015-002

\section{La plume}

Les plumes peuvent avoir des emplois techniques et prosaïques, ou bien ornementaux. Les plumes des poules, déchets de la préparation alimentaire, peuvent être employées pour du rembourrage domestique.

Pour les usages techniques (plumeaux) ou ornementaux, ce sont les plumes des coqs qui sont particulièrement propices, celles de la queue, longues et souples, ou du cou et du croupion, longues et étroites.

\section{Accessoires en plumes}

Les petites plumes résultant du plumage des volailles sont employées en literie pour rembourrer coussins ou oreillers (cf. Lacroix-Danliard $1891: 331$ ).

\section{Rembourrage}

12- Taie d'oreiller brodée 


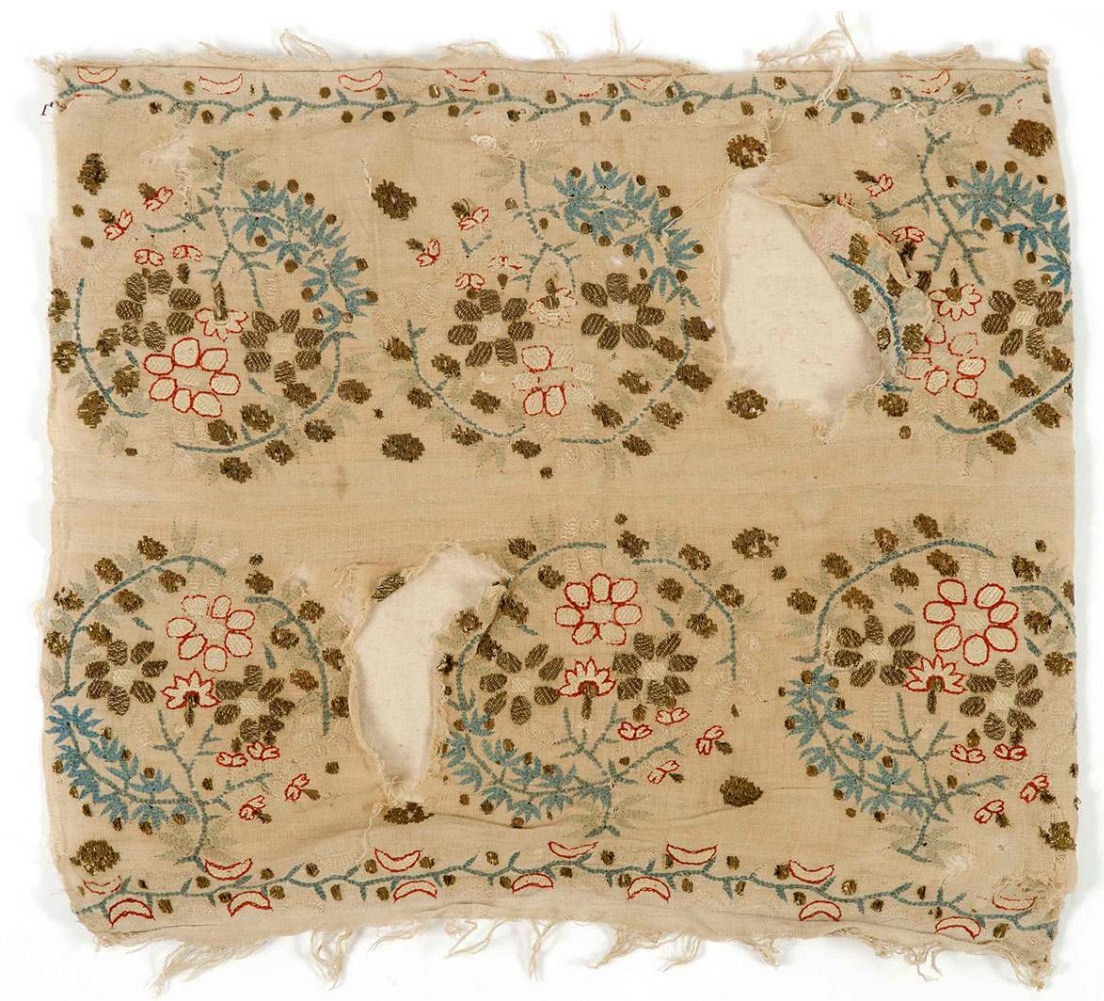

\section{(C) J.-C. Domenech}

Ex-Yougoslavie ou Roumanie.

Linge de maison. Taie d'oreiller de forme rectangulaire cousue pour une face avec un fragment de serviette en toile de coton et pour l'autre, avec une toile de coton au tissage plus resserré; couture sur trois côtés. Le fragment de serviette est composé de deux morceaux rectangulaires cousus ensembles, la couture étant renforcée par un ourlet. Décor de fils de coton perlé bleu, de fils de soie rouge et blanc et de lames métalliques, composé de six motifs floraux identiques bordés par une frise. Restes de plumes et de duvet à l'intérieur de la taie d'oreiller.

Années 60-70 ; collecteur Frank Wohlfahrt

largeur 44,5 cm x longueur $38,5 \mathrm{~cm}$

MNHN-E-2011.10.25

\section{Entretien de la maison}

41

Ce sont généralement les plumes du cou des coqs qui sont employées pour fabriquer des plumeaux.

13- Plumeau 
Figure 17 : Plumeau ETB-MX-SB-2012-041

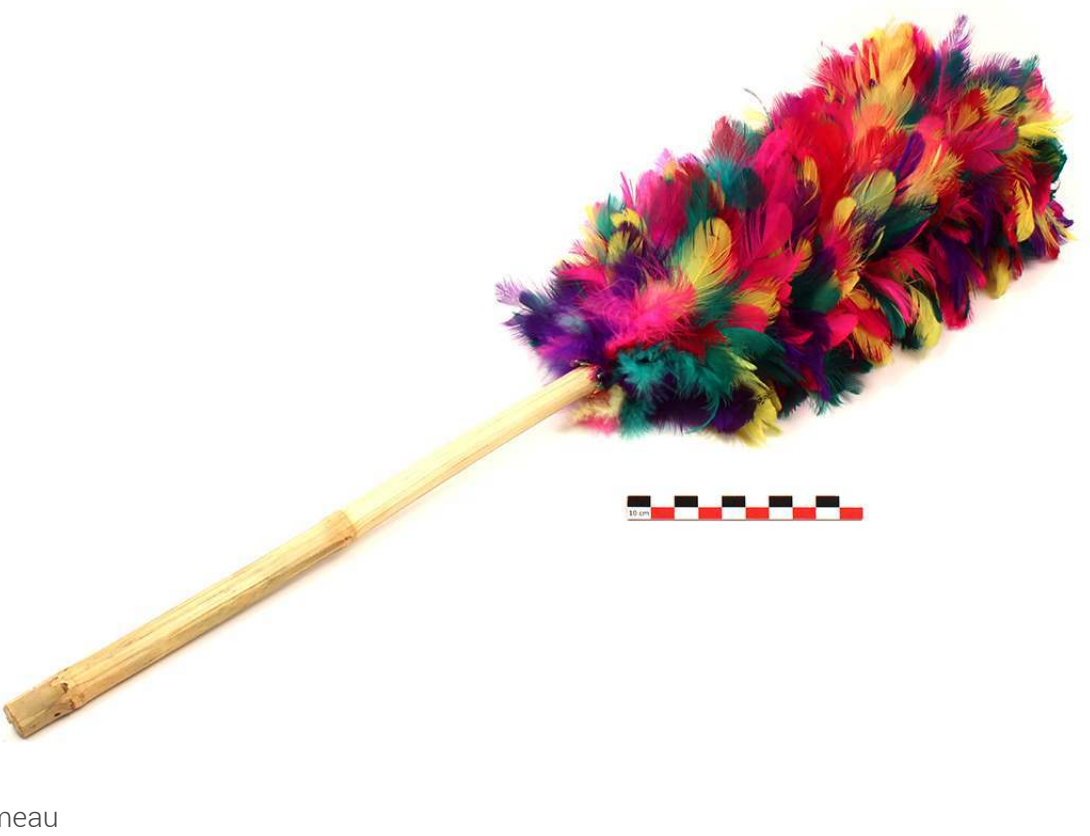

43 Mexique. Guadalajara, Jalisco, marché San Juan de Dios.

Plumero; balai à poussière en plumes de coq, multicolores et teintes, sur armature de bambou otate.

Avril 2012 ; collecteur Serge Bahuchet

longueur $67 \mathrm{~cm}$ x largeur $16 \mathrm{~cm}$

ETB-MX-SB-2012-041

44 14- Plumeau 
Figure 18 : Plumeau ETB-MX-SB-2012-042

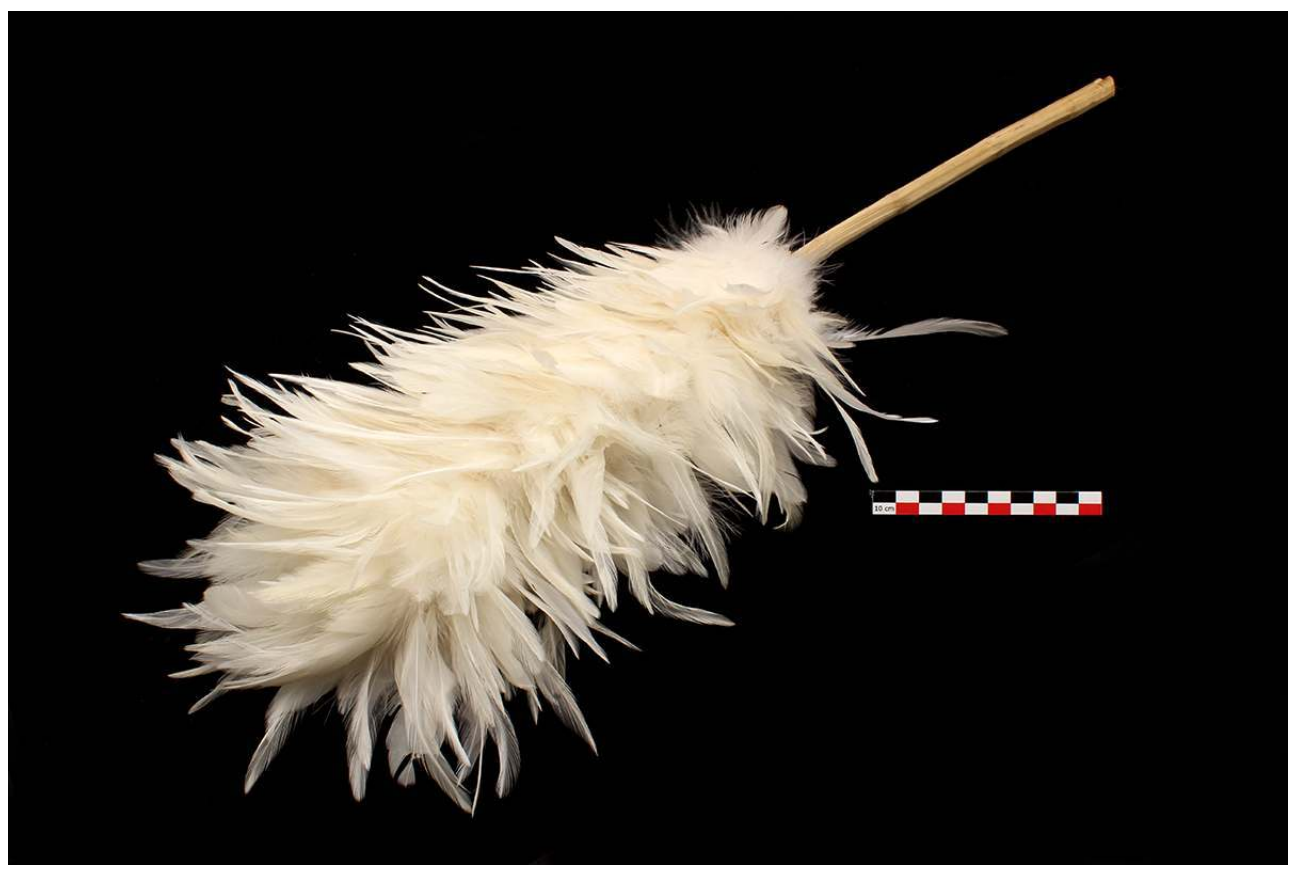

(C) P. Rameau

Mexique. Guadalajara, Jalisco, marché San Juan de Dios.

Plumero; balai à poussière en plumes de coq blanches, sur armature de bambou otate. Avril 2012 ; collecteur Serge Bahuchet longueur $63 \mathrm{~cm}$ x largeur $25 \mathrm{~cm}$ ETB-MX-SB-2012-042

15- Plumeau 


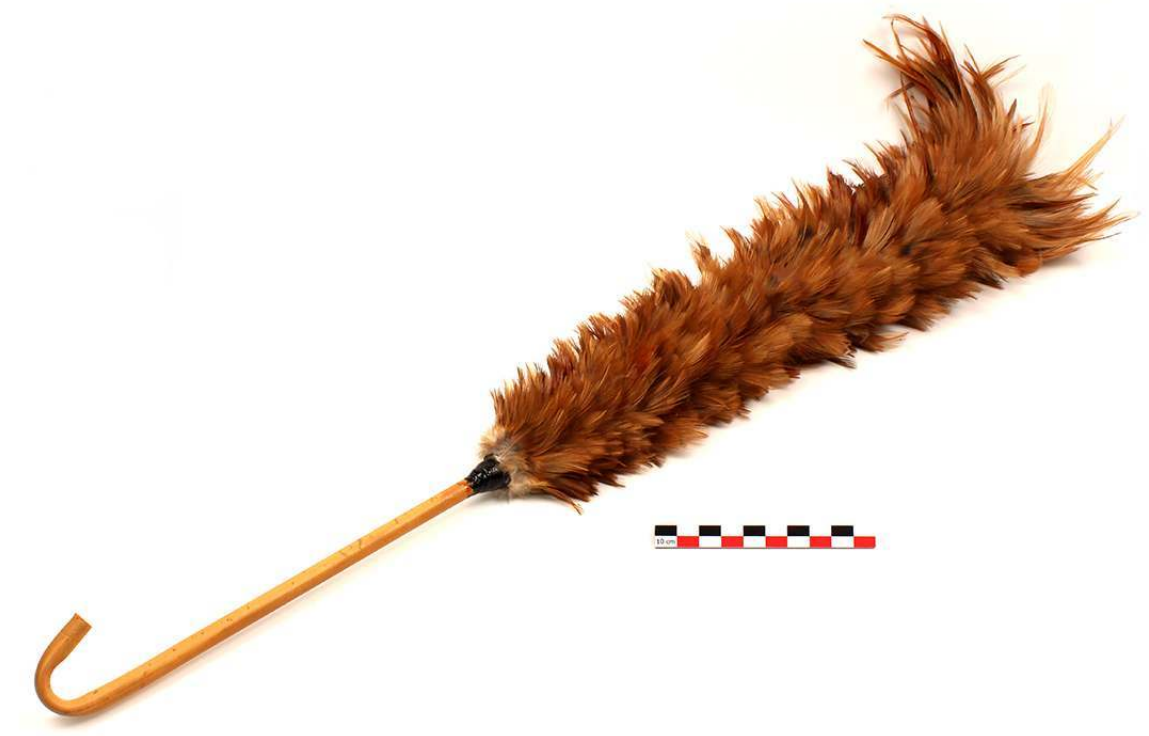

(c) P. Rameau

47 France.

Plumes de coq fixées sur une tige de rotin.

Années 70 (?) ; collecteur Raymond Pujol

longueur $62 \mathrm{~cm}$, diamètre $8 \mathrm{~cm}$

ETB-FR-RP-2012-001

\section{Ornements corporels} souplesse qui les font rechercher pour des usages ornementaux.

49 16- Paire de boucles d'oreilles 


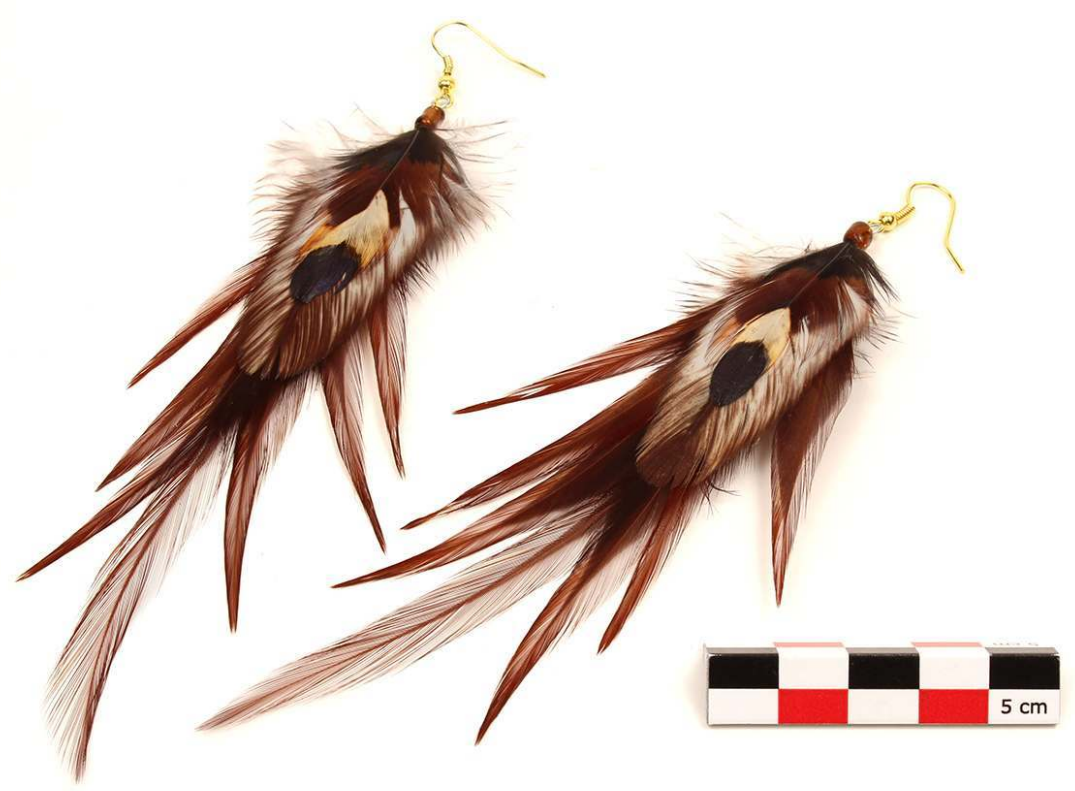

(c) P. Rameau

Mexique. Guadalajara, Jalisco, marché Corona.

Boucles d'oreille en plumes de coq, support en fil de laiton. Aretes de pluma de gallo

5 juin 2017 ; collecteurs Serge Bahuchet et Pauline Rameau

longueur $16 \mathrm{~cm}$ (avec le crochet) x largeur $4 \mathrm{~cm}$

ETB-MX-SBPR-2017-10

\section{La Poule en Océanie}

51 La très large présence des poules dans les sites archéologiques d'Océanie indique que « ... pour les peuples préhistoriques du Pacifique, les poulets étaient clairement une part importante de leur régime alimentaire et/ou de leur culture, comme le prouve leur présence dans les sites archéologiques qui couvrent le Pacifique de Santa Cruz à l'île de Pâques et Hawaii » (Storey et al. 2008 : 241).

La poule a suivi la migration des Austronésiens dans leur installation à travers le Pacifique, depuis le continent asiatique jusqu'à l'île de Pâques, transportée d'île en île à travers tout l'immense Pacifique, associée à la culture céramique Lapita à partir de 3000 avant le présent (BP). On a trouvé des os à Vanuatu datés de 3250 à 2950 BP, à Santa Cruz (3150-2850 BP), en Micronésie vers 2000 BP, à Samoa (1000-500 BP)... Il a même été proposé que la poule ait atteint le Chili par le Pacifique, puisqu'on y a trouvé des os dans un site précolombien daté de 1304 à 1450 (cf. Storey et al. 2013)

Cette volaille faisait partie de ce que l'on a appelé « le paysage transporté » (transported landscape, Kirch 1980), avec le chien et le porc, mais aussi le rat et les plantes adventices. Toutefois il semble actuellement que les introductions, n'aient pas toujours été 
simultanées, car dans plusieurs sites, la poule précède le porc et le chien. Les études phylogénétiques de ces animaux suggèrent plusieurs routes différentes, à des temps différents.

Les usages multiples des poulets fournissent les raisons de leur circulation, certes les usages alimentaires mais aussi l'utilisation technique des os, attestée archéologiquement (aiguilles, perles), et l'utilisation ornementale vraisemblable des plumes, par analogie ethnographique.

On trouvera des données synthétiques et des discussions sur la diffusion de la poule dans les articles successifs de Storey et al. (2008, 2011, 2012, 2013).

17- Ornements de cheveux

Figure 21 : Ornement de cheveux ETB-CL-JLL-2012-030

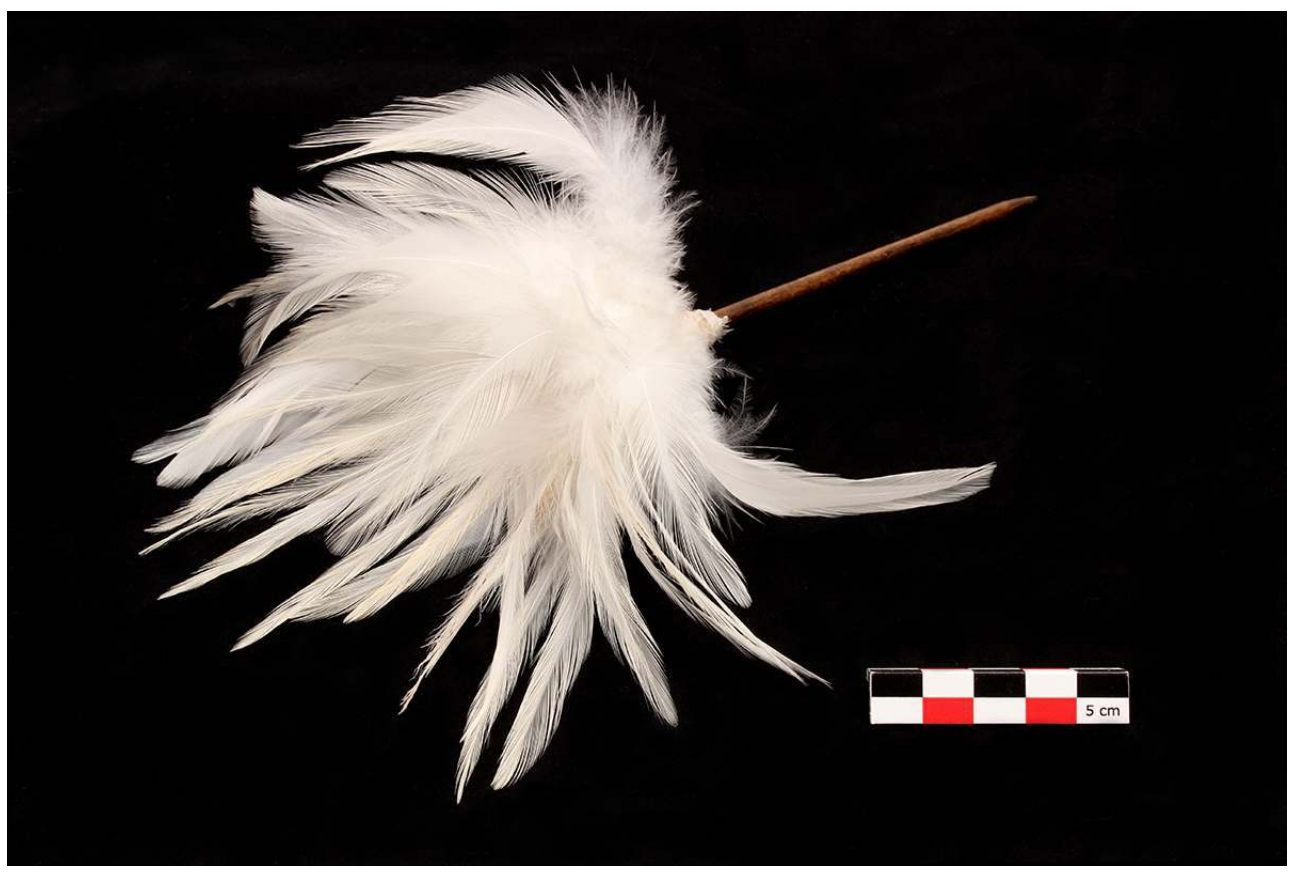

(C) P. Rameau

57 Chili. Rapa Nui (île de Pâques).

Ornement capillaire en plumes blanches de coq créole de l'île de Pâques, fixées sur une pique de bois. Pukao

26/10/2012 ; collectrice Johana Larco-Laurent

longueur $21 \mathrm{~cm}$

ETB-CL-JLL-2012-030

18- Ornements de cheveux 


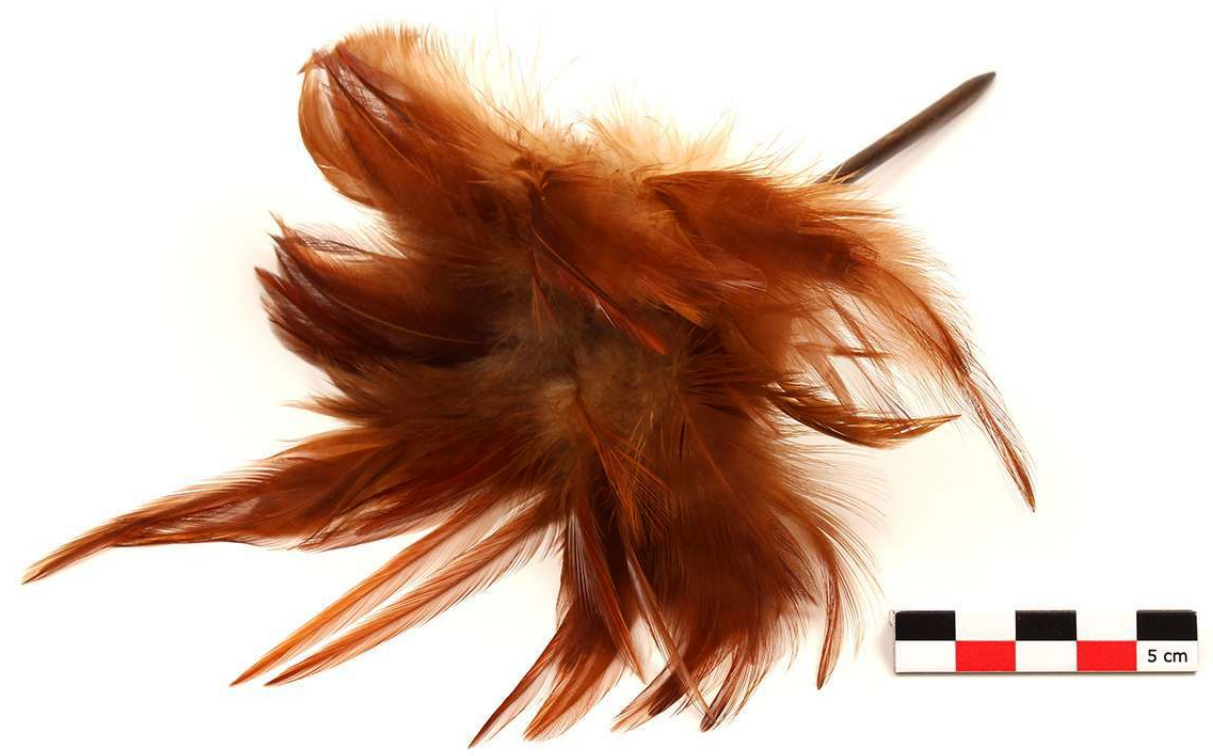

(C) P. Rameau

Ornement capillaire en plumes marron de coq créole de l'île de Pâques, fixées sur une pique de bois. Pukao.

26/10/2012 ; collectrice Johana Larco-Laurent

longueur $21 \mathrm{~cm}$

ETB-CL-JLL-2012-031

60 19-Ornements de cheveux 


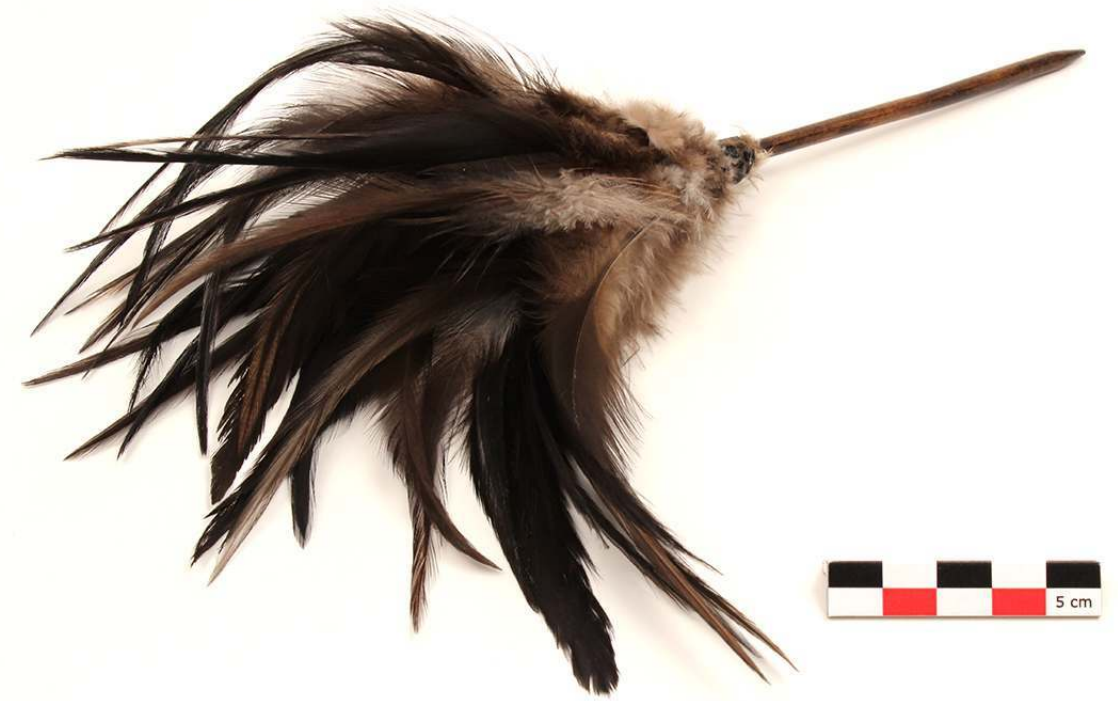

(c) P. Rameau

61 Chili. Rapa Nui (Île de Pâques).

Ornement capillaire en plumes noires de coq créole (de Tahiti), fixées sur une pique de bois. Pukao.

26/10/2012 ; collectrice Johana Larco-Laurent

longueur $27 \mathrm{~cm}$

ETB-CL-JLL-2012-032

62 20-Ornements de cheveux 
Figure 24 : Ornement de cheveux ETB-CL-JLL-2012-034

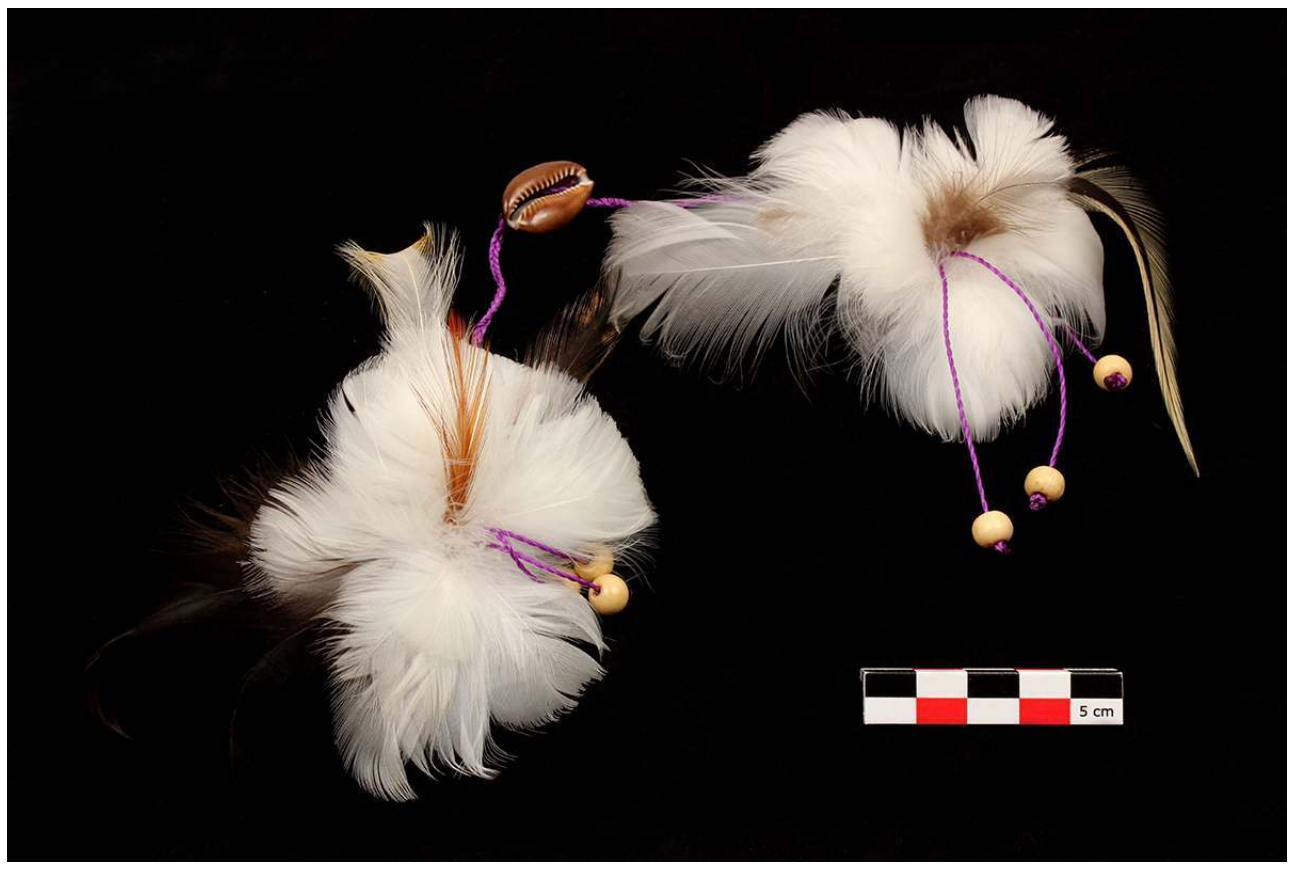

(C) P. Rameau

Chili. Rapa Nui (Île de Pâques).

Ornement pour cheveux: cordelette de fil violet tressé reliant deux fleurs faites de plumes blanches (coq créole de l'île de Pâques), de perles de bois. Au milieu de la cordelette est attaché un coquillage brun.

26/10/2012 ; collectrice Johana Larco-Laurent

longueur $44 \mathrm{~cm}$

ETB-CL-JLL-2012-034

21- Parure de chevelure d' « initié » en bois et son étui 


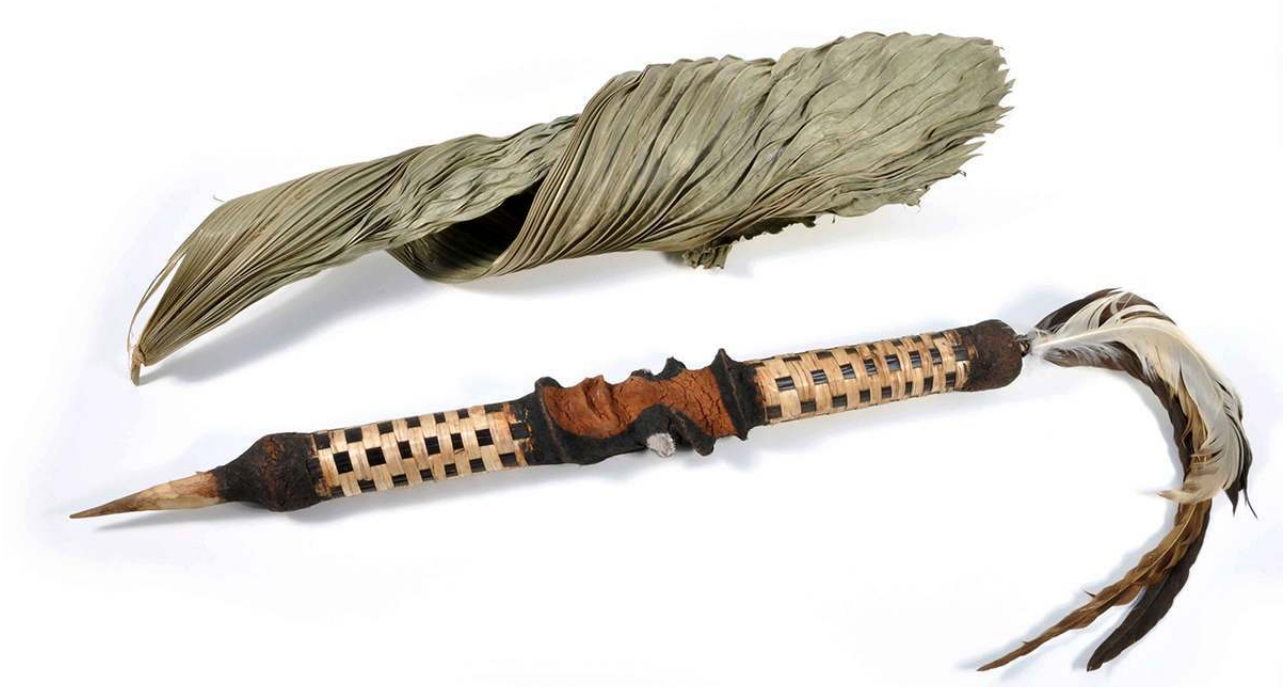

(c) D. Brabant

Vanuatu.

(1) parure de chevelure d' « initié » en bois. Constituée d'un bâton recouvert de fibres de Pandanus de couleur naturelle et noire. Partie médiane figurant une tête humaine, en pâte végétale colorée de pigments noirs, ocre-rouges et blancs. Une pâte végétale noire recouvre également les extrémités du bâton. La partie supérieure est surmontée de quatre plumes de coq. (2) étui fabriqué avec une feuille de Pandanus enroulée. Cette parure est destinée à être piquée dans une coiffe ; elle rappelle les cimiers des toitures des maisons de village.

2008 ; collecteur Christian Coiffier

(1) hauteur $79 \mathrm{~cm}$, diamètre $5 \mathrm{~cm}$; (2) longueur $50 \mathrm{~cm}$, diamètre $10 \mathrm{~cm}$ MNHN-E-2009.14.1(1,2)

22- Parure de tête 
Figure 26 : Parure de tête MNHN-E-2013.5.5

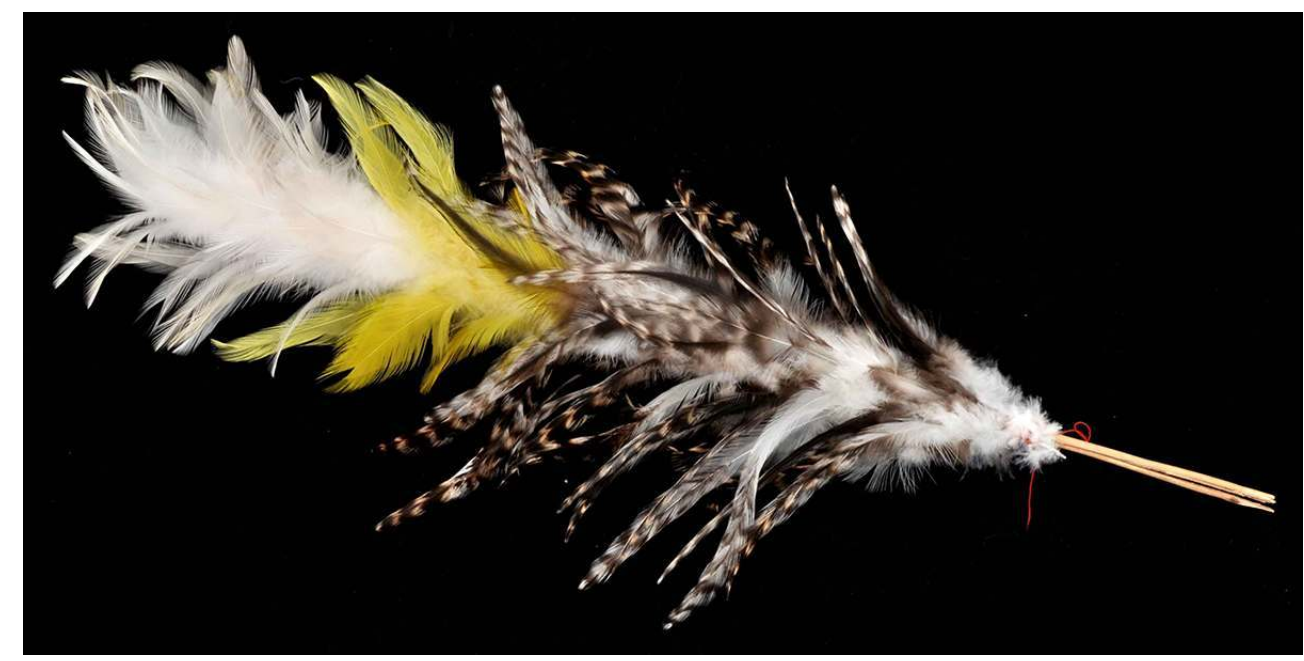

(c) D. Brabant

67 Vanuatu. Village d'Ipaï, Île de Tanna.

Plumet en plumes de coq.

Septembre/octobre 2011 ; collecteur Christian Coiffier ; don Société des amis du Musée de l'Homme

longueur $50 \mathrm{~cm}$ x largeur $7 \mathrm{~cm}$, épaisseur $2 \mathrm{~cm}$

MNHN-E-2013.5.5

\section{Décor d'objets}

23- Filet de portage décoré de duvet 


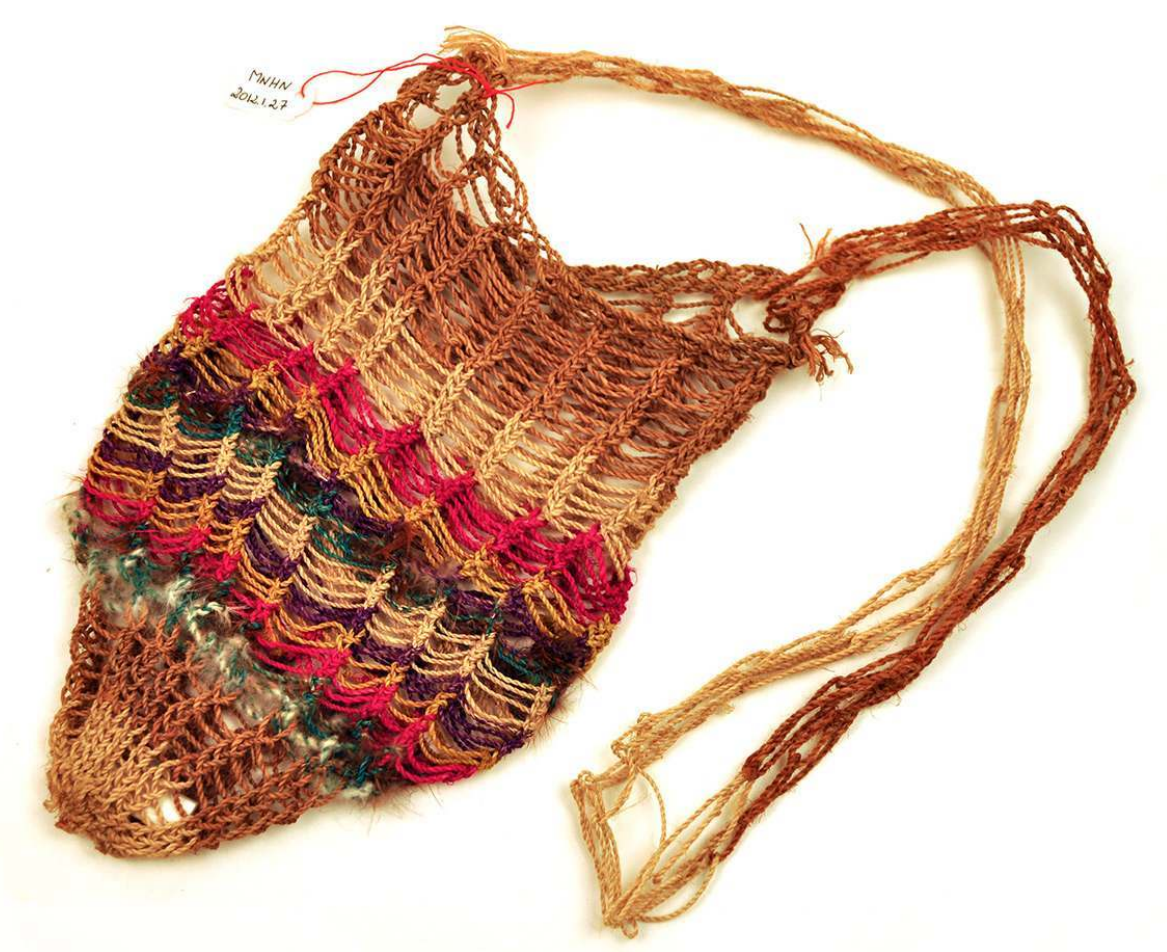

(c) D.Brabant

Ethnie Iatmul. Papouasie-Nouvelle-Guinée. Village de Palimbeï, province du Sépik Est.

Filet de portage en forme d'entonnoir tressé à la main en cordelettes de fibres végétales de couleur naturelle ou teintées ; bord resserré monté sur une cordelette maillée en fibre végétale de deux couleurs, naturelle et plus foncée; anse fixée aux extrémités de l'ouverture du filet (passée dans les mailles de la bordure). Du duvet de poulet blanc ou brun est entortillé sur quelques brins.

Ce type de filet est porté par tous les Néo-Guinéens, à l'épaule par les hommes, sur la tête par les femmes. Il est fabriqué par les femmes.

Collecteur Christian Coiffier

diamètre de l'ouverture $17 \mathrm{~cm}$, longueur de la base $3 \mathrm{~cm}$ x hauteur $22 \mathrm{~cm}$; longueur de l'anse $91,5 \mathrm{~cm}$ x largeur env. $3,5 \mathrm{~cm}$.

MNHN-E-2012.1.27

24- Filet de portage 


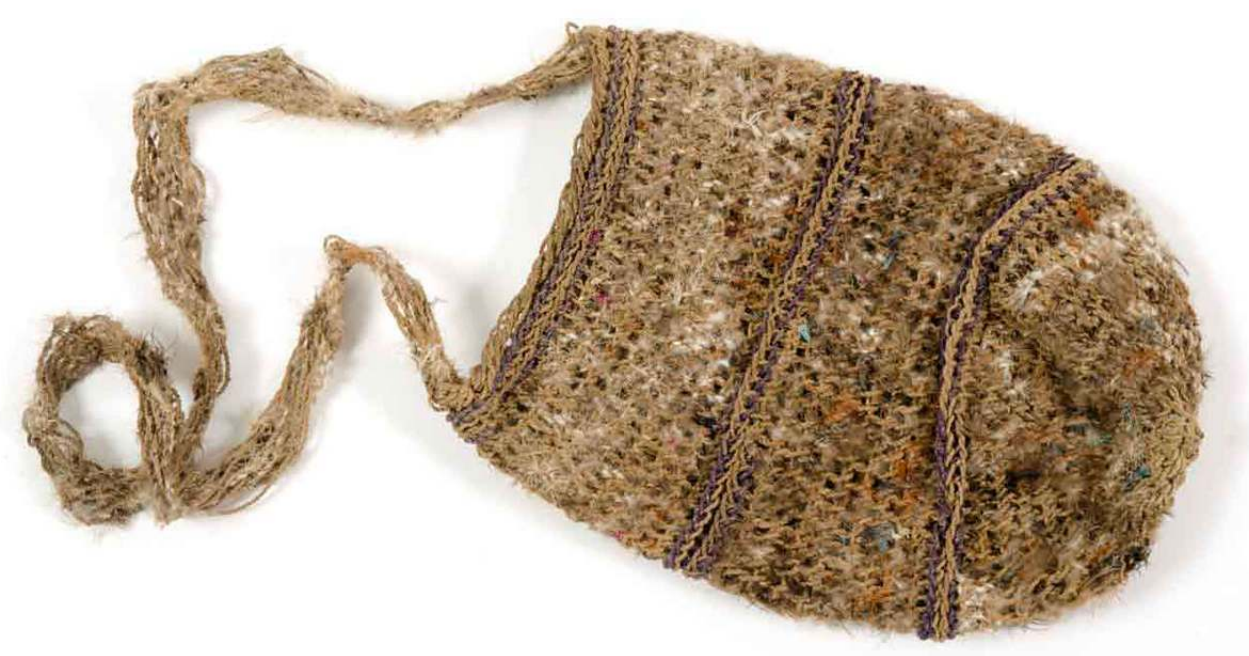

(c) D. Brabant

71 Papouasie-Nouvelle Guinée / province du Sépik Est.

Filet de portage de forme arrondie en fibres végétales, tressé au crochet en cordelettes de fibres végétales de couleur naturelle ou teintée, dans lesquelles sont insérées du duvet de poulet blanc, brun-orangé, brun et noir, et des plumes de coq. Le bord est resserré, monté sur une cordelette maillée en fibre végétale de couleur naturelle, tout comme l'anse. Collecteur Christian Coiffier diamètre de l'ouverture $16,5 \mathrm{~cm}$, largeur env. $19 \mathrm{~cm}$ x hauteur au centre $23 \mathrm{~cm}$; longueur de l'anse $75 \mathrm{~cm}$ x largeur env. $2 \mathrm{~cm}$.

MNHN-E-2012.1.38

72 25- Masque conique nelenga 
Figure 29 : Masque MNHN-E-2013.5.32

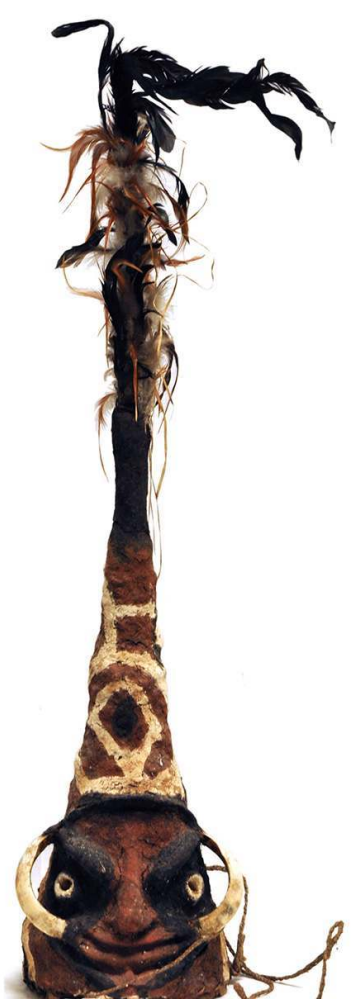

(c) D. Brabant

73 Vanuatu. Île Malakula (Malekula), centre.

Masque conique nelenga (masculin), anthropomorphe. Plumet constitué de plumes de coq attachées à un bâton de bambou par des liens végétaux.

Septembre-octobre 2011 ; collecteur Christian Coiffier ; don Société des amis du Musée de l'Homme

hauteur (masque) $60 \mathrm{~cm}$, hauteur (plumet) $55 \mathrm{~cm}$ x largeur $24 \mathrm{~cm}$, profondeur $25 \mathrm{~cm}$ MNHN-E-2013.5.32

74 26- Masque conique natamasmara 
Figure 30 : Masque MNHN-E-2013.5.37

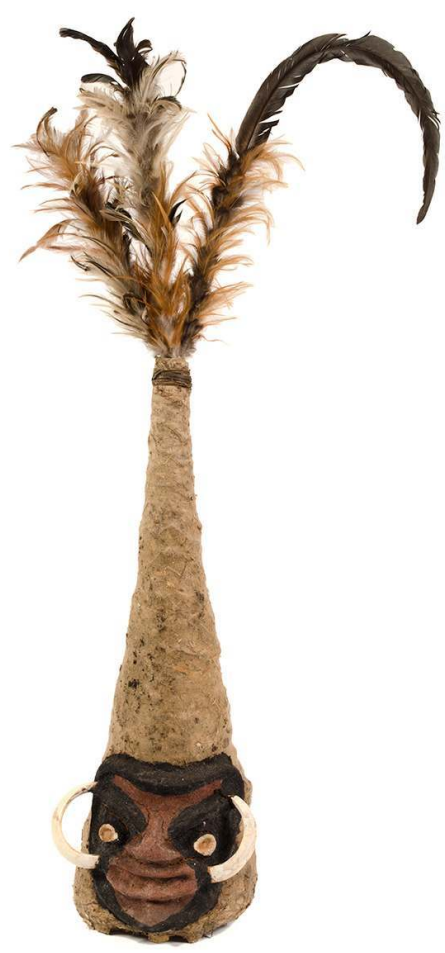

(c) D. Brabant

Vanuatu. Île Malakula (Malekula).

Masque conique natamasmara. Fabriqué à partir d'une pâte végétale recouvrant une armature en éléments de bambou (nevimbua) et en Pandanus (nimien), assemblés par des ligatures en fibres de Ficus-banyan (nambanga). Un feutrage en toile d'araignée ( nangangao) entoure toute la partie supérieure du masque. Des dents de cochon (naluf nanluas) sont fixées aux extrémités de la bouche. Masque peint de trois couleurs : des pigments ocre-rouge (memel) et blanc (fafalao) ainsi que du colorant noir (metemet) d'origine végétale. Trois plumets constitués de plumes de coq attachées à un bâton de bambou par des liens végétaux ou en plastique. Objet rituel. Les hommes initiés conservent jalousement les secrets de fabrication et l'histoire des personnages, mais sont très fiers de les voir exposés dans des musées. Fabriqué par Keski Kamansigao.

Septembre-octobre 2011 ; collecteur Christian Coiffier ; don Société des amis du Musée de l'Homme

hauteur (masque) $69 \mathrm{~cm}$, hauteur (plumet) $55 \mathrm{~cm}$ x largeur $25 \mathrm{~cm}$, profondeur $27 \mathrm{~cm}$ MNHN-E-2013.5.37 (exposé dans la Galerie de l'Homme)

\section{Jeux : les combats de Coqs}

Pour introduire cette section, aucun texte n'est plus explicite que celui que Buffon consacre au Coq, dans son Histoire naturelle des oiseaux :

«Les hommes qui tirent parti de tout, pour leur amusement, ont bien su mettre en œuvre cette antipathie invincible, que la Nature a établie entre un coq et un coq; ils ont cultivé cette haine innée avec tant d'art, que les combats de deux oiseaux de basse-cour sont devenus des spectacles dignes d'intéresser la curiosité des peuples, 
même des peuples polis; et en même temps des moyens de développer ou entretenir dans les âmes cette précieuse férocité, qui est, dit-on, le germe de l'héroïsme; on a vu, on voit encore tous les jours dans plus d'une contrée, des hommes de tous états accourir en foule à ces grotesques tournois, se diviser en deux partis ; chacun de ces partis s'échauffer pour son combattant, joindre la fureur des gageures les plus outrées, à l'intérêt d'un si beau spectacle, et le dernier coup de bec de l'oiseau vainqueur, renverser la fortune de plusieurs familles: c'étoit autrefois la folie des Rhodiens, des Tangriens, de ceux de Pergame; c'est aujourd'hui celle des Chinois, des habitans des Philippines, de Java, de l'Isthme de l'Amérique, et de quelques autres Nations des deux continens. " (Buffon 1771: 72-73)

On ne saurait mieux indiquer, encore aujourd'hui, la pratique tant répandue des combats de coqs, sur presque tous les continents (cf. Finsterbusch 1929). En Asie, région d'origine de la Poule, on a des évidences archéologiques et historiques de combats de coqs en Chine centrale il y a 2800 ans (Qu et al. 2009). Plus près de nous, des bas-reliefs, des peintures sur les vases ou des mosaïques attestent de la pratique des combats en Grèce vers le $\mathrm{IV}^{\mathrm{e}}$ siècle av. JC, puis chez les Romains (De Witte 1868, Blanc 2017 ce numéro, Bruneau 1965).

On sait que Christophe Colomb apporte des poules à Hispaniola dès son deuxième voyage en 1495, mais il ne semble pas qu'elles aient échappé à la consommation; puis tous les conquistadors en transportent également (cf. Storey et al. 2011 pour une revue des sources historiques). Les Espagnols introduisent ensuite les combats de coqs. Une aquarelle $d u \mathrm{XVIII}^{\mathrm{e}}$ siècle, conservée à la Bibliothèque royale de Madrid, présente un gallodrome (Coliseo de gallos) dans la ville de Trujillo del Perú (planche 128 du $2^{\mathrm{e}}$ volume); cf. Biblioteca Virtual Miguel de Cervantes : http://www.cervantesvirtual.com/obra-visor/ trujillo-del-peru--volumen-ii/html/966bf129-a181-4dd1-996b-ac44db7844e2_135.html )

\section{Élevage des coqs de combat}

27- Attache, laisse pour coq de combat 
Figure 31 : Attache pour coq de combat ETB-MX-SBPR-2017-51

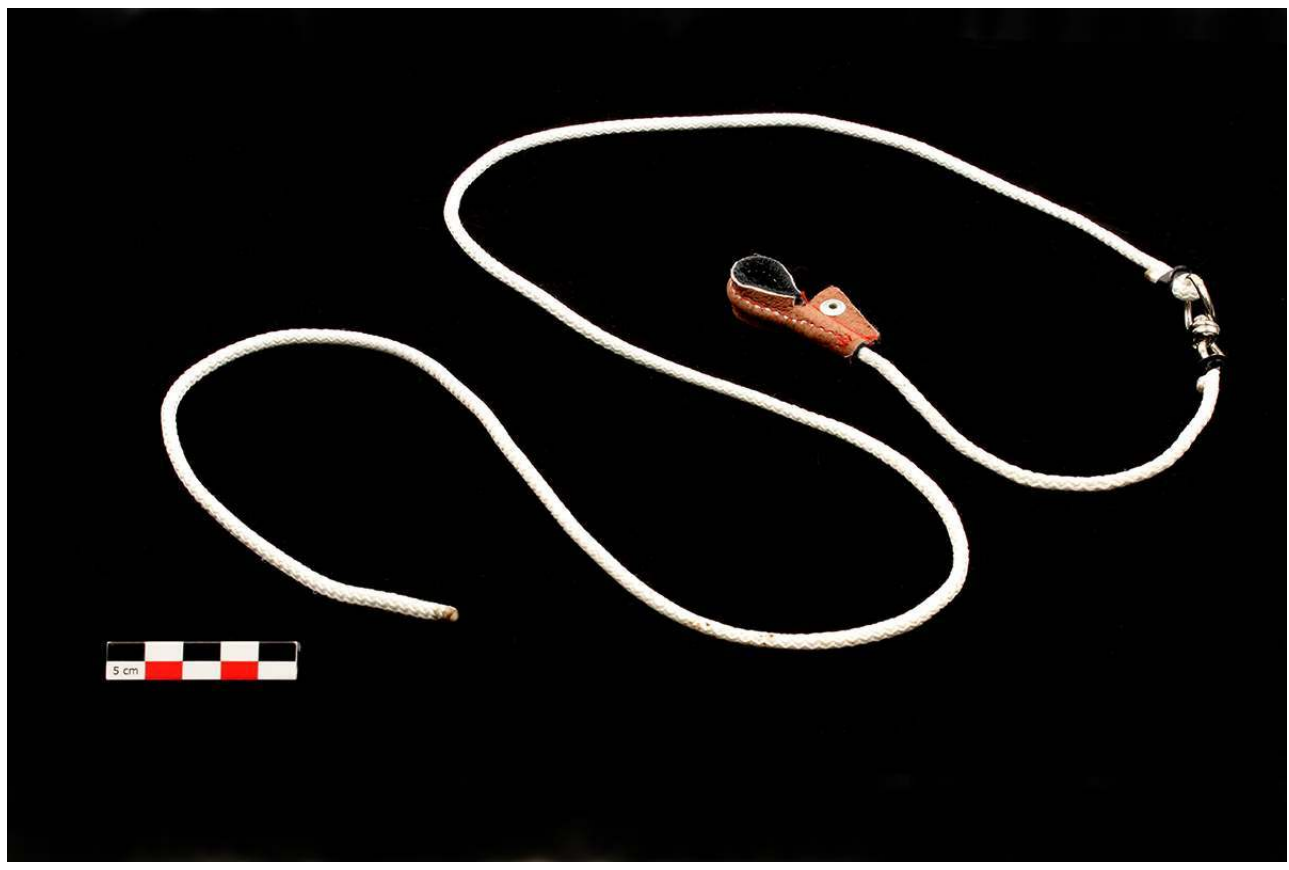

(C) P. Rameau

80 Mexique. Chiquilistlán, Jalisco. Fait à Ciudad Guzman. Achat à la boutique de vétérinaire Veterinaria.

Cuir, nylon, métal. Ce genre de laisse, liée à la patte à une extrémité et fixée au sol par un piquet, permet au coq de se mouvoir sans se mêler à ses congénères, et de se réfugier dans un abri, pour se protéger du soleil ou de la pluie (Figure 32).

03/08/2017 ; collecteurs Serge Bahuchet et Pauline Rameau

longueur $140 \mathrm{~cm}$; boucle $5,5 \mathrm{~cm} \times 2 \mathrm{~cm}$

ETB-MX-SBPR-2017-51 
Figure 32 : Un élevage de coqs de combat vers Mascota (Jalisco, avril 2014)

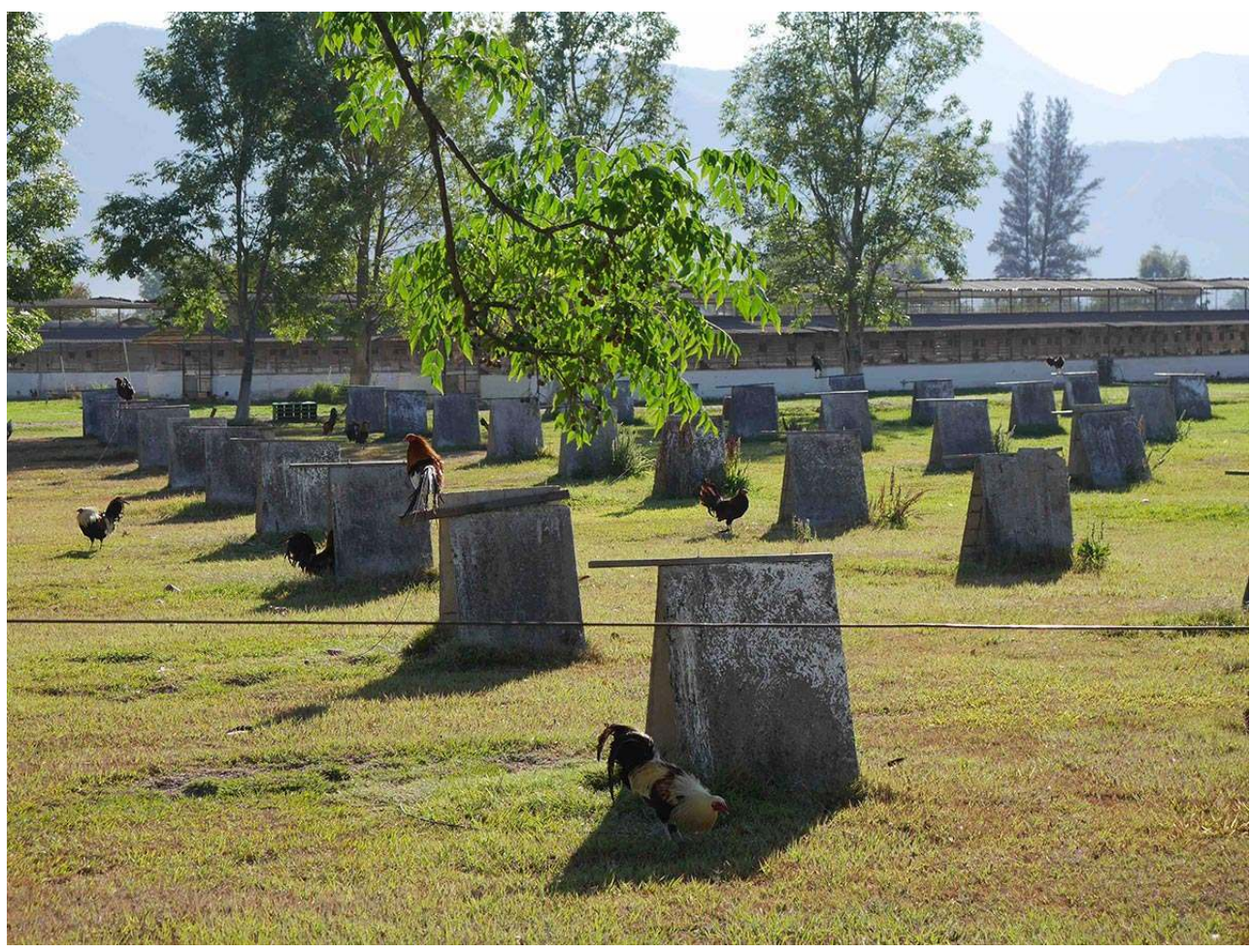

(c) S. Bahuchet

81 28- Ex-voto figurant un coq de combat

Figure 33 : Ex-voto ETB-MX-SB-2013-050

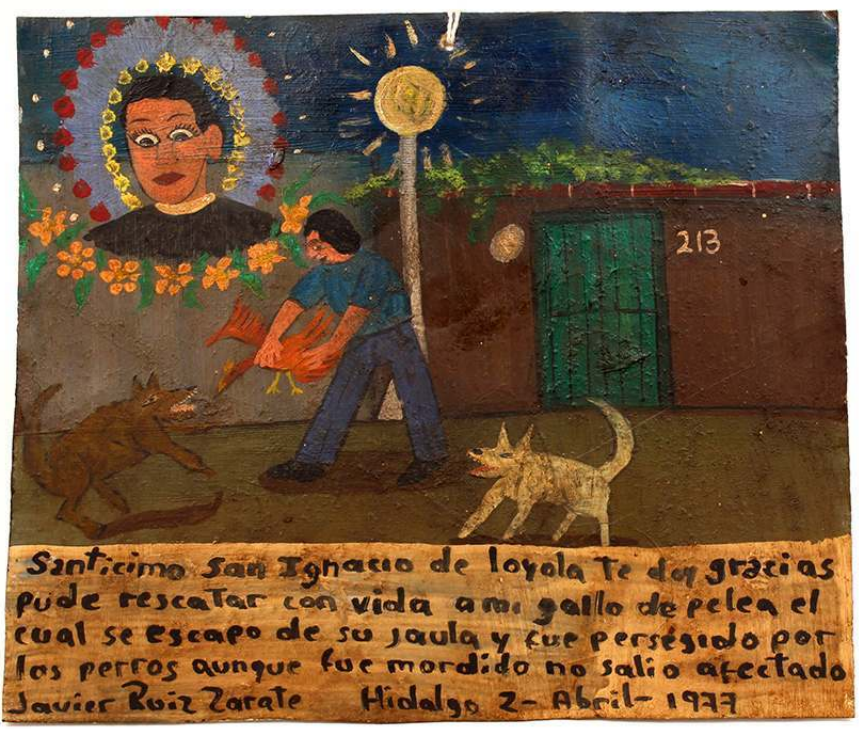

(c) P. Rameau 
Mexique. Oaxaca, achat à Mexico (Musée des arts populaires).

Peinture sur tôle. Offrande faite à Saint Ignace de Loyola en remerciement d'une grâce obtenue : «Très saint Ignace de Loyola, je te rends grâce [car] j'ai pu sauver la vie de mon coq de combat, qui s'était échappé de sa cage et fut poursuivi par les chiens, bien qu'il fut mordu, il n'en fût pas affecté. Javier Ruiz Zarate, Hidalgo, 2 avril 1977 ».

$22 / 8 / 2013$; collecteur Serge Bahuchet

longueur $17,5 \mathrm{~cm} \times$ largeur $20,5 \mathrm{~cm}$

ETB-MX-SB-2013-050

\section{Accessoires de combat}

\section{Au Mexique}

Les combats de coqs peuvent être menés au village sans installation particulière, mais dans les villes ils ont lieu dans des arènes spécifiques, les palenques (Figures 34, 47). Avant chaque combat, les éperons sont soigneusement mesurés à l'aide d'escuadras (Figure 48). La forme et l'angle de la lame sont eux, au goût de l'éleveur.

Figure 34 : Harnachement d'un coq et combat au Mexique en 1913

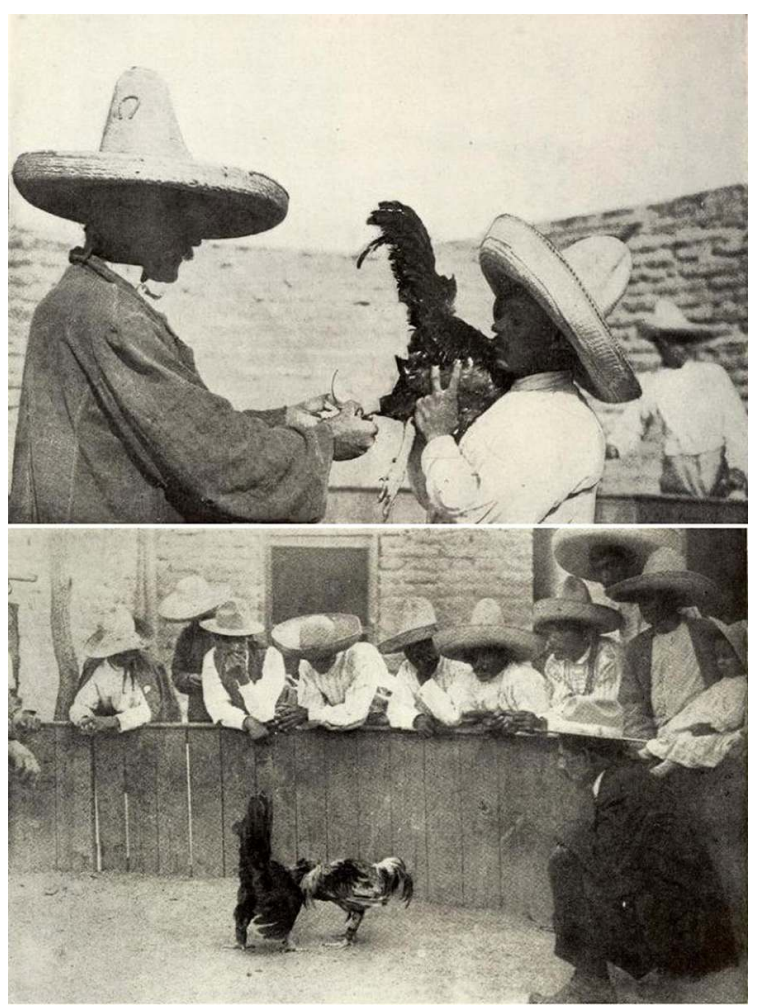

Photos Shirley C. Hulse, in National Geographic 1914 26(1-6): 478-479

29- Harnachement de coq de combat 


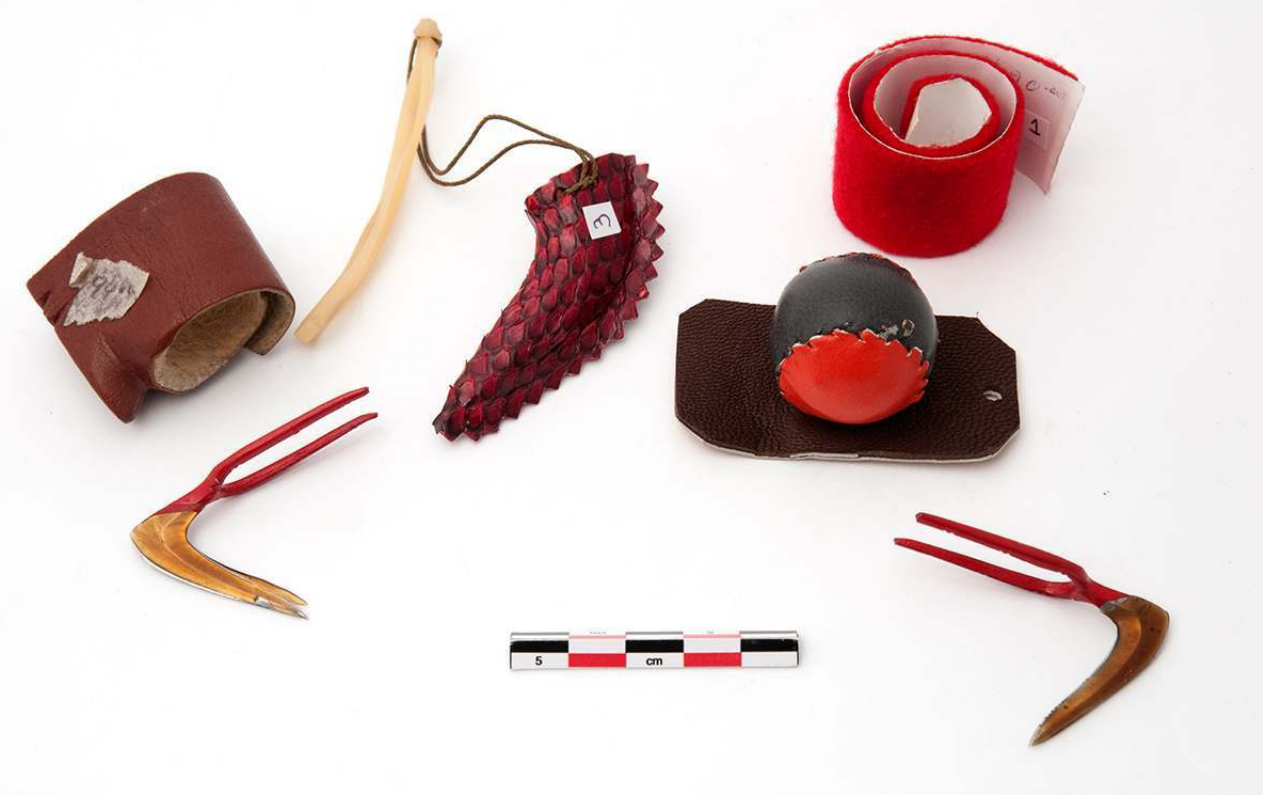

(c) P. Rameau

Mexique. Manzanillo (Colima).

Six pièces. Différents éléments de harnachement utilisé sur les coqs pour les combats : protecteur du bec, étui protecteur de la lame avec son élastique de fixation, deux lames en forme de faucille affutée, le support de bois évidé et de cuir sur lequel enfiler l'éperon, et une bande velcro à coller pour serrer la bande de cuir sur le tarse et fixer l'ensemble à la patte. Arneses para pelea de gallos.

26/11/2009 ; collectrice Françoise Aubaile

longueur $5 \mathrm{~cm} \times$ largeur $4 \mathrm{~cm}$ et longueur $5 \times$ largeur $3,5 \mathrm{~cm} \quad$ (couteaux);

longueur $4 \mathrm{~cm} \times$ largeur $3 \mathrm{~cm} \quad$ (support); longueur $7 \mathrm{~cm} \times$ largeur $3 \mathrm{~cm} \quad$ (étui); longueur $6,5 \mathrm{~cm} \times$ largeur $3 \mathrm{~cm}$ (protecteur de bec)

ETB-MX-FA-2009-011

30- Accessoires pour les combats de coqs 

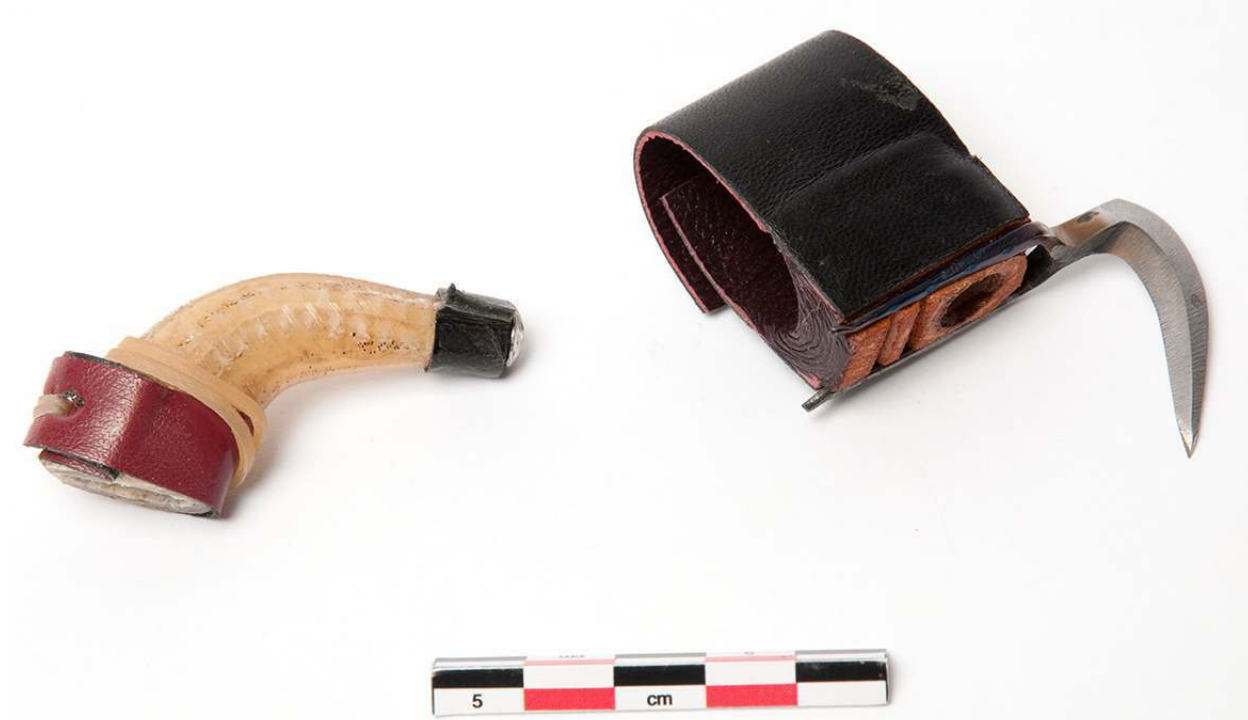

(c) P. Rameau

Mexique. Autlán de Navarra (Jalisco).

Trois pièces. Lame en acier et son attache en cuir et bois, protège lame (en résine, cuir et métal). L'éperon s'enfile sur le support de bois, évidé pour laisser passer m'ergot naturel ; fixé au tarse par la sangle de cuir. Accesorios para gallos de pelea.

20/04/2010; collecteur Serge Bahuchet

longueur $5 \mathrm{~cm} \times$ largeur $4 \mathrm{~cm} \quad$ (éperon); longueur $3,5 \mathrm{~cm} \times$ largeur $3 \mathrm{~cm} \quad$ (support); longueur $6 \mathrm{~cm}$ x largeur $3 \mathrm{~cm}$ (étui)

ETB-MX-SB-2010A-033a, b, c

31- Deux éperons (navajas) pour combat de coq

Figure 37 : Deux éperons ETB-MX-SBPR-2017-59, éperon et protection ETB-MX-SBPR-2017-50
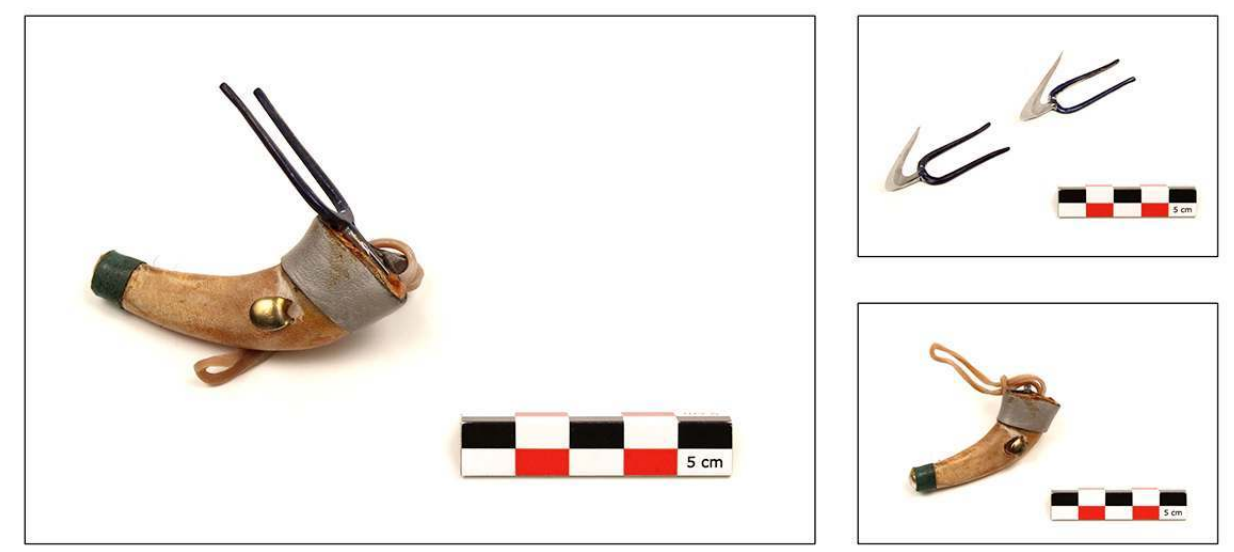

(C) P. Rameau 
Mexique. Villa Corona (Jalisco). Achat à l'atelier de forge Société El Asustado.

Acier forgé ; se vendent par 12 ou à la pièce. Navaja.

07/08/2017; collecteurs Serge Bahuchet et Pauline Rameau

(1) longueur $5 \mathrm{~cm}$ x largeur $3,6 \mathrm{~cm}$; (2) longueur $5 \mathrm{~cm}$ x largeur $3,1 \mathrm{~cm}$

ETB-MX-SBPR-2017-59a et b

Figure 38 : La forge et le forgeron
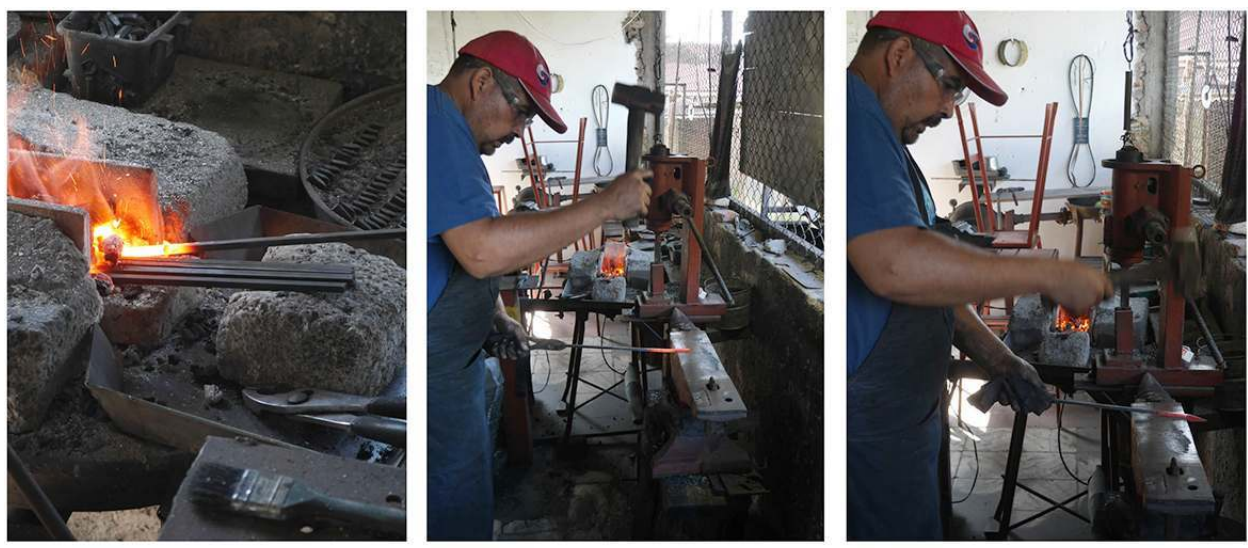

(c) S. Bahuchet

Figure 39 : Le dégrossissage, l'affûtage et le marquage des éperons
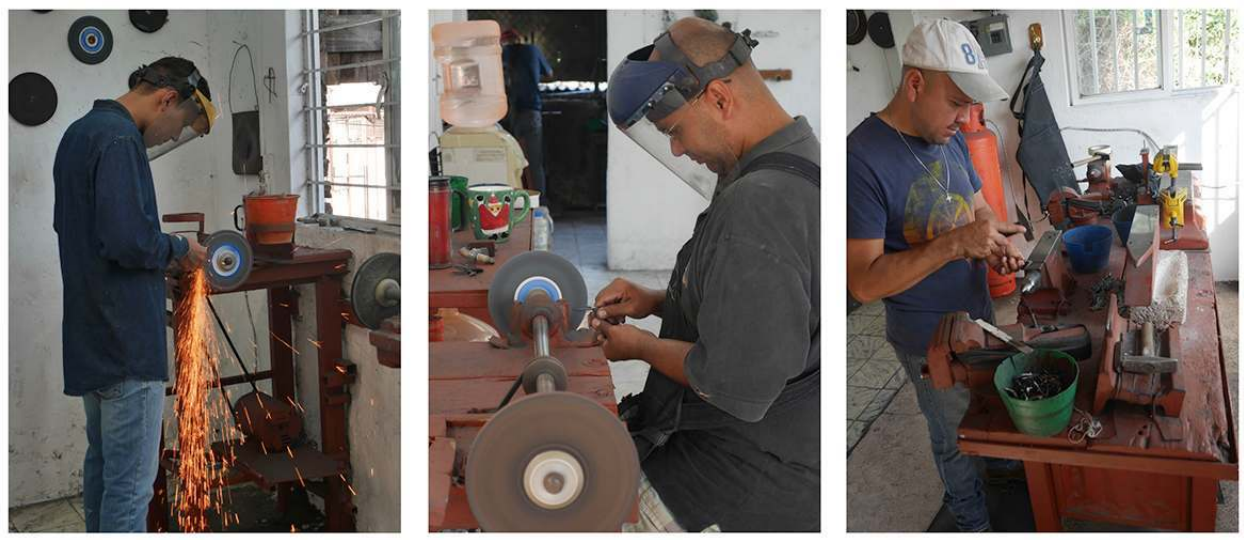

(c) S. Bahuchet 
Figure 40 : Trois stades de fabrication : éperons forgés, affûtés et terminés (Villa Corona, Jalisco, juillet 2017)
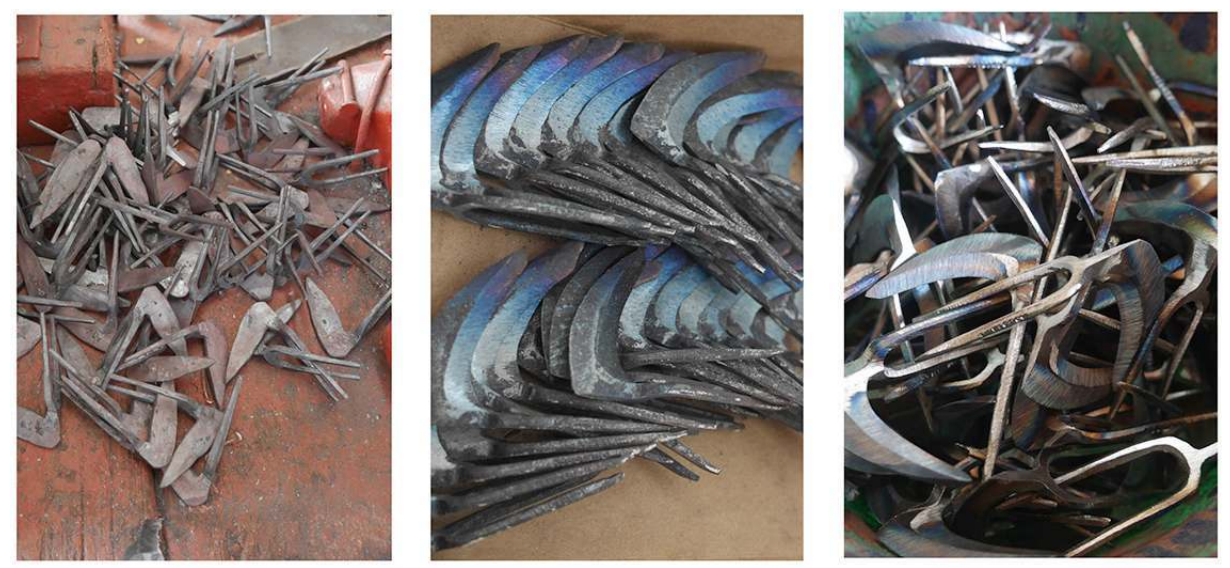

(c) S. Bahuchet

\section{Veterinaria.}

Cuir. Protection de la lame.

03/08/2017 ; collecteurs Serge Bahuchet et Pauline Rameau

longueur $6,6 \mathrm{~cm}$ x largeur $2,8 \mathrm{~cm}$

ETB-MX-SBPR-2017-50

\section{En France}

Les combats de coqs sont interdits en France par le Code pénal, dans l'article « Des sévices graves ou actes de cruauté envers les animaux », article 521-1 (modifié le 5 octobre 2006) : un animal domestique, ou apprivoisé, ou tenu en captivité, est puni de deux ans d'emprisonnement et de 30000 euros d'amende. » « Les dispositions du présent article ne sont pas applicables aux courses de taureaux lorsqu'une tradition locale ininterrompue peut être invoquée. Elles ne sont pas non plus applicables aux combats de coqs dans les localités où une tradition ininterrompue peut être établie. Est punie des peines prévues au présent article toute création d'un nouveau gallodrome. »

Les régions de "tradition ininterrompue » sont le Nord-Pas de Calais, la Réunion, la Guyane, la Polynésie et les Antilles (Figure 41). Le but de la loi est bien d'amener ces pratiques à s'éteindre.

Le conseil constitutionnel a confirmé le 31 juillet 2015 l'interdiction de la construction de nouveaux « gallodromes » (Décision $n^{\circ}$ 2015-477).

Danaë 1989. 
Figure 41 : Combats de coqs en Martinique. En haut, fixation des éperons ; en bas l'arène (gallodrome Pitt Colonnette, Ducos, juillet 2014)

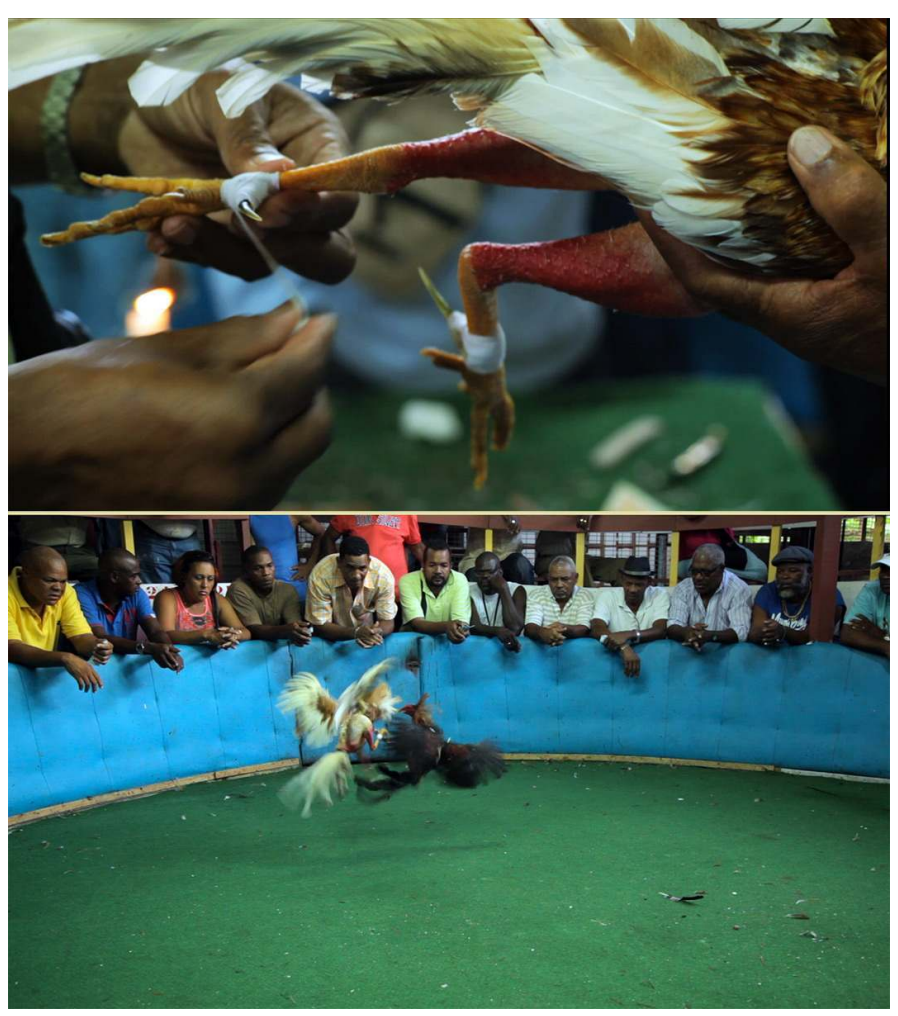

(c) Ritual Inhabitual

97 33-Accessoires pour les combats de coqs

Figure 42 : Accessoires pour coqs de combat ETB-FR-RP-2011-062
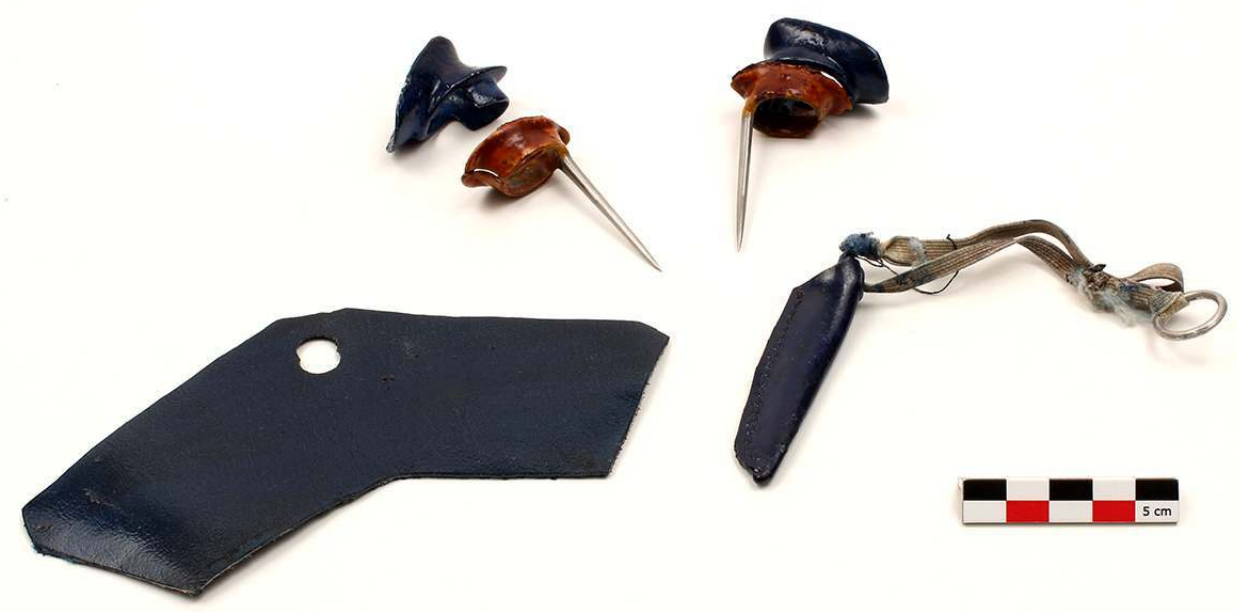

(c) P. Rameau 
France; région du Nord.

Six éléments : deux éperons (pointes) d'acier, deux montures qui vont sur les pattes ; une attache en cuir et un étui pour éperon. L'ergot naturel du jeune coq est scié, à une longueur qui permet d'y poser le support de la pointe d'acier. Celle-ci («l'arme ») est une aiguille droite, pointue mais non tranchante. Elle sera montée sur une douille enfilée sur l'ergot naturel du coq, l'ensemble étant maintenu par une pièce de cuir, serrée autour du tarse par un fil de cordonnier. Le coq est armé par son « coqueleur » avant d'arriver dans le "gallodrome », la pointe étant protégée par un étui afin d'éviter les blessures (Danaë 1989 : 219). Les coqs sont nommés, soulignant ainsi la relation singulière que le coqueleur entretient avec eux.

Années 70 ; collecteur Raymond Pujol

longueur $6 \mathrm{~cm} \quad$ (éperons); longueur $2 \mathrm{~cm} \times$ largeur $3,5 \mathrm{~cm} \quad$ (support); longueur $2 \mathrm{~cm}$ x largeur $3,8 \mathrm{~cm}$ (support); 4 x 2,3 x 2,5 cm (monture), $3,7 \times 2,2 \times 2,5 \mathrm{~cm}$ (monture); longueur $7 \mathrm{~cm} \times$ largeur $2 \mathrm{~cm}$ (étui); longueur $6,4 \mathrm{~cm} \times$ largeur $16,3 \mathrm{~cm}$ (attache de cuir)

ETB-FR-RP-2011-062a, b, c, d, e, f

Figure 43 : La fixation de l'arme sur la patte du coq dans le Nord-Pas-de-Calais

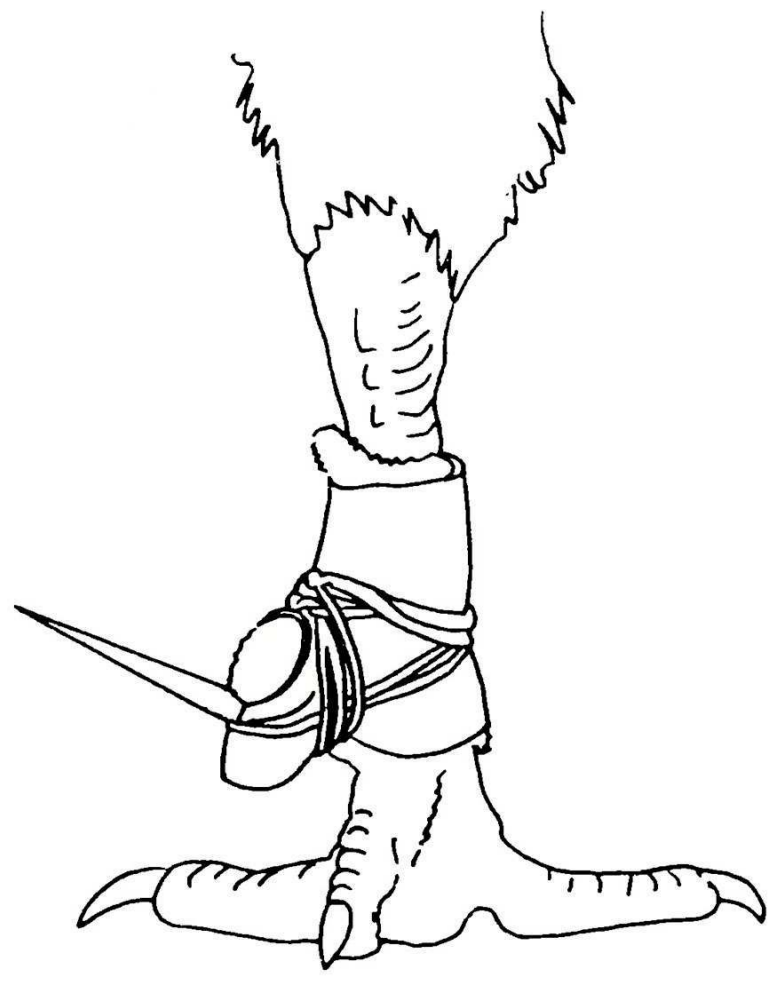

D’après Danaë 1989 : 134

Le combat

34- Maquette d'une arène 

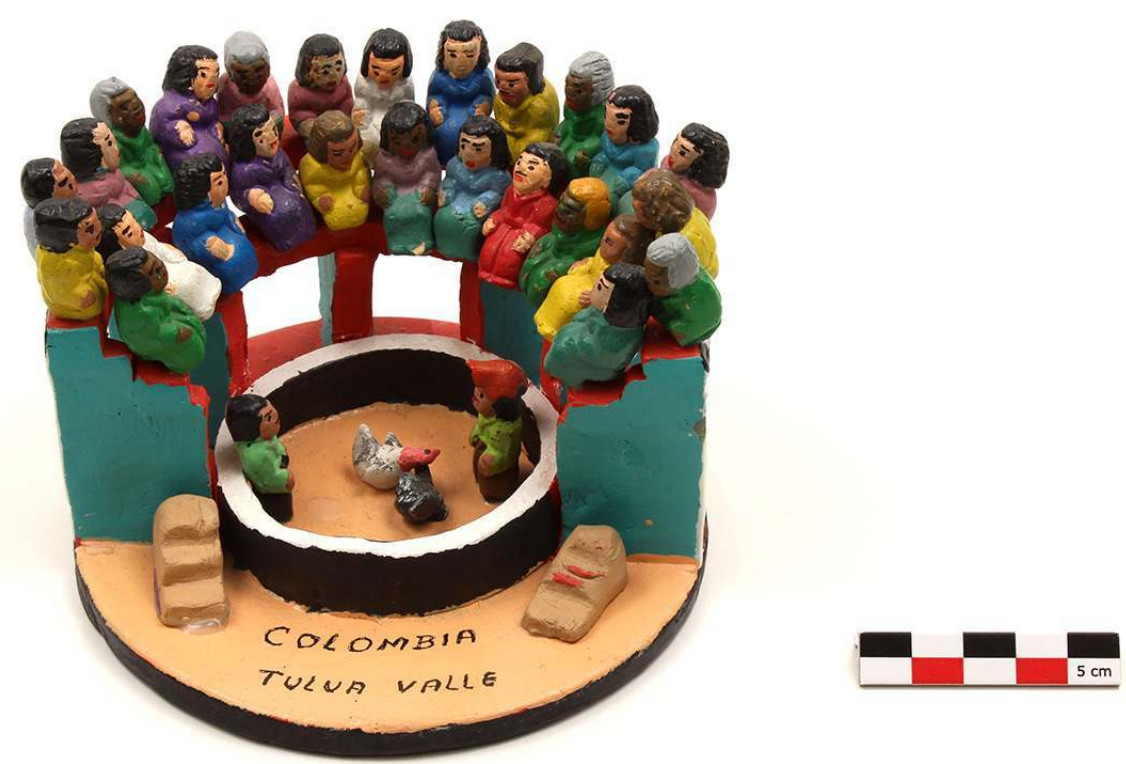

(c) P. Rameau

100 Colombie. Tulua (Valle de Cauca).

En terre cuite peinte. Spectateurs sur deux gradins; dans l'arène, les deux propriétaires des deux coqs combattants. Inscription sur le socle : Colombia. Tulua Valle.

2001 ; collectrice Monica Castro Carreño

diamètre $13 \mathrm{~cm}$, hauteur $8 \mathrm{~cm}$

ETB-CO-MCC-2017-001

101 35- Figurines montrant deux coqs en position de combat 

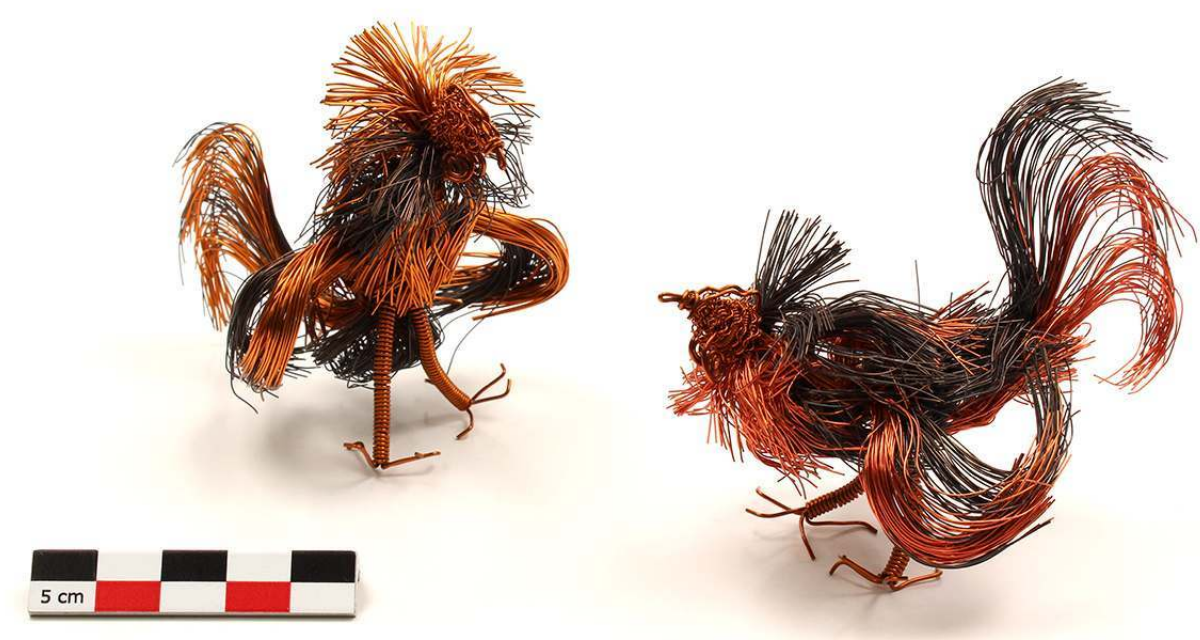

(c) P. Rameau

102 Mexique. Coyoacan, (Ciudad de México), artisan dans la rue.

Sculpture décorative en fils de fer et de cuivre représentant un combat de coqs. Juillet 2017 ; collectrice Pauline Rameau

(1) longueur $7 \mathrm{~cm}$ x largeur $10 \mathrm{~cm}$; (2) longueur $8 \mathrm{~cm}$ x largeur $10 \mathrm{~cm}$ ETB-MX-PR-2017-001 a et $b$ 
Figure 46 : Coqs à El Terrero (Jalisco, avril 2010)
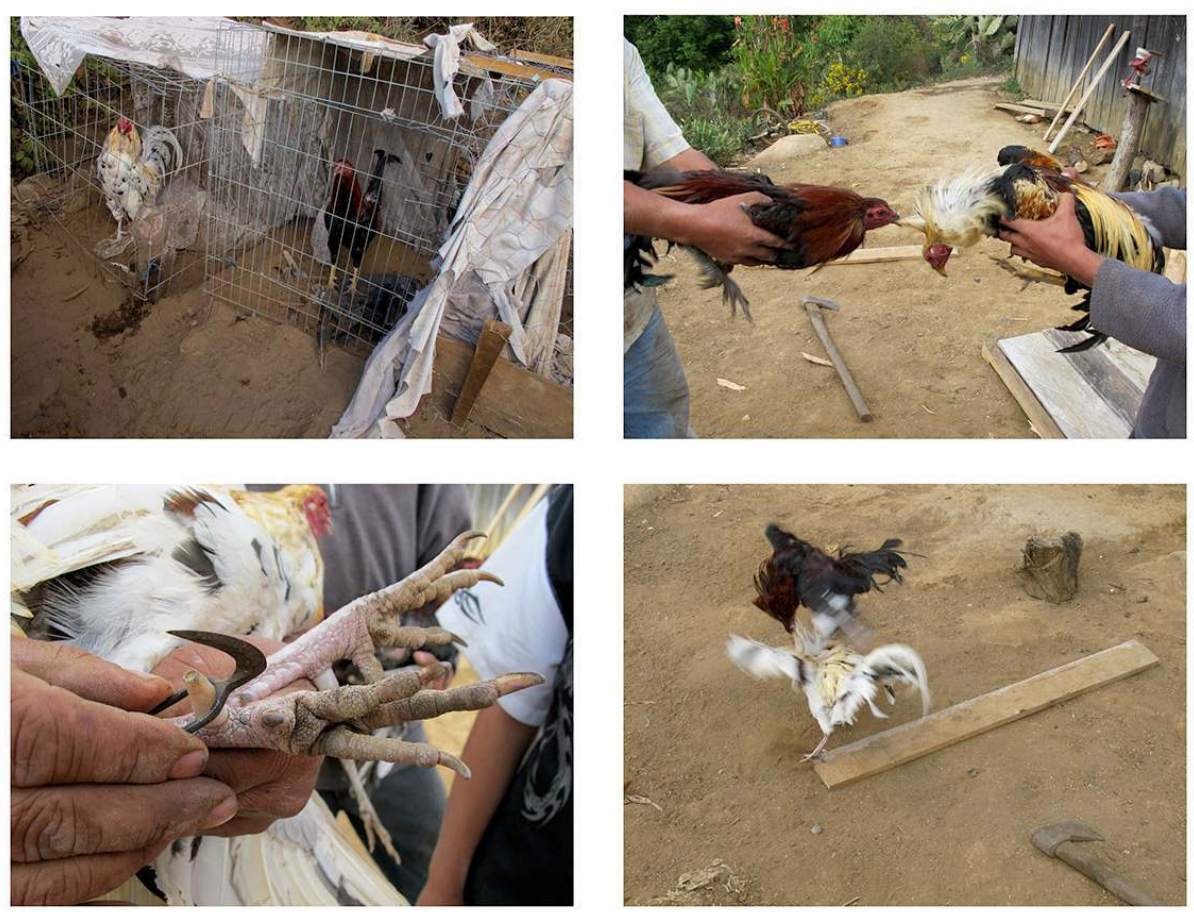

Les cages d'élevage, confrontation de deux combattants, mise en place de l'éperon, combat au village (c) S. Bahuchet 
Figure 47 : Un combat à El Grullo (Jalisco, octobre-novembre 2011)
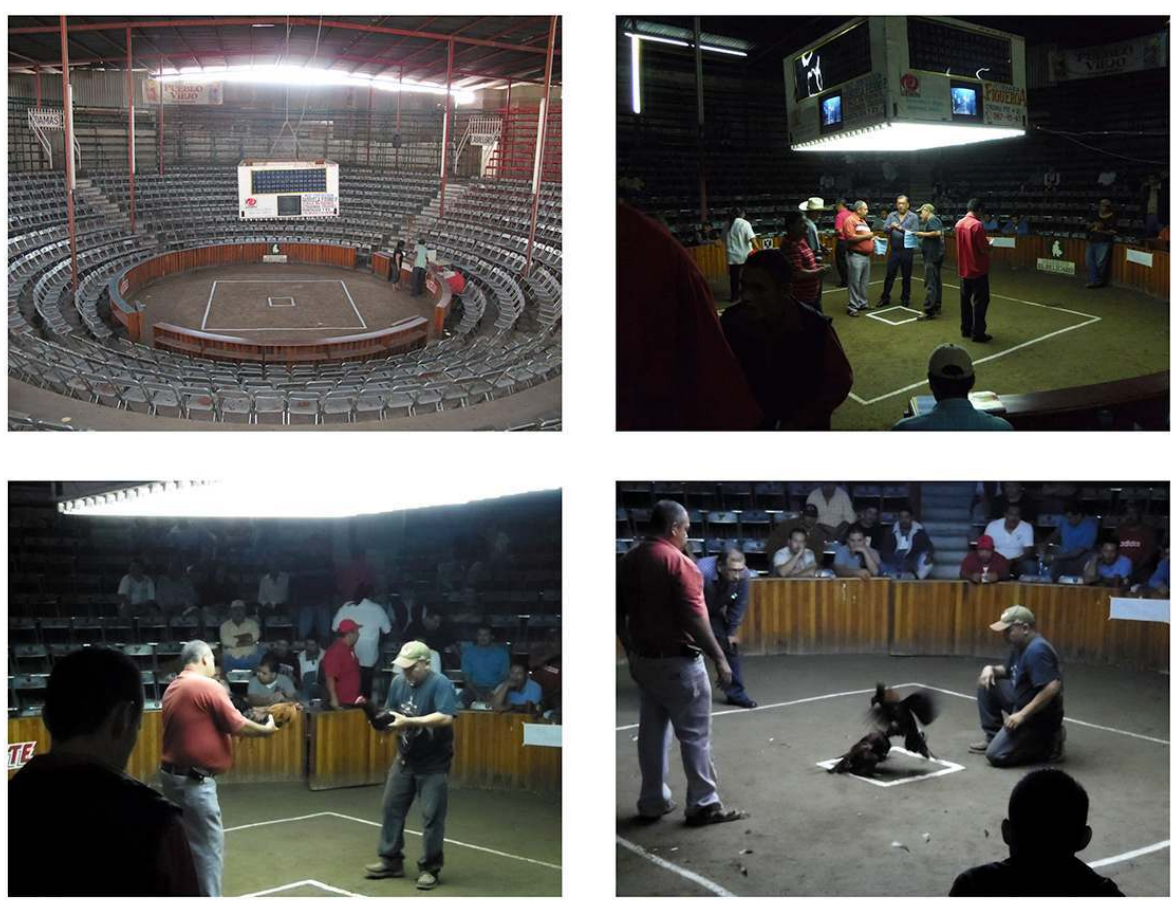

L'arène palenque, la vérification de la taille des couteaux, présentation des coqs, le combat (c) S. Bahuchet

Figure 48 : Escuadra, mesure des lames des éperons (Villa Corona, Jalisco, août 2017)

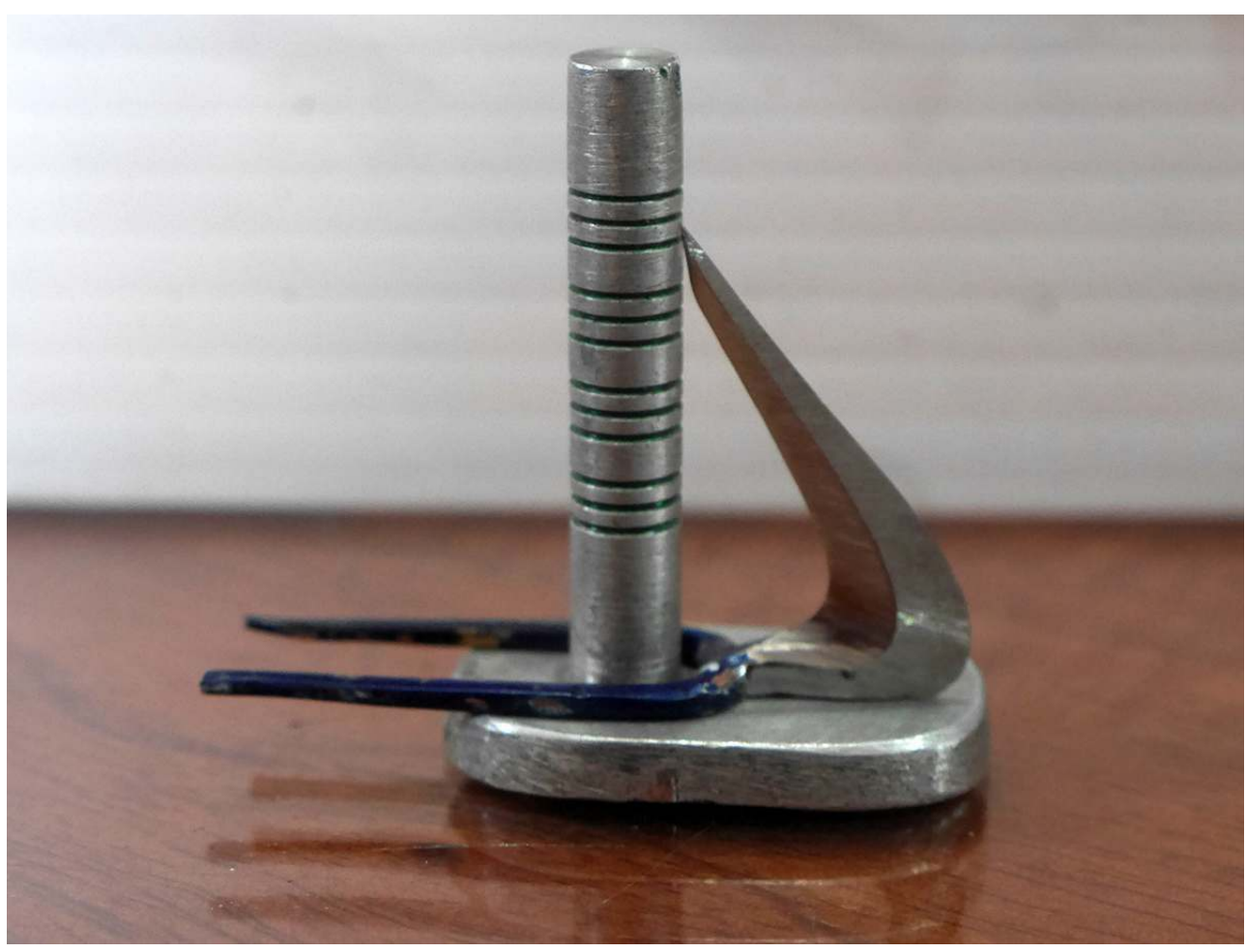

(c) S. Bahuchet 


\section{Usages rituels}

\section{Offrandes}

36- Offrande pour autel funéraire

Figure 49 : Autel funéraire chinois MNHN-E-2015.14.1

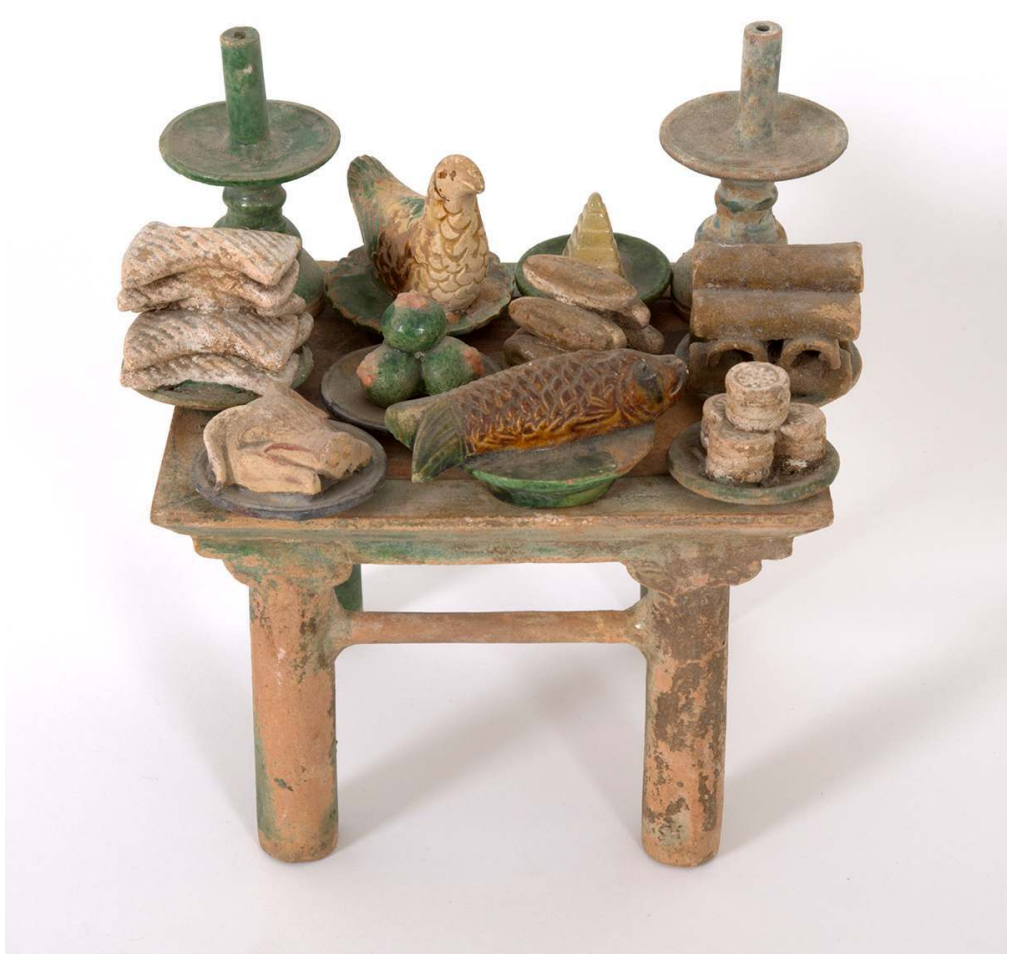

(c) J.-C. Domenech

104 Chine. Province du Henan ; XVII ${ }^{\mathrm{e}}$ siècle, dynastie Ming (1368-1644).

Terre cuite; céramique polychrome. Pièce d'un autel funéraire dont le plateau de table rectangulaire porte huit objets de dévotion liés à l'alimentation (carpe, poulet, porc, gâteaux, fruits, pains) flanqués de deux candélabres. "L'autel a la forme d'une table rectangulaire [...] [qui] accueille des objets de dévotion, ici un ensemble de dix pièces significatives, liées à l'alimentation autant qu'à leur poids symbolique fort. » « Le coq est l'animal choisi, d'une part en raison de la facilité avec laquelle son élevage est large dès le Néolithique dans les foyers de peuplements du cours du Fleuve Jaune et dans les provinces alentour, d'autre part, le jeu avec l'homophonie du caractère 'ji' (favorable) permet de montrer l'importance des aliments dans ce contexte précis. " (Comentale 2015).

8 avril 2015 ; collecteur Chengan Sun ; don Société des amis du Musée de l'Homme longueur $20 \mathrm{~cm}$ x hauteur $14 \mathrm{~cm}$, profondeur $15,7 \mathrm{~cm}$.

MNHN-E-2015.14.1 (exposé dans la Galerie de l'Homme)

37- Trois offrandes (ofrendas) pour autel de la fête des morts 

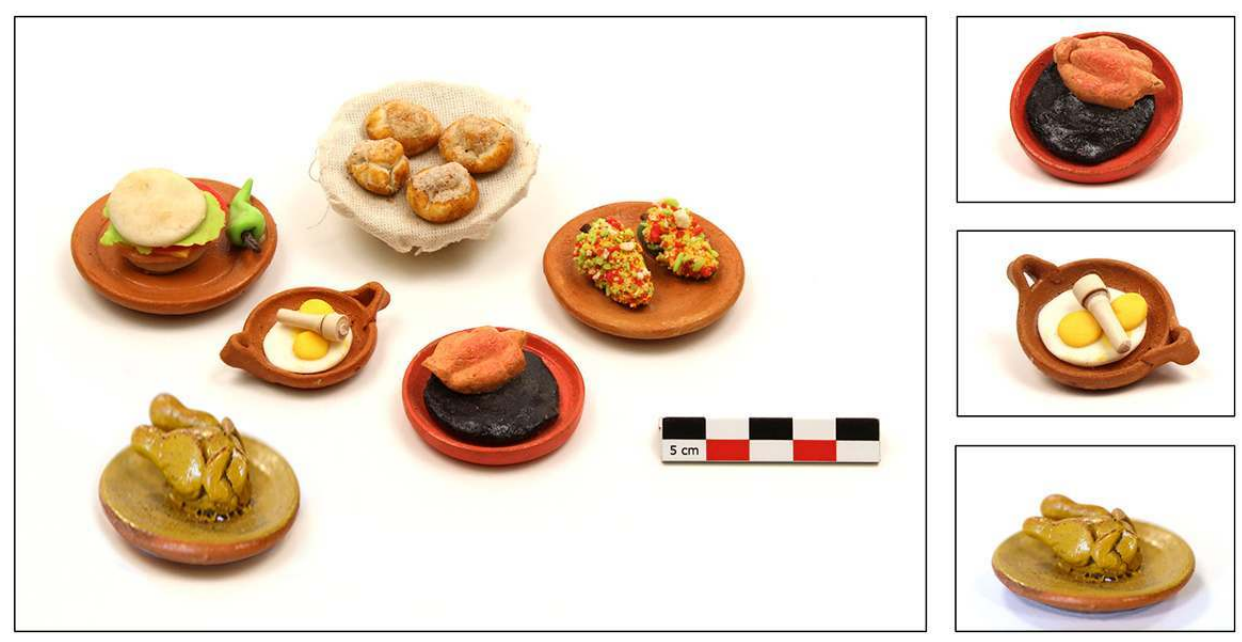

(C) P. Rameau

\section{Mexique. Guadalajara (Jalisco).}

Ensemble de 11 poteries et vanneries miniatures dont trois représentent des plats à base de poulet: poulet à la sauce mole (pollo con mole), œufs sur le plat (huevos estrellados) et poulet à la sauce de grains de courge (pipian de pollo). Pour le jour des morts (Día de los Muertos), le $1^{\text {er }}$ novembre, on construit un autel dans les maisons ou dans les lieux publics, pour honorer les défunts de l'année. Sur cet autel sont disposés, outre le portrait, des objets personnels du défunt et les aliments qu'il aimait, soit réels, soit en modèles de céramique comme ceux présentés ici. Ofrendas.

21/10/2011; collecteur Serge Bahuchet diamètre $4,5 \mathrm{~cm}$ (poulets en sauce); diamètre $3 \mathrm{~cm}$ (œufs)

ETB-MX-SB-2011-11 (une partie est exposée dans la galerie permanente du Musée de l'Homme)

\section{Amulettes d'Afrique occidentale}

En Afrique sahélo-soudanienne, la volaille, essentiellement les poulets, plus rarement les pintades, est l'objet d'un élevage domestique par les femmes. À l'occasion de la survenue d'un visiteur de marque, il est fréquent d'en égorger un poulet après une course poursuite souvent animée et sa capture par un enfant habile. La mise à mort par égorgement est toujours masculine et la cuisine féminine.

Lors de consultations de devins-guérisseurs d'obédience non islamique, il est fréquent qu'un poulet soit égorgé et son sang versé sur les objets qui constituent l'autel du génie, de même que parfois des plumes et des lambeaux d'entrailles (Figure 51). Ce peut être en même temps une occasion de guetter la réponse positive ou négative de ce génie aux sollicitations du client, par l'examen des «œufs du dos » du poulet, c'est-à-dire ses testicules, qui sont censés être de la même couleur en cas de réponse positive (Figure 52), ou de scruter le sens de la chute de l'animal après sa mise à mort, sur le dos ou sur le ventre. 
Enfin, la mise à mort d'un poulet et sa consommation par certaines personnes sont souvent une prescription de devins-guérisseurs, tout particulièrement de marabouts. L'aumône, le sacrifice, la sadaka (terme arabe), prescrits par le devin-guérisseur, sont un complément du traitement permettant de détourner les porteurs de mauvais œil, de mauvaise langue et sorciers-anthropophages qui cherchent à vous nuire, à compromettre le rétablissement de votre santé ou la réussite de vos entreprises. Le choix de la couleur du plumage, noir, rouge, blanc, « bariolé », est toujours précis.

110 En islam, le sang de l'animal mis à mort est versé sur le sol, le corps de l'animal étant orienté vers La Mecque.

111 Des plumes, une patte avec ses griffes, ou le crâne de l'animal sacrificiel sont parfois conservés, transformés en amulette ${ }^{2}$.

112 En Afrique, la poule est très usuellement un médiateur pour la communication avec les défunts ou les entités invisibles, ce qui se marque par son usage dans les sacrifices lors des cérémonies de guérison, de deuil ou de consécration. On en aura quelques exemples dans les vidéos suivantes.

Ce média ne peut être affiché ici. Veuillez vous reporter à l'édition en ligne http:// journals.openedition.org/ethnoecologie/3388

Ce média ne peut être affiché ici. Veuillez vous reporter à l'édition en ligne http:// journals.openedition.org/ethnoecologie/3388

Ce média ne peut être affiché ici. Veuillez vous reporter à l'édition en ligne http:// journals.openedition.org/ethnoecologie/3388

116 Sur les amulettes sénégalaises on consultera Epelboin et al. (2014). 
Figure 51 : Sacrifice d’un coq sur un autel bedik (Sénégal oriental, 1979)
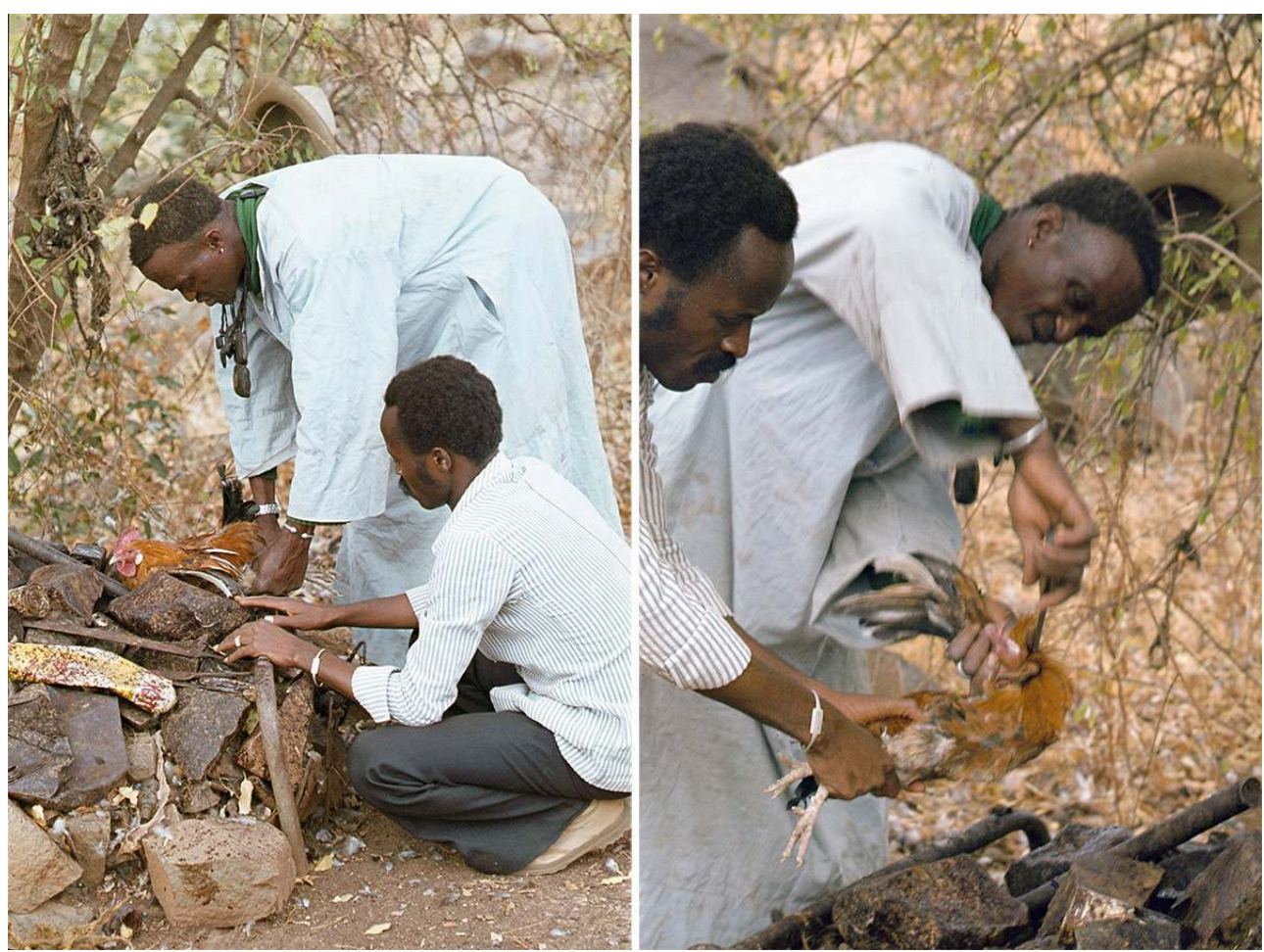

(C) A. Epelboin

Figure 52 : Sacrifice d'un coq sur une nouvelle tombe bukul et examen de ses entrailles (Guinée Bissau, 2001)
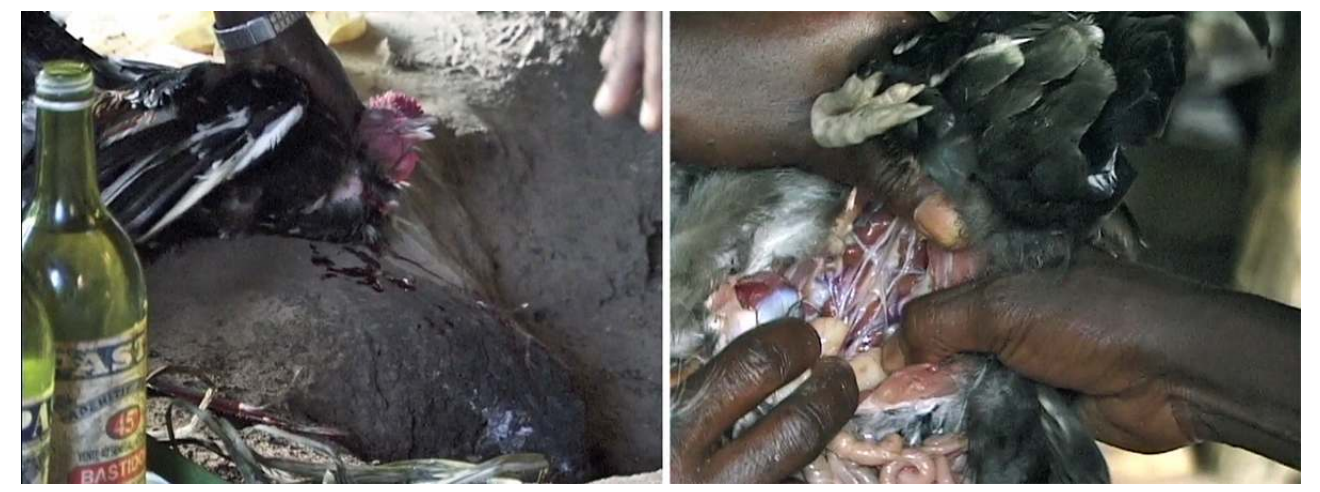

(c) M. Texeira

117 38- Amulette en plumes avec un cadenas 

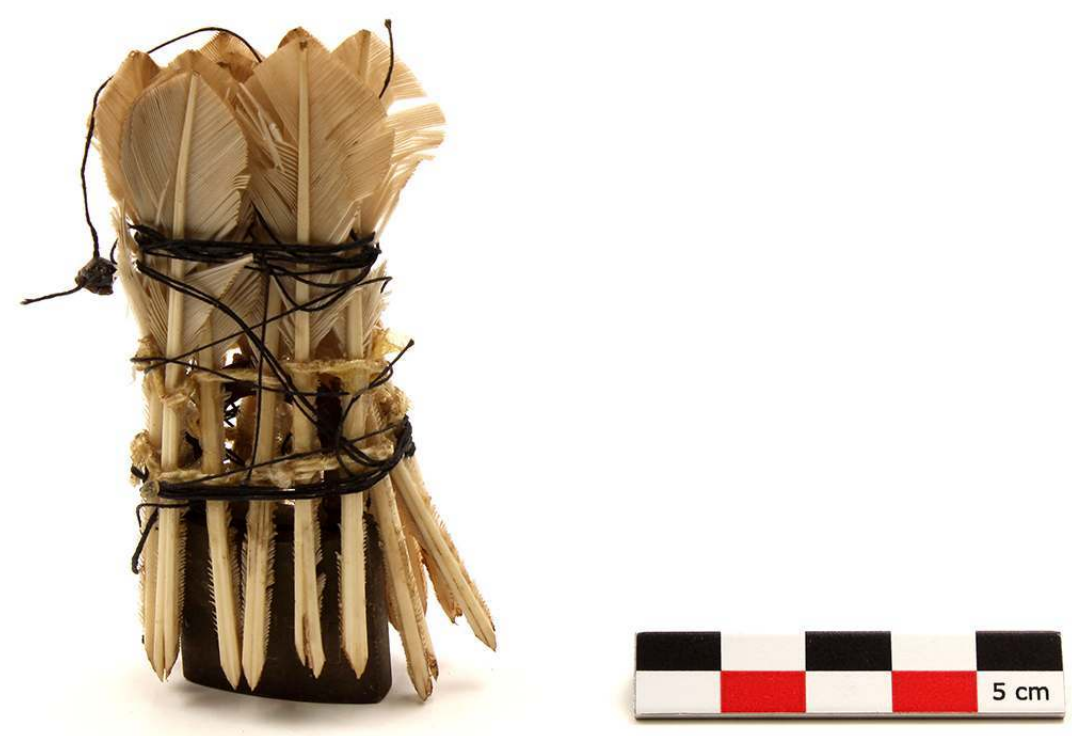

(c) P. Rameau

\section{Togo. Lomé.}

Seize plumes blanches taillées, attachées en cercle par deux fils de coton blanc, enroulées d'un faisceau de fils noir, et accrochées à un cadenas par un fil noir. Protège contre les accidents. À ne pas toucher au moment de rapports sexuels, lors des règles ou lorsqu'une femme est enceinte.

longueur $8 \mathrm{~cm}$ x largeur 3,5 cm (plumes) ; longueur $4 \mathrm{~cm}$ x largeur 2,5 cm (cadenas) 11/08/1993 ; collecteur Alain Epelboin ALEP10505

39- Amulette en patte de poulet 


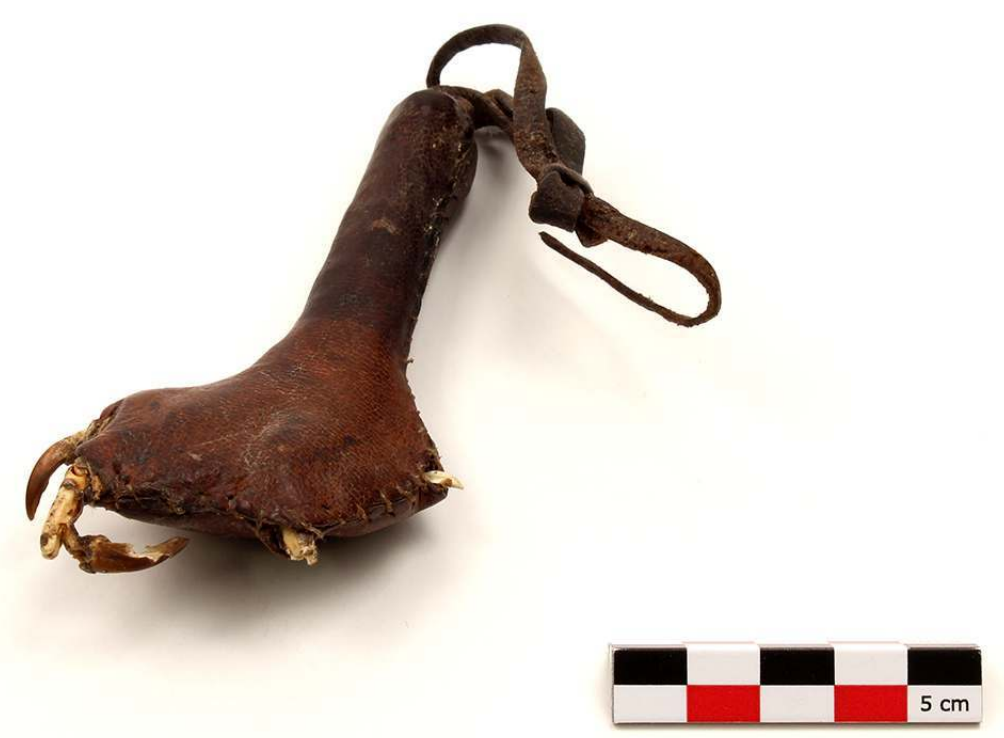

(c) P. Rameau

Sénégal. Dakar, décharge à ordures de Mbebess.

Patte de poulet dans un étui de cuir cousu - seules les griffes sont nues. Un brin de cuir pour la suspendre. Probable reste d'un poulet sacrifié sur un autel de génie. La patte est gainée de cuir, ce qui facilite sa prise en main pour l'agiter au cours de son usage rituel. 1997 ; collecteur Alain Epelboin longueur $12 \mathrm{~cm}$ x largeur $6 \mathrm{~cm}$; longueur $7 \mathrm{~cm}$ (brin de suspension) ALEP07008

121 40-Amulette en patte de poulet 
Figure 55 : Amulette en patte de poulet ALEP00175

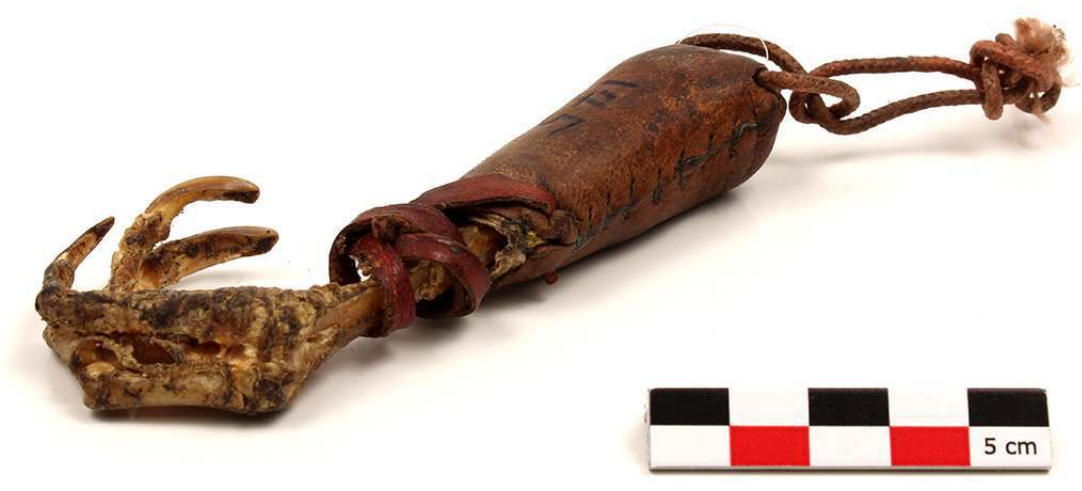

(c) P. Rameau

Sénégal. Dakar, décharge à ordures de Mbebess.

Patte de poulet dans un étui de cuir cousu - l'ensemble de la patte est nue. Un cordon noué pour la suspendre.

1985 ; collecteur Alain Epelboin

longueur $12 \mathrm{~cm}$ x largeur $5 \mathrm{~cm}$; longueur $7 \mathrm{~cm}$ (brin de suspension)

ALEP00175

123 41- Amulette en crâne de poulet 


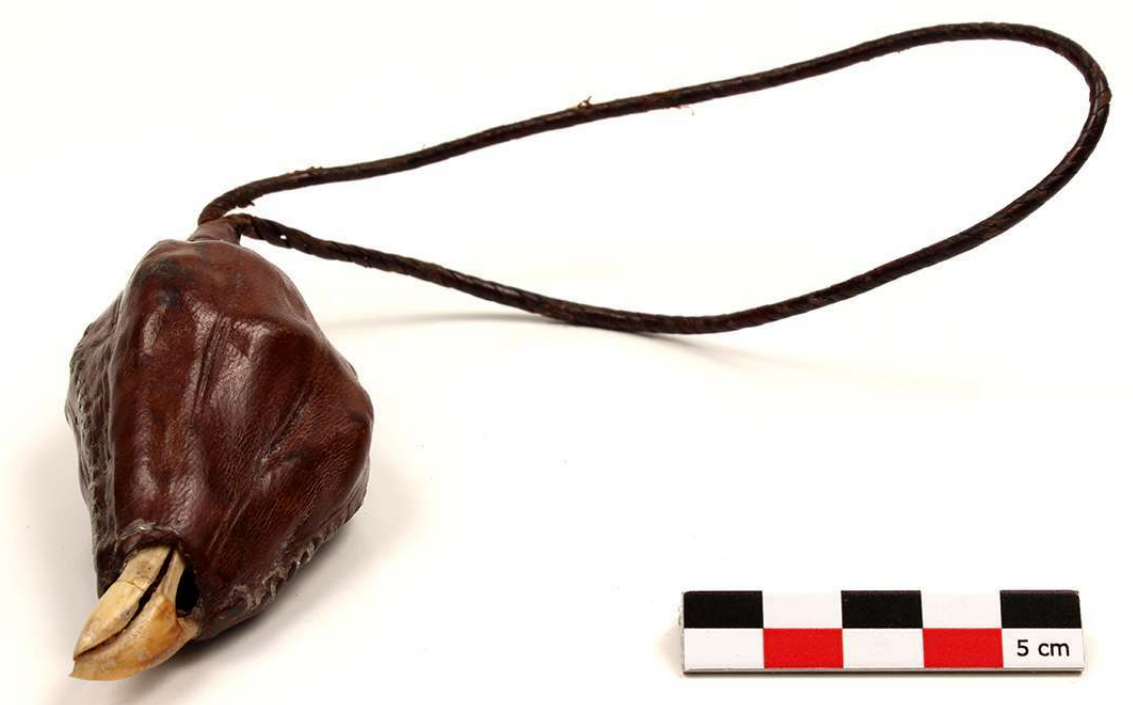

(c) P. Rameau

124 Sénégal. Dakar, décharge à ordures de Mbebess.

Crâne de poulet cousu dans un étui de cuir de chèvre. Le bec est apparent. Un brin de cuir tressé pour la porter en bracelet sur le haut du bras.

2009 ; collecteur Alain Epelboin

longueur $10 \mathrm{~cm}$ x largeur $4 \mathrm{~cm}$; longueur $10 \mathrm{~cm}$ (boucle de suspension)

ALEP45104

125 42-Amulette triple 
Figure 57 : Amulette triple ALEP $35113 a$

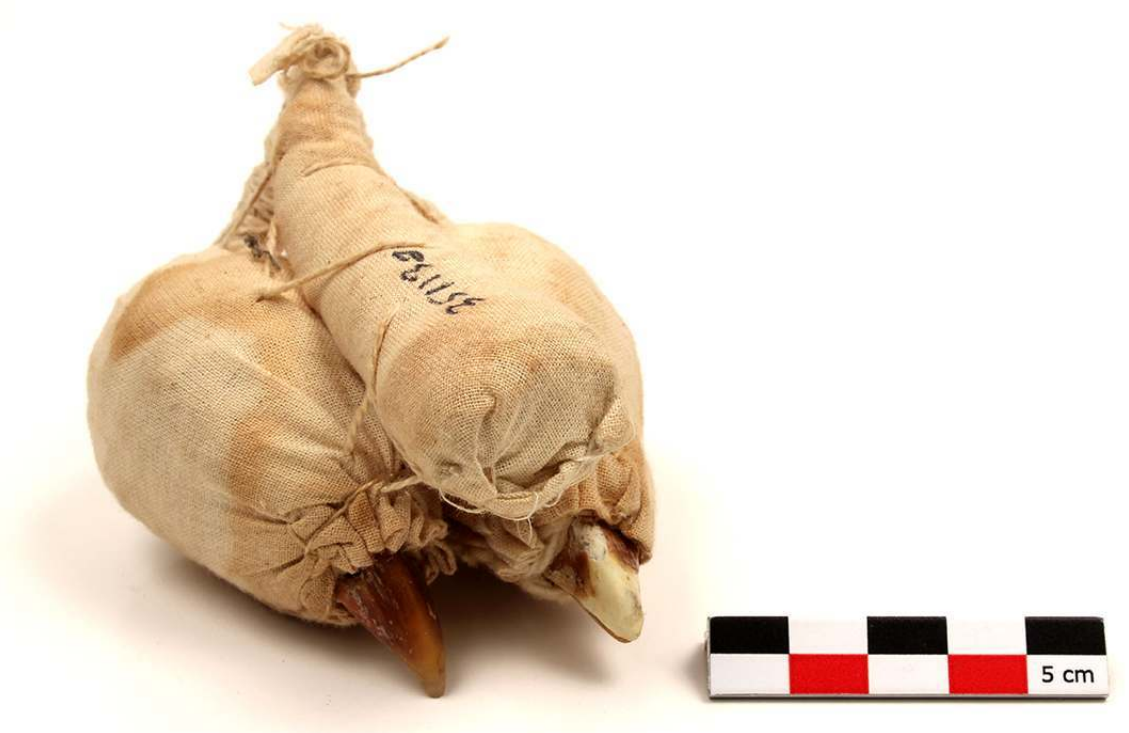

(c) P. Rameau

126 Sénégal. Dakar, décharge à ordure de Mbebess.

Composée de deux crânes de poulets avec le bec apparent et d'une corne animale, cousus dans un tissu de coton blanc, probablement de fabrication hausa.

2005 ; collecteur Alain Epelboin

longueur $8 \mathrm{~cm}$ x largeur $7 \mathrm{~cm}$

ALEP35113a

127 43- Amulette triple 


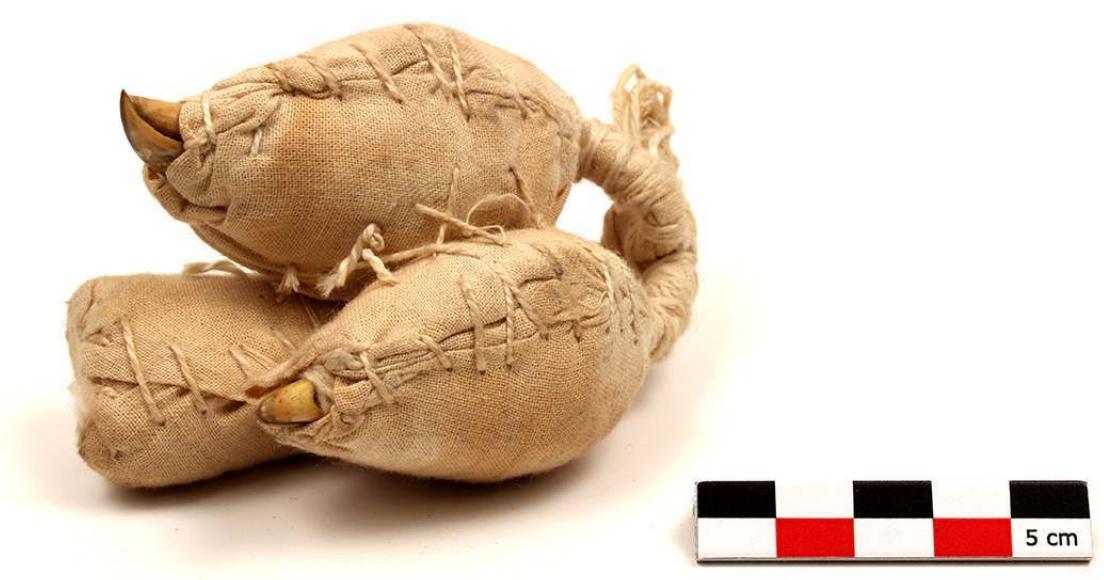

(c) P. Rameau

128 Sénégal. Dakar, décharge à ordures de Mbebess.

Composée de deux crânes de poulets avec le bec apparent et d'une corne animale, cousus dans un tissu de coton blanc. 2005 ; collecteur Alain Epelboin longueur $10 \mathrm{~cm}$ x largeur $6 \mathrm{~cm}$ ALEP35113b

129 44- CEuf dans une petite bouteille 


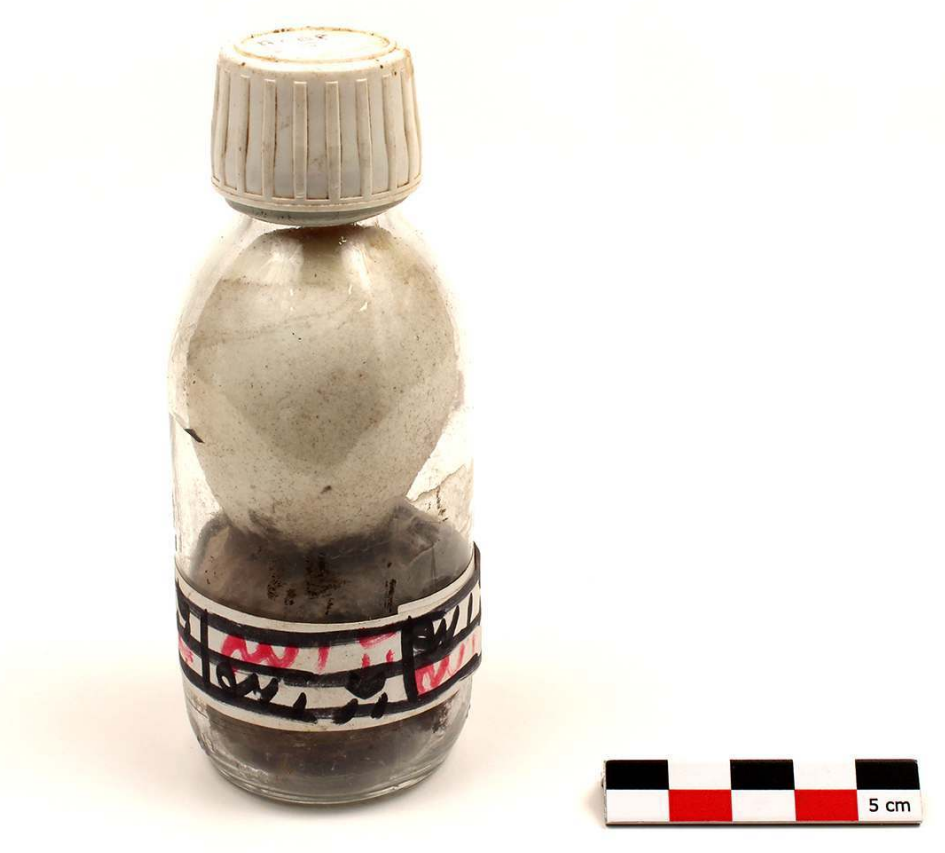

(c) P. Rameau

Sénégal. Dakar, marché de Tilène.

Bouteille de verre transparent, avec bouchon en plastique à vis, contenant une coquille d'œuf entière, vide, posée sur un bobinage de fil noir. Une bande de papier portant des inscriptions illisibles, à l'encre noire et rouge, est collée autour de la bouteille. Cette bouteille « magique » a été fabriquée et vendue à proximité du marché de Tilène de Dakar par des commerçants hausa, originaires du Nigéria. L'introduction de gros objets, œuf, cadenas..., est basée sur l'obtention d'un trait de fracture du verre par un choc thermique, masqué par le papier recouvert d'écritures talismaniques. Ce type d'objets, basés sur des techniques d'illusionnisme, impressionne énormément et fait attribuer à son propriétaire des pouvoirs surnaturels.

2003 ; collecteur Alain Epelboin

diamètre $4,5 \mathrm{~cm}$, hauteur $12 \mathrm{~cm}$

ALEP40067

Cf. Epelboin 2017 : 178-183.

45- Tunique de chasseur/devin-guérisseur 


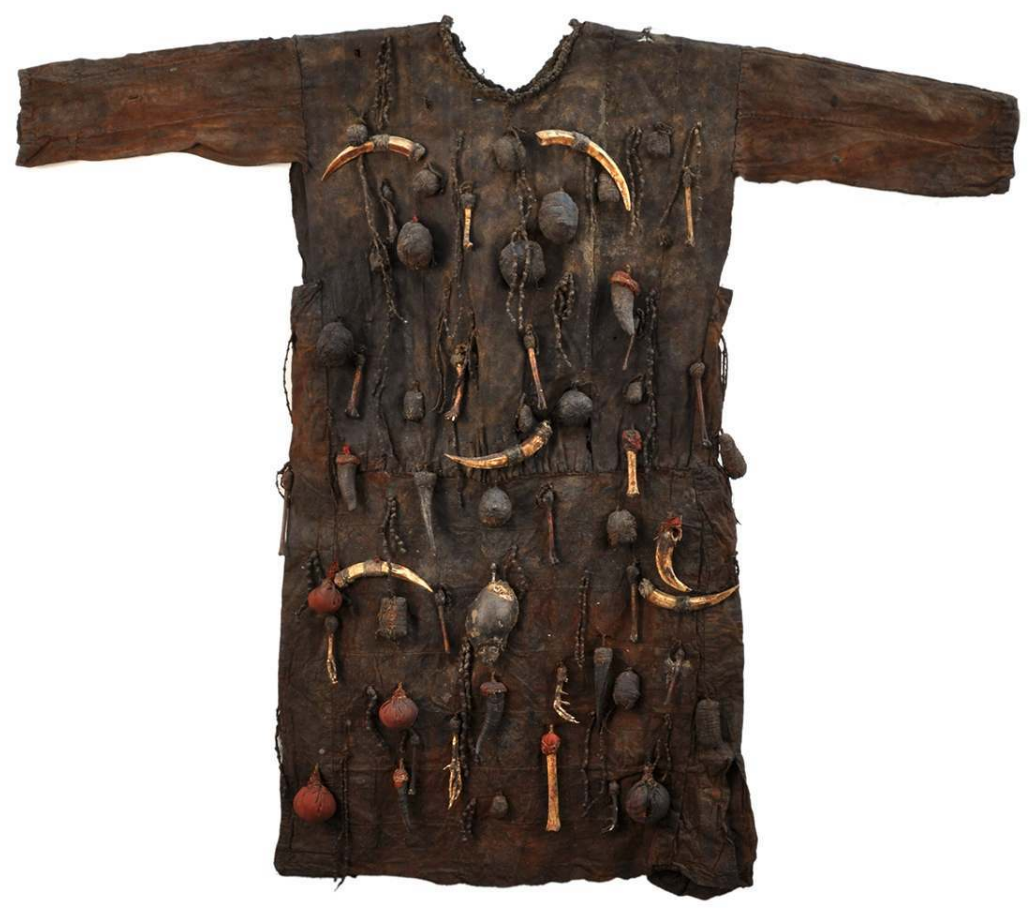

(C) D. Brabant

Guinée.

Tunique de chasseur en toile de coton, légèrement évasée vers le bas, manches troisquarts, encolure ronde. 83 amulettes fixées sur le devant et 67 , sur le dos : nouets en tissu contenant des matières végétales, paquets en tissu ficelés, cordelettes et rubans de coton comportant des nœuds, cornes, os longs, dents de phacochère, coquilles d'Achatine. Deux pattes de coqs (nues, avec l'ergot bien visible) et deux pattes de poule (voir détail Figure 61).

Don anonyme, d'une personne résidente l'ayant obtenu sur place auprès du devinguérisseur.

longueur $107 \mathrm{~cm}$ x largeur $120 \mathrm{~cm}$

MNHN-E-2002.37.1 
Figure 61 : Détails de la tunique
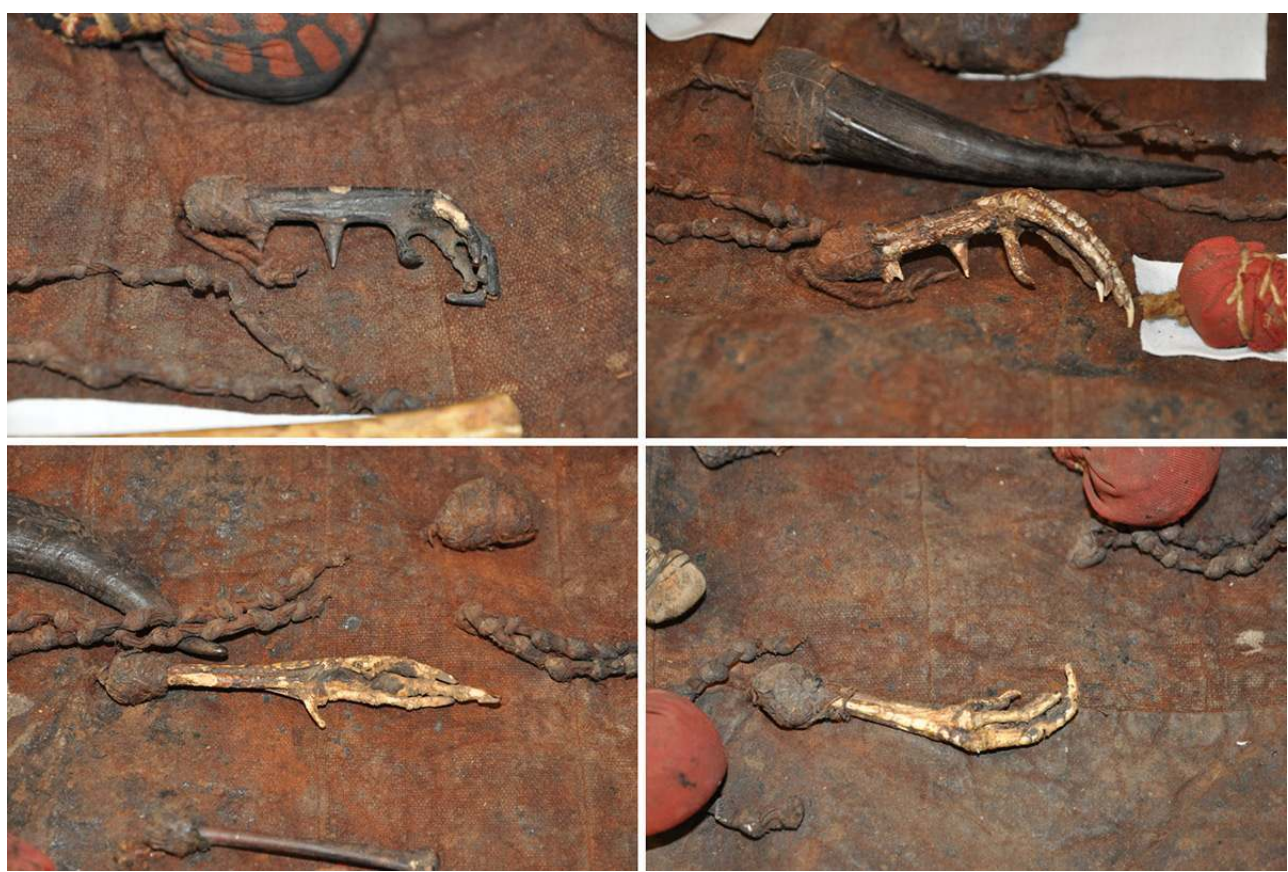

(C) D. Brabant

\section{Amulettes du zodiaque asiatique}

\section{Le Coq dans le zodiaque asiatique}

Le coq est le dixième animal du zodiaque de douze. L'année 2017 était une année du coq (calendrier lunaire, 28 janvier 2017-15 février 2018.

\section{Le Coq selon la symbolique chinoise ${ }^{3}$}

Le coq fait partie des douze animaux cycliques, correspondant à un cycle de douze ans. Chacun de ces animaux possède son symbolisme. Aussi certaines années sont-elles considérées comme plus fastes que d'autres (l'année du dragon par exemple, pour la naissance d'un garçon). Le coq est de nature yang, comme le soleil (et il crie lorsque le soleil se lève). Il a le pouvoir de chasser les fantômes, les mauvais esprits, il les disperse au matin (car les fantômes rôdent la nuit). Il symbolise aussi la protection, puisqu'il mange les insectes, susceptibles d'apporter la maladie, des morsures, etc. Étant yang, il protège des incendies. On le représente pour chasser les influences néfastes. C'est pourquoi il est aussi représenté sur des images de Nouvel An.

Coq se dit ji 鸡 ce qui est homophone de $j i$ 吉 « de bonne augure». Beaucoup de symboles chinois jouent sur les homophonies (la chauve-souris, $f u$ 蝠, symbole du bonheur fu 福, sera représentée fréquemment dans le décor de la maison, des meubles, de la céramique, etc.). Le coq, avec sa crête guan 冠, symbolise la possibilité d'entrer dans la bureaucratie (et donc d'avoir un chapeau de mandarin guan 冠) et de réussir comme fonctionnaire.

46- Amulette chinoise, pendentif « coq » du zodiaque 
Figure 62 : Trois pendentifs, de gauche à droite ETB-FR-SB-2017-004, 2017-003, 2017-005
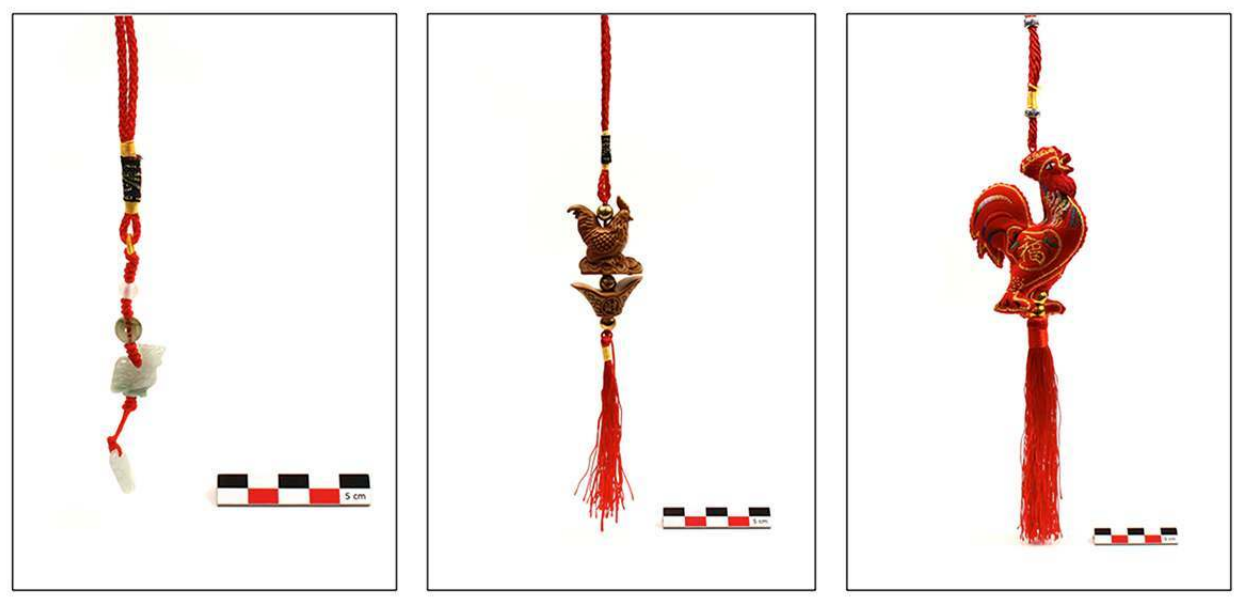

(C) P. Rameau

Chine. Achat à Paris.

Petit pendentif en jade, pour téléphone portable. Fil rouge tressé.

2 octobre 2017 ; collecteur Serge Bahuchet

longueur totale $19 \mathrm{~cm}$ x largeur $1,5 \mathrm{~cm}$

ETB-FR-SB-2017-004

47- Amulette chinoise, pendentif « coq » du zodiaque

Chine. Achat à Paris.

Petit pendentif en plastique, sur fil rouge tressé.

2 octobre 2017 ; collecteur Serge Bahuchet

longueur totale $24 \mathrm{~cm} \times$ largeur $3 \mathrm{~cm}$

ETB-FR-SB-2017-003

48-Gros pendentif chinois « coq » du zodiaque

Chine. Achat à Paris.

Pendentif en tissu brodé, pour la maison.

2 octobre 2017 ; collecteur Serge Bahuchet

longueur totale $34,5 \mathrm{~cm}$, longueur $\mathrm{du}$ coq $10,5 \mathrm{~cm}$ x largeur $8,5 \mathrm{~cm}$

ETB-FR-SB-2017-005

49-Grelot japonais en forme de « coq » du zodiaque 


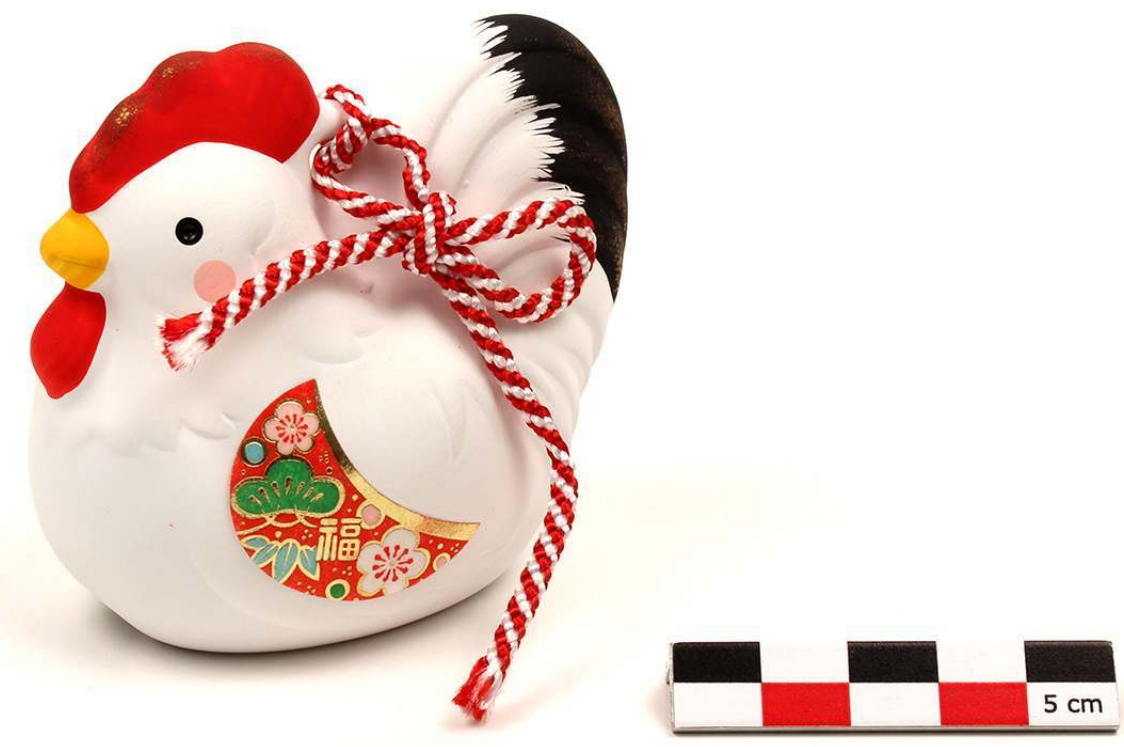

(c) P. Rameau

144 Japon. Achat à Paris.

Grelot en plâtre peint. Un cordon tressé pour le tenir. Se pose sur un petit carré de feutre rouge, sur un meuble.

2 octobre 2017 ; collecteur Serge Bahuchet

longueur $8,6 \mathrm{~cm}$ x largeur $7,5 \mathrm{~cm}$

ETB-FR-SB-2017-002

50- Amulette japonaise, pendentif « coq » du zodiaque 
Figure 64 : Pendentif « coq » ETB-FR-SB-2017-001

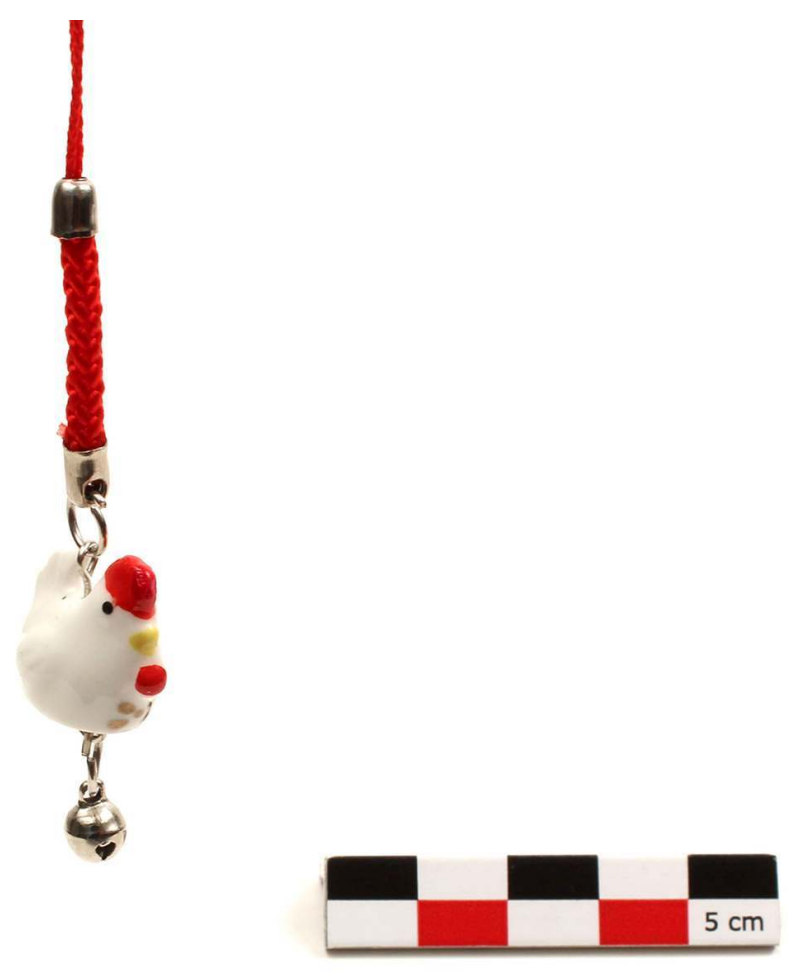

(c) P. Rameau

Japon. Achat à Paris.

Petit pendentif en porcelaine, pour téléphone portable. Fil rouge tressé.

2 octobre 2017 ; collecteur Serge Bahuchet

longueur $2 \mathrm{x}$ largeur $3,5 \mathrm{~cm}$; fil 7,2 cm

ETB-FR-SB-2017-001

\section{Esthétique}

\section{Motifs zoomorphes}

\section{Représentations à plat}

\section{Impressions}

147 Trois estampes populaires vietnamiennes, insérées dans une pochette de 13 estampes, intitulée Tranh Dân Gian Viêt Nam.

Estampes populaires de Dong Ho (province septentrionale de Bac Ninh).

Xylogravure : impression par blocs de bois gravés, 1 bloc différent pour chaque couleur. Le papier est fait de l'écorce de Rhamnoneuron balansae (Drake) Gilg (Thymelaeaceae), nom vietnamien dó, que l'on enduit d'un mélange de nacre moulue et de poudre de riz, passé avec une large brosse en aiguilles de pin. La surface ainsi obtenue, pourvue d'un éclat iridescent, est à la fois douce, résistante et absorbante, sur laquelle l'encre entre facilement sans déborder de ses contours.

Ces estampes sont ou étaient offertes aux adultes au moment de la fête du Têt, au nouvel an, pour exprimer des souhaits. Elles ornent les maisons pendant l'année. 
Cette technique propre au village de Dong Ho a été reconnue comme Patrimoine culturel immatériel national. Le nombre d'artisans a considérablement régressé, du fait d'un net désintérêt pour ces gravures, remplacées par des photographies ou des imprimés. Mais la clientèle touristique permet à cette production de rester vivante. Sur les gravures de Dong Ho, voir Trang \& Kim 2015.

Ancienne collection du laboratoire d'Ethnobotanique du Muséum

ETB-VN-ETB-2017-1

51- La poule et ses poussins

Figure 65 : Estampe vietnamienne ETB-VN-ETB-2017-1a

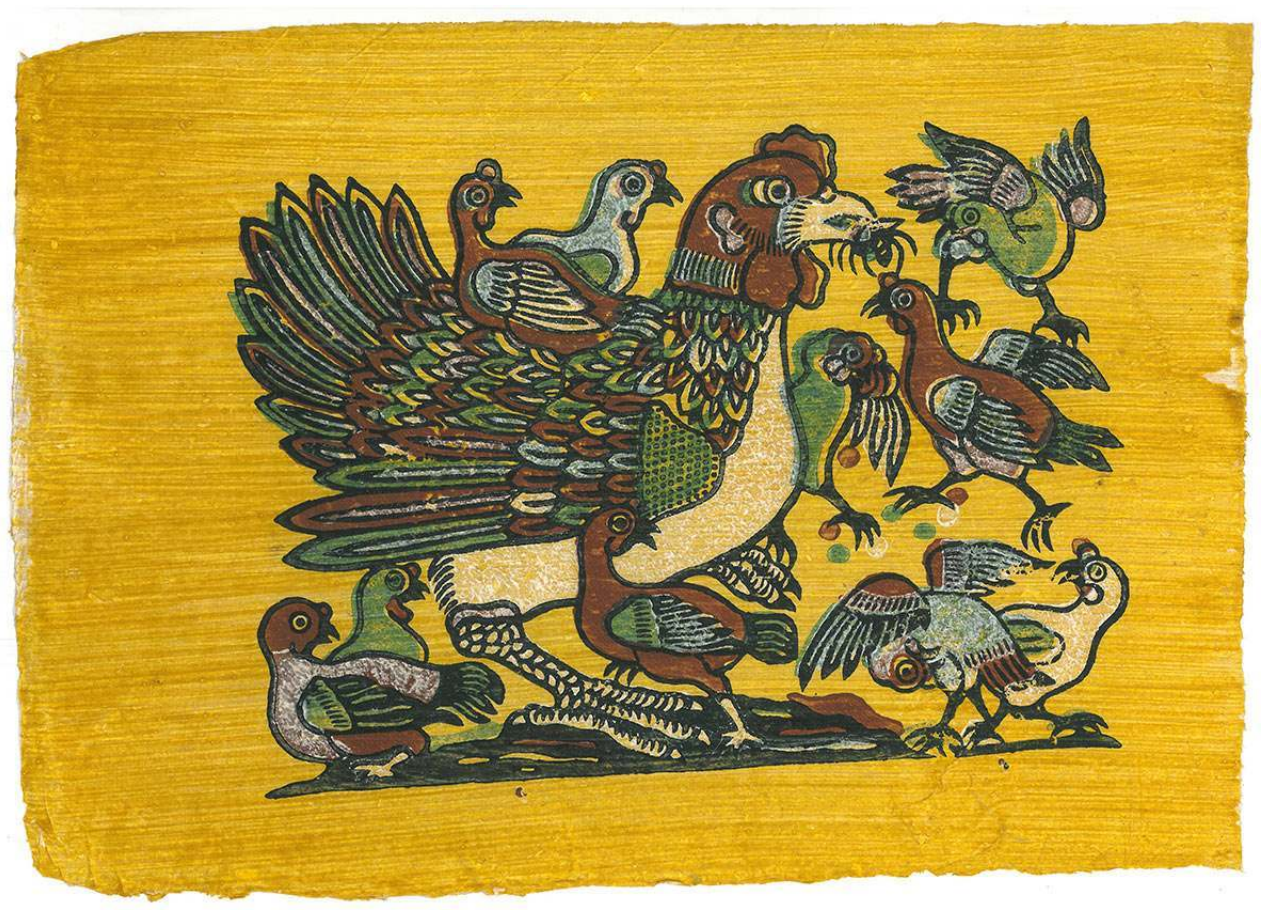

149 Vietnam. Dong Ho (Bac Ninh)

Estampe représentant une poule entourée de ses poussins (Gia dinh gà «famille de poulets »). C'est pour exprimer le souhait d'une famille nombreuse et heureuse, ce que symbolise la poule entourée par ses poussins.

Papier coloré en orange, couleur obtenue par la térébenthine. Impression en cinq couleurs.

Longueur $25 \mathrm{~cm}$ x largeur $36,3 \mathrm{~cm}$

ETB-VN-ETB-2017-1a

52- Un garçon tenant un coq 
Figure 66 : Estampe vietnamienne ETB-VN-ETB-2017-1b

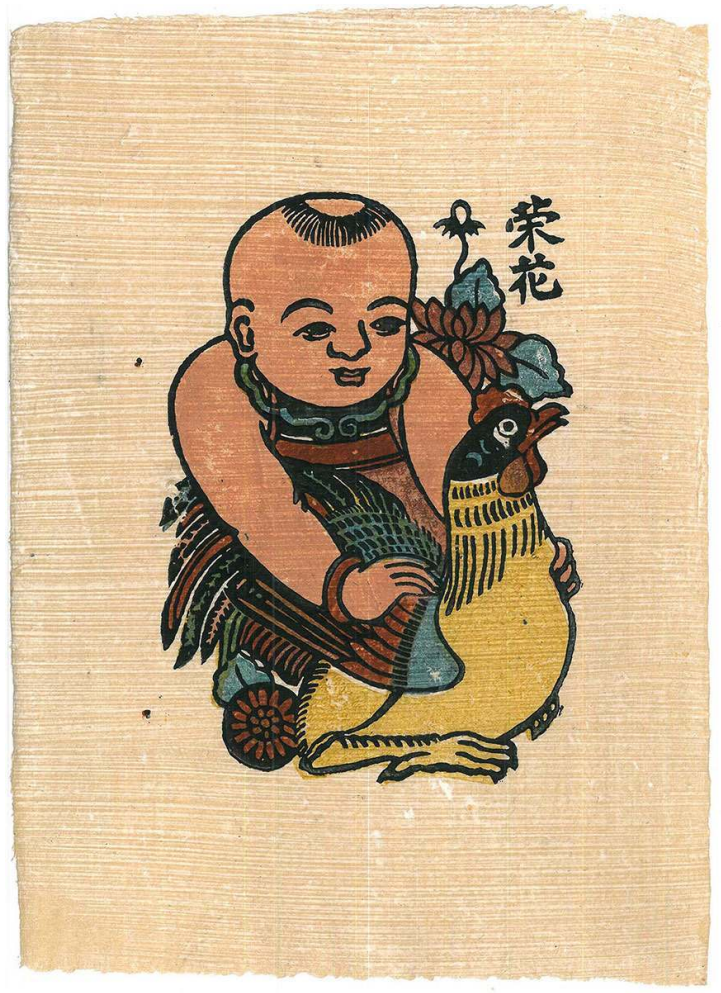

151 Vietnam. Dong Ho (Bac Ninh)

Estampe représentant un garçon tenant un coq, représentant la vertu, l'honneur (vinh hoa ). Cette image va de pair avec celle d'une fillette tenant un canard, signifiant prospérité et richesse (phú quý).

Papier blanc. Impression en cinq couleurs.

Longueur $36 \mathrm{~cm}$ x largeur $26 \mathrm{~cm}$

ETB-VN-ETB-2017-1b

152 53- Deux coqs face à face 
Figure 67 : Estampe vietnamienne ETB-VN-ETB-2017-1c

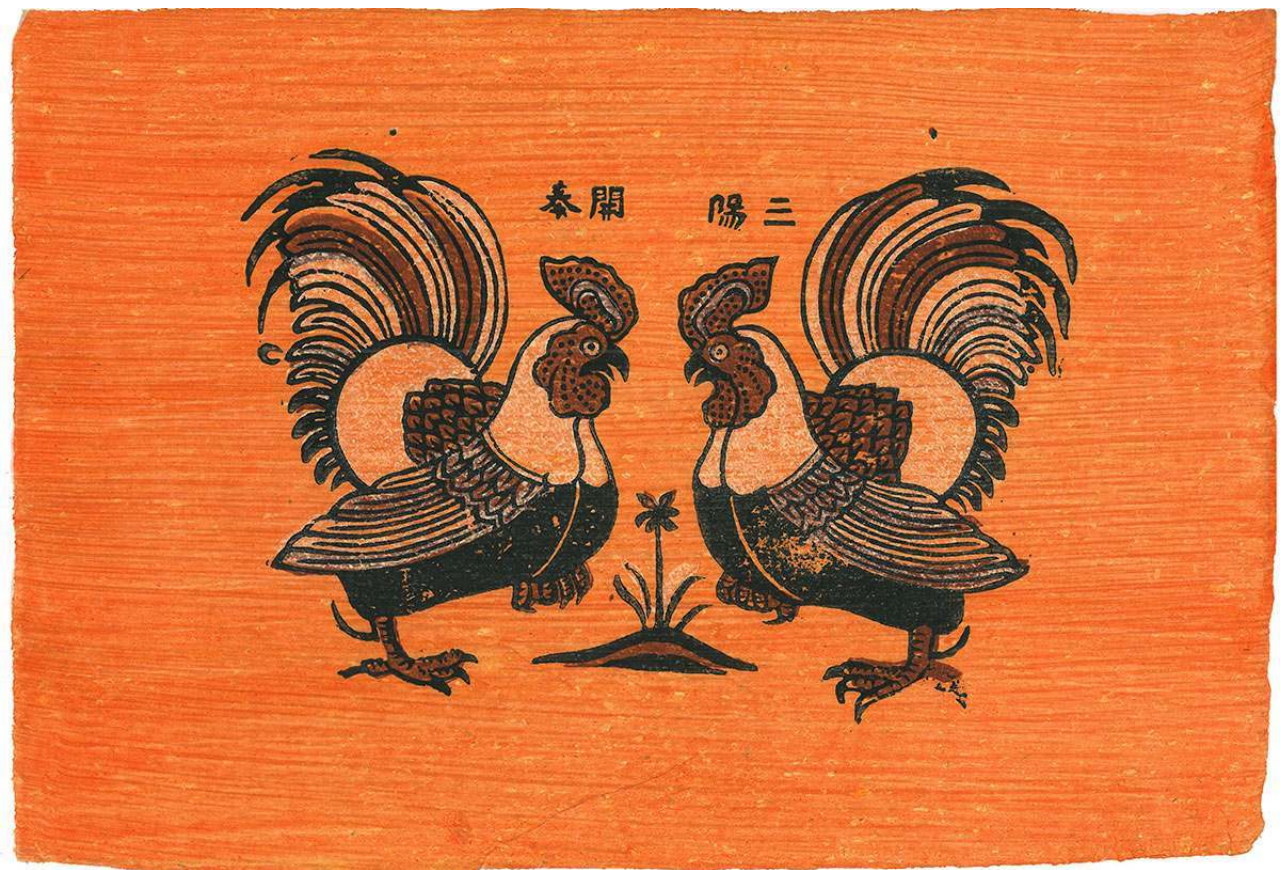

Vietnam. Dong Ho (Bac Ninh)

Estampe représentant deux coqs face à face. Le coq symbolise la force, le courage. Les deux coqs représentent le jour (à droite) et la nuit (à gauche), c'est à dire les heures auxquelles ils chantent, « les cinq veilles ", chassant les mauvais esprits et annonçant les bonnes choses.

Papier coloré en rouge, obtenue par de la poudre de terre rouge. Impression en quatre couleurs.

Longueur $24,3 \mathrm{~cm}$ x largeur $36,3 \mathrm{~cm}$

ETB-VN-ETB-2017-1c

\section{Broderie de fil}

54- pochette de ceinture brodée 


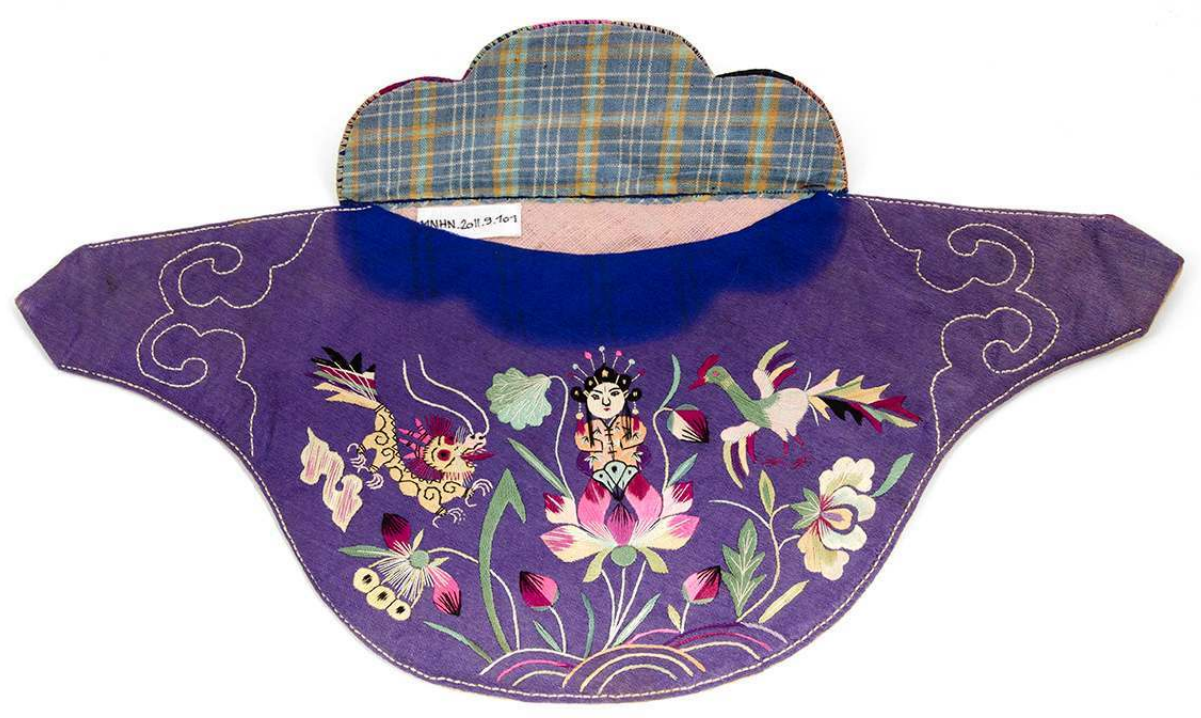

(C) D. Brabant

Chine. Province du Yunnan ou du Shanxi.

Pochette de ceinture, en soie bleue brodée à l'avant et en tissu de coton type " écossais " dans les tons bleus à l'arrière; doublée de tissu de coton rose.

De forme semi-circulaire, elle comporte de chaque côté une patte à bord triangulaire, ouverte, permettant de passer la bande de la ceinture. La pochette est fermée par un rabat trilobé, brodé de deux fleurs (jaune et rose) et bordé d'un point de bourdon en fils multicolores. Sur le devant, le décor est composé au centre d'un personnage en kimono jaune, sortant d'une fleur de lotus à dominante rose. À sa gauche sont placés une feuille verte et un dragon jaune ; à sa droite sont placés un bouton de fleur blanche et rose et un coq vert et blanc, aux plumes des ailes et de la queue multicolores. Le bas de la pochette est orné de deux autres fleurs, une de chaque côté du lotus, et de deux boutons de fleurs roses. A l'arrière est brodé un motif géométrique en fil noir.

Entre 1970 et 1985 ; collecteurs Jean-Louis Boissier et Liliane Terrier

hauteur $15,7 \mathrm{~cm}$ x largeur max. (de pointe à pointe) $34 \mathrm{~cm}$

MNHN.E.2011.9.101.2

\section{Broderies de perles}

55- Quatre tabliers de perles 
Figure 69 : Quatre tabliers de perles MNHN-E-2008.2.143, MNHN-E-2008.2.144, MNHNE-2008.2.145, MNHN-E-2008.2.154
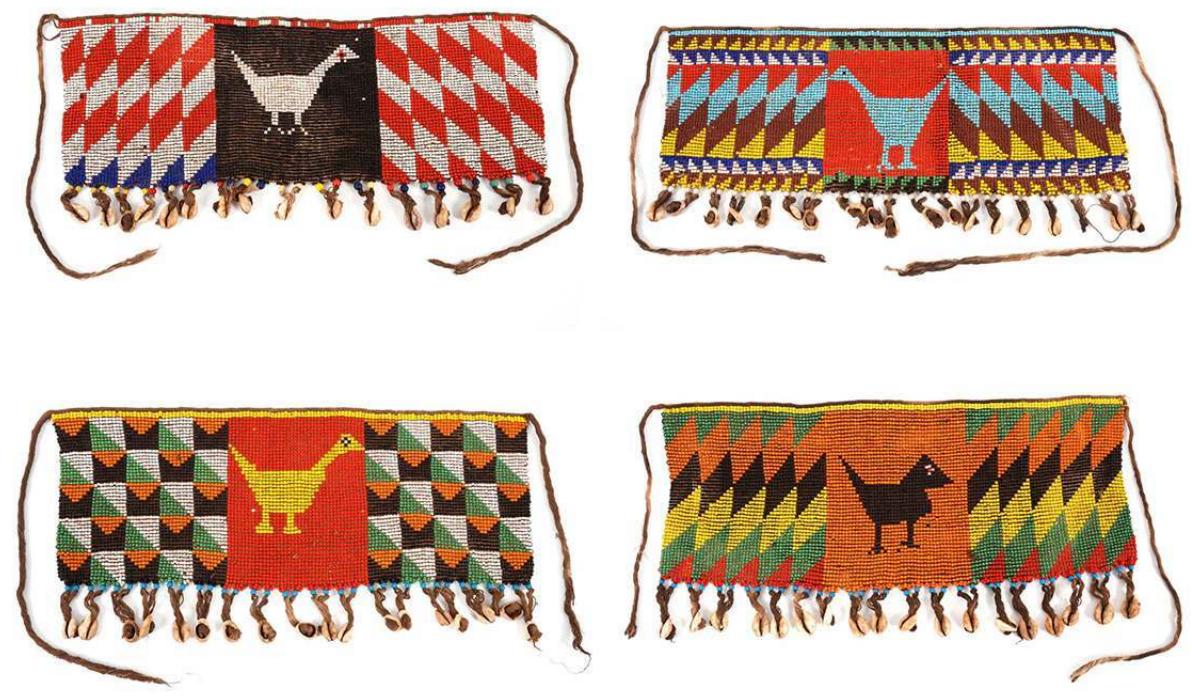

(C) J.-C. DOMENECH

157 Nord Cameroun.

Tabliers de perles de verre multicolores.

2008. Saisie. Don Direction régionale des Douanes de Paris longueur $20 \mathrm{~cm}$ x largeur $43 \mathrm{~cm}$

MNHN-E-2008.2.143

MNHN-E-2008.2.144

MNHN-E-2008.2.145

MNHN-E-2008.2.154

\section{Représentations en relief}

Gravure incisée

56- Seau en écorce de bouleau 


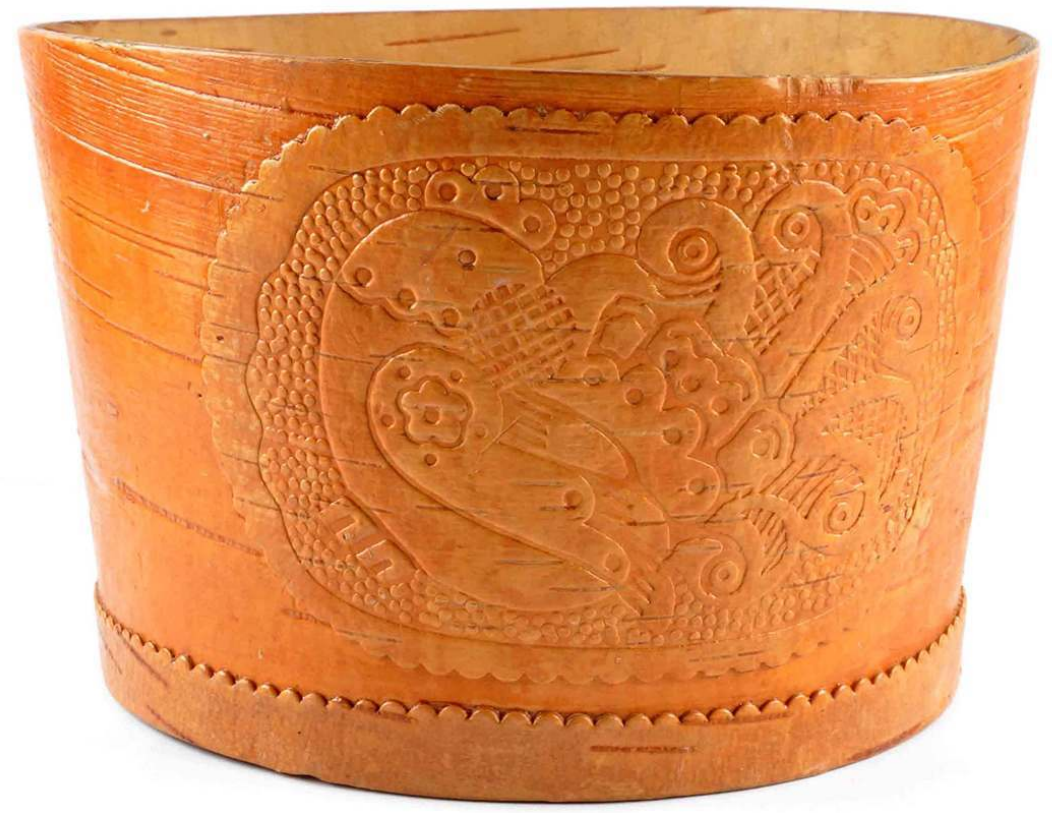

(c) D. Brabant

Russie. Acheté à Paris (vide-grenier).

Seau touiess en écorce de bouleau Betula pour contenir des aliments secs. Forme ronde évasée. Décor sur empiècement de forme ovale en écorce collée de chaque côté du panier, avec motif de coq. Fond renforcé par une bande d'écorce collée le long de la base. Écorce externe vernis. Couvercle manquant.

hauteur $12,6 \mathrm{~cm}$, diamètre $19,6 \mathrm{~cm}$

2010 ; collectrice Tatiana Fougal

MNHN-E-2010.7.14

\section{Moulage, fonderie}

57- Deux poids à peser la poudre d'or 

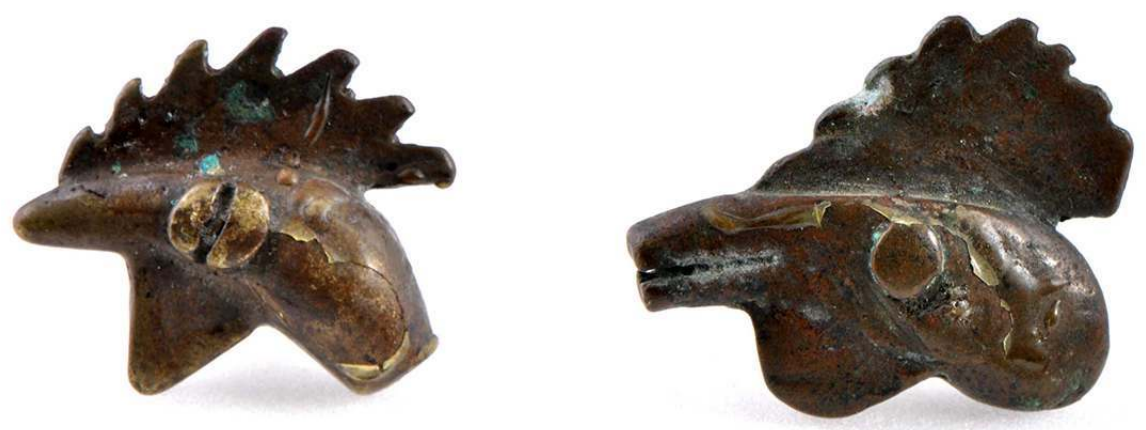

(C) D. Brabant

161 Akan, Ashanti. Côte d'Ivoire.

Poids à peser en laiton représentant une tête de coq.

Années 1960 ; collecteur Jacques David

hauteur $2,5 \mathrm{~cm}$ x largeur $2 \mathrm{~cm}$

MNHN-E-2003.10.59

MNHN-E-2003.10.60

58- Fer à repasser en fonte

Figure 72 : Fer à repasser MNHN-E-2013.14.8

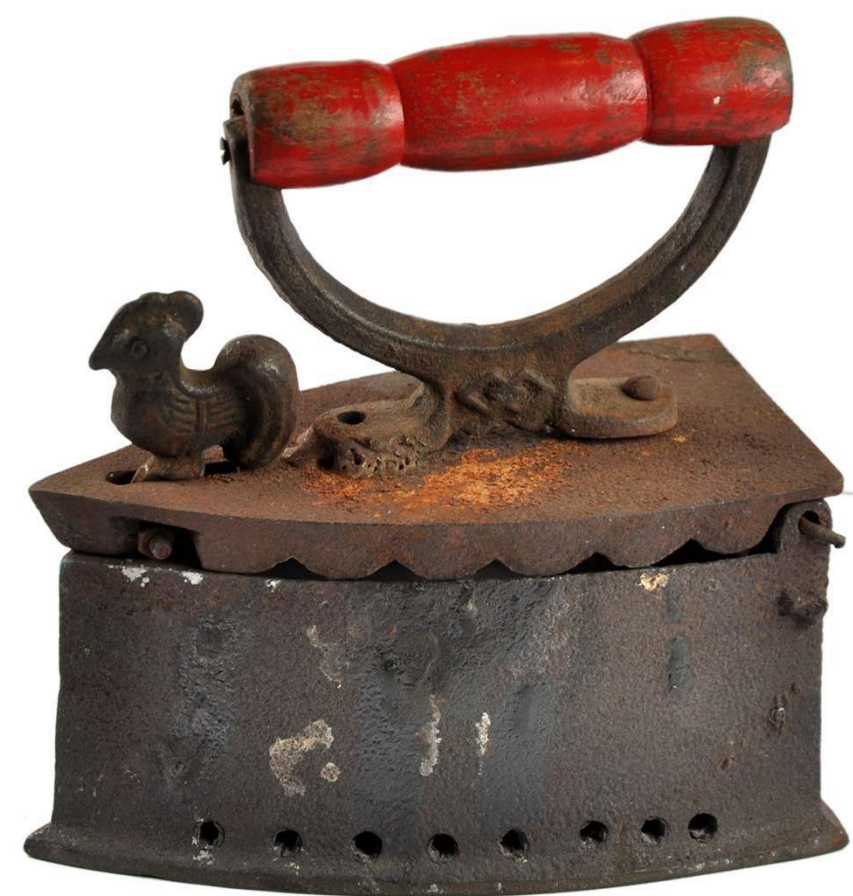

(c) D. Brabant 
Libéria. Quartier Bye-Pass, Monrovia, dans une boutique de couture.

Fer à repasser creux à charbon, en fonte. Constitué de deux parties, corps principal et couvercle. Le corps principal comporte des trous d'aération disposés horizontalement près de la base; une grille amovible est disposée au fond. Le couvercle comporte un rebord festonné et une poignée constituée d'une partie basse demi circulaire rivetée au couvercle, surmontée d'une partie en bois à section ronde peinte en rouge. Le couvercle est fixé à la base du fer par une charnière ; le système de fermeture est assuré par un crochet mobile surmonté d'un coq.

longueur $17 \mathrm{~cm}$ x largeur max. 9,2 cm x hauteur $17,5 \mathrm{~cm}$

20 juillet 2013 ; collecteur Carlo de' Reguardati

MNHN-E-2013.14.8

Pains

59- Pain d'épice en biscuit

Figure 73 : Pain d'épices MNHN-E-2009.4.15

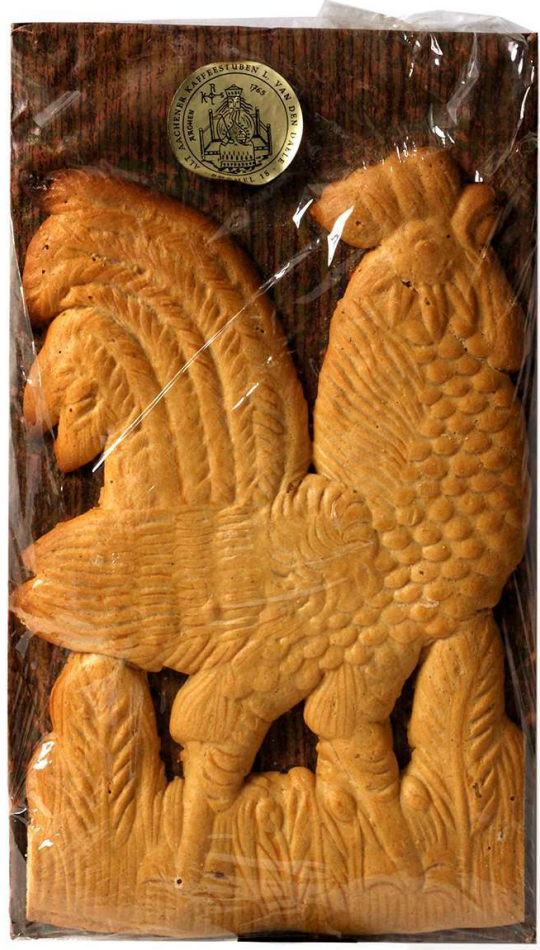

\section{(C) J.-C. Domenech}

Allemagne. Aix-la-Chapelle (Rhénanie du Nord-Wesphalie). Alt Aachener Kaffeestuben Van den Daele.

Biscuit en forme de coq dressé, moulé dans un moule de bois gravé. «A Aix-la-Chapelle [... ] ce ne sont plus de véritables pains d'épices, mais des printen, dans une pâte plus dure qui est plus celle d'un biscuit. Cette fabrication de "gâteaux d'art au miel » [...depuis 1765...] a été, en fait, importée de Dinant en Belgique. » (Dupaigne 1979 : 157).

Août 1977 ; collecteur Bernard Dupaigne 
longueur $30 \mathrm{~cm}$ x largeur $19 \mathrm{~cm}$

MNHN-E-2009.4.15

60- Pain d'épice en biscuit

Figure 74 : Pain d'épices MNHN-E-2009.4.16

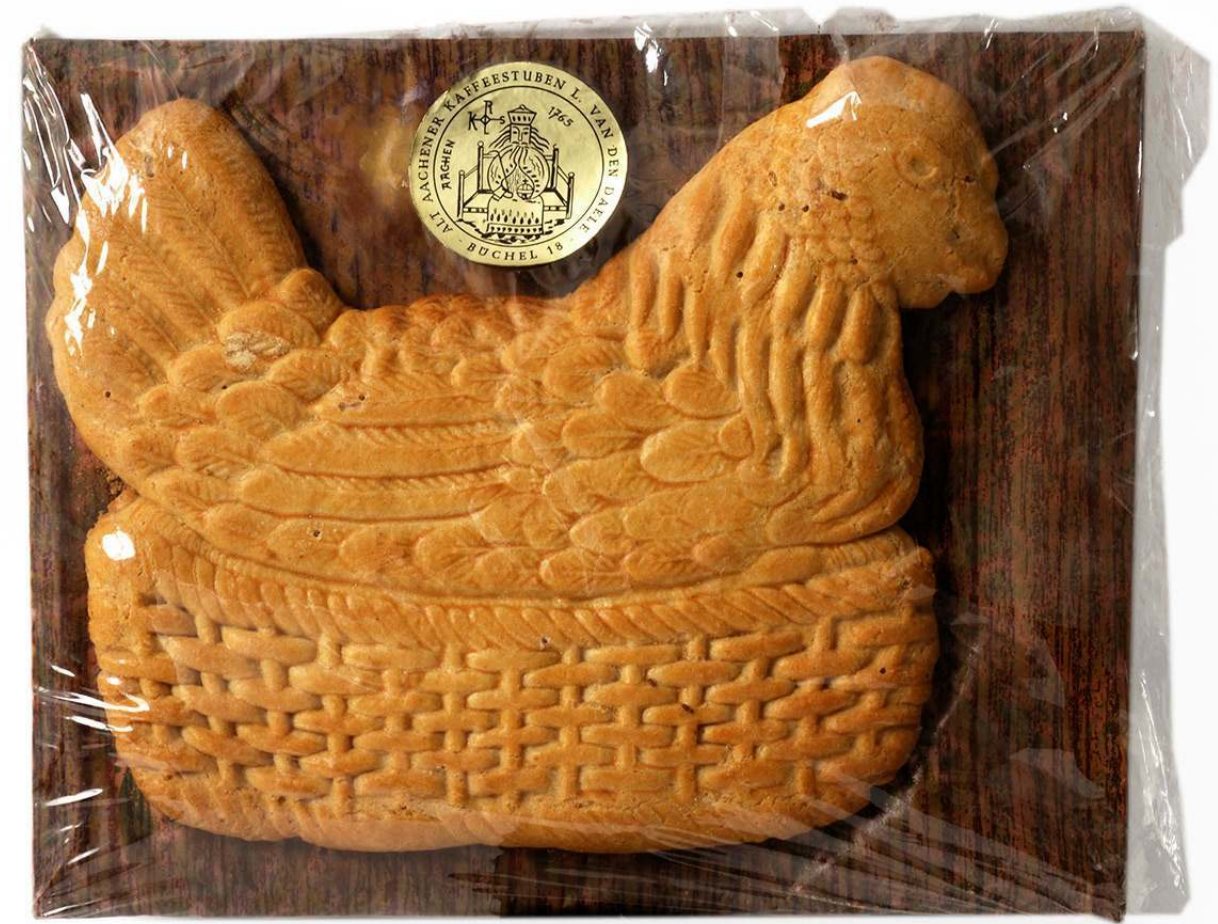

(c) J.-C. Domenech

Allemagne. Aix-la-Chapelle (Rhénanie du Nord-Wesphalie). Alt Aachener Kaffeestuben Van den Daele.

Biscuit en forme de poule couchée dans un panier tressé, moulé dans un moule de bois. Décor de petites et grandes plumes alternées depuis le cou jusqu'à la queue.

Août 1977 ; collecteur Bernard Dupaigne

longueur $23 \mathrm{~cm}$ x largeur $19 \mathrm{~cm}$ x épaisseur $2 \mathrm{~cm}$

MNHN-E-2009.4.16

61- Pain 


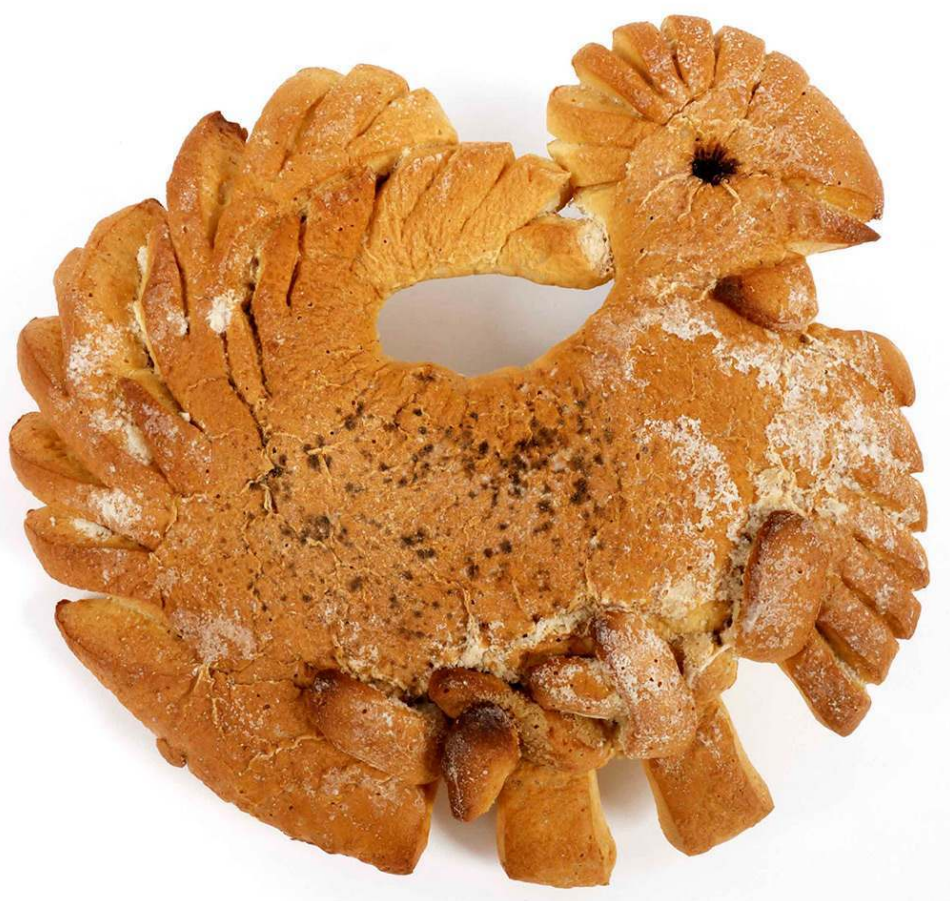

(C) J.-C. DOMENECH

Italie (Autriche). Klobenstein (Collalbo), Trentino-Süd Tirol (Bolzano). Boulangerie Treibenreif.

Biscuit en forme de poule. Associé à la mort ou au jour des Saints - pour la Toussaint, le parrain ou la marraine faisaient cadeau à sa filleule d'une poule, des pièces de monnaie étaient parfois insérées à la place des raisins secs pour illustrer les yeux. Pour le filleul, c'est un pain en forme de lièvre (Dupaigne 1979 : 94-96).

Août 1977 ; collecteur Bernard Dupaigne

longueur $30 \mathrm{~cm}$ x largeur $28 \mathrm{~cm}$ x épaisseur 7,5 cm MNHN-E-2009.4.6

\section{Poterie}

62- Pichet en forme de poule 


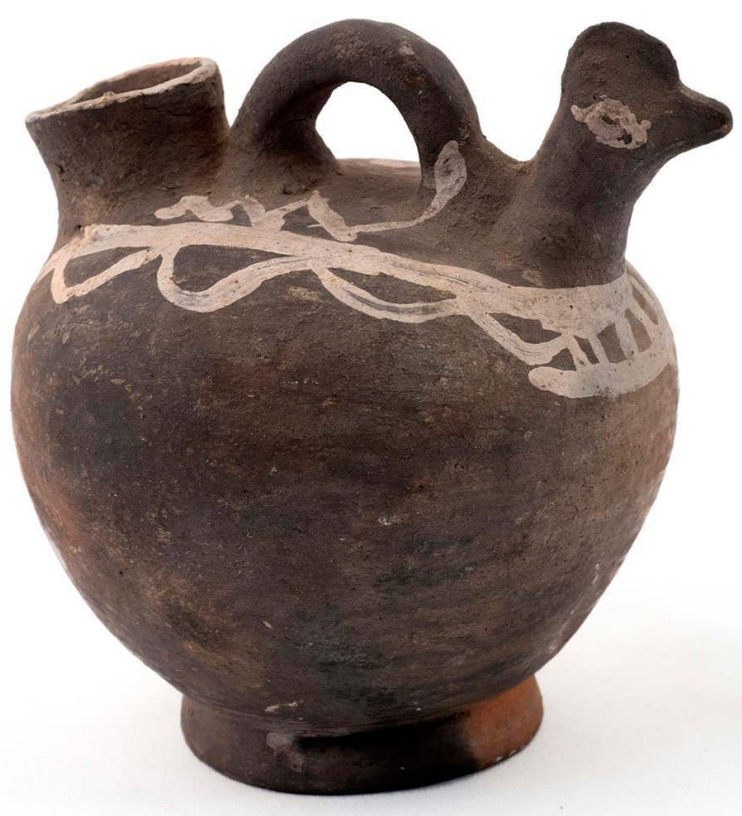

(c) J.-C. Domenech

171 Maghreb?

Pichet en terre cuite de forme sphéroïde avec pied, le dessus est constitué de trois parties, une tête d'oiseau modelé (poule), une anse horizontale, un goulot. Décor peint au trait blanc, plusieurs lignes en zigzag entourent les trois parties du dessus, points blancs sur la tête représentant les yeux. Un côté de la poterie est plus sombre que l'autre, traces noires de cuisson.

Ancienne collection de technologie comparée du Musée de l'Homme hauteur $11 \mathrm{~cm}$, diamètre à la base $5,5 \mathrm{~cm}$, diamètre à l'ouverture $2,5 \mathrm{~cm}$ MNHN-E-2009.30.21

\section{Liste des pays d'origine des objets}

Allemagne : pains, MNHN-E-2009.4.15, MNHN-E-2009.4.16

Burkina Faso : panier, MNHN-E-2011.12.2

Cambodge : panier, ETB-KH-BA-2015-001

Cameroun: tabliers de perles, MNHN-E-2008.2.143, MNHN-E-2008.2.144, MNHNE-2008.2.145, MNHN-E-2008.2.154

Chili (Rapa Nui): ornements, ETB-CL-JLL-2012-030, ETB-CL-JLL-2012-031, ETB-CLJLL-2012-032, ETB-CL-JLL-2012-034

Chine : autel funéraire, MNHN-E-2015.14.1 ; pendentifs zodiacaux, ETB-FR-SB-2017-003, ETBFR-SB-2017-004, ETB-FR-SB-2017-005 ; pochette brodée, MNHN.E.2011.9.101.2 
Colombie : maquette d'arène, ETB-CO-MCC-2017-001

Côte d'Ivoire : poids pour l'or, MNHN-E-2003.10.59, MNHN-E-2003.10.60

France : accessoires de coq, ETB-FR-RP-2012-001 ; plumeau, ETB-FR-RP-2011-062

Gabon : panier, ETB-GA-MR-2007-001

Guinée : panier, ETB-GN-RP-2017-001 ; tunique-amulette, MNHN-E-2002.37.1

Italie : pain, MNHN-E-2009.4.6

Japon: amulettes-zodiaque, ETB-FR-SB-2017-001, ETB-FR-SB-2017-002 ; pince, ETB-FRSB-2007-001

Libéria : fer à repasser, MNHN-E-2013.14.8 ; paniers, MNHN-E-2013.1.43, MNHN-E-2014.9.6

Maghreb ? : pichet, MNHN-E-2009.30.21

Mexique : accessoires de coq de combat, ETB-MX-FA-2009-011, ETB-MX-SB-2010A-033, ETBMX-SBPR-2017-50, ETB-MX-SBPR-2017-59 ; boucles d'oreille, ETB-MX-SBPR-2017-10 ; ex-voto , ETB-MX-SB-2013-050 ; figurine de coqs, ETB-MX-PR-2017-001 ; laisse pour coq, ETB-MXSBPR-2017-51 ; ceillères, ETB-MX-SB-2010A-032 ; offrandes, ETB-MX-SB-2011-11 ; plumeaux, ETB-MX-SB-2012-041, ETB-MX-SB-2012-042

Papouasie-Nouvelle Guinée : filets de portage, MNHN-E-2012.1.27, MNHN-E-2012.1.38

Roumanie : fouet à œuf, ETB-RO-PL-2015-001; œuf de Pâques, ETB-RO-PL-2015-002

Russie : seau d'écorce, MNHN-E-2010.7.14

Sénégal: amulettes, ALEP00175, ALEP07008, ALEP35113a, ALEP35113b, ALEP40067, ALEP45104

Togo : amulette, ALEP10505

Ukraine: ceufs de Pâques, MNHN-E-2013.15.7, MNHN-E-2013.15.8, MNHN-E-2013.15.9, MNHN-E-2013.15.10, MNHN-E-2013.15.11, MNHN-E-2013.15.12, MNHN-E-2014.8.13

Vanuatu: masques, MNHN-E-2013.5.32, MNHN-E-2013.5.37; parures de tête, MNHNE-2009.14.1, MNHN-E-2013.5.5

Viet Nam : xylogravures, ETB-VN-ETB-2017-1

Yougoslavie (ex) : tissu brodé, MNHN-E-2011.10.25

\section{BIBLIOGRAPHIE}

Bahuchet S., Kozlowski V., Merlin M. \& Parent A. 2016 - Exposer l'Ethnoécologie au Musée de l'Homme. Revue d'ethnoécologie [En ligne], 9 | 2016, URL : http://ethnoecologie.revues.org/2600 ; DOI : 10.4000/ethnoecologie.2600, consulté le 02 décembre 2017.

Bahuchet S. \& Rameau P. 2016 - Quelques engins de pêche en eau douce d'Afrique centrale. Revue d'ethnoécologie [En ligne], 10 | 2016 URL : http://ethnoecologie.revues.org/2877 ; DOI : 10.4000/ ethnoecologie.2877, consulté le 29 novembre 2017. 
Blanc N. 2017 - Pullus, gallus et gallina : déclinaisons antiques. Revue d'ethnoécologie [En ligne], 12 | 2017 URL : http://ethnoecologie.revues.org/3264, consulté le 29 novembre 2017.

Bruneau P. 1965 - Le motif des coqs affrontés dans l'imagerie antique. Bulletin de correspondance hellénique 89 (1) : 90-121.

Buffon G. de 1771 - Histoire naturelle des oiseaux. Tome XVII de l'Histoire naturelle.

Cegarra M. 1988 - Les coqs combattants. Terrain 10 : 51-62.

Cegarra M. 1992 - Les fils du sang. Coqs combattants du Nord. Luneray, Bertout, 153 p.

Comentale C. 2015 - Autel funéraire Ming (XVII ${ }^{\mathrm{e}}$ siècle), province du Henan. Lettre de la Société des Amis du Musée de l'Homme, septembre $81: 1$.

Cretin N. 1999 - Fêtes et traditions occidentales. Paris, PUF, 128 p. (Que sais-je ? : 3518).

De Witte J. 1868 - Le génie des combats de coqs. Revue Archéologique 17 : 372-381.

Danaë O. 1989 - Combats de coqs. Histoire et actualité de l'oiseau guerrier. Paris, L'harmattan, 254 p.

Dupaigne B., 1979 - Le pain. Éditions la Courtille, 208 p.

Epelboin A. 2017 - Cornes, bobinages, nouages et cadenas de la collection ALEP : amulettes et objets magiques collectés dans les ordures du Sénégal. In : Peiry L. (Ed.) Inextricabilia. Enchevêtrements magiques. Paris, la maison rouge/Flammarion : 178-183.

Epelboin A., Hamès C. et al. 2014 - Collection ALEP : amulettes et objets magiques collectés dans les ordures (Mbebess Joal, Mbour, Sénégal, Afrique, Europe) 1983-2014. Catalogue multimédia de l'exposition « Arts secrets : les écritures talismaniques d'Afrique de l'Ouest », IMA, Tourcoing. 788 p., 130 MO, [en ligne] URL : https://hal.archives-ouvertes.fr/hal-01081672/document Finsterbusch C.A. 1929 - Cock fighting all over the world. Gaffney, Grit \& Steel, 471 p.

Kirch P.V. 1980 - Polynesian Prehistory: Cultural Adaptation in Island Ecosystems: Oceanic islands serve as archaeological laboratories for studying the complex dialectic between human populations and their environments. American Scientist 68 (1) : 39-4.

Lacroix-Danliard 1891 - La plume des oiseaux. Paris, Baillière, 368 p.

Matras-Troubetzkoy J. 1983 - Un village en forêt. L'essartage chez les Brou du Cambodge. Paris, SELAF, $430 \mathrm{p}$.

Newall V. 1965 - Decorated eggs. Folklore 76 (4) : 266-272.

Qu L.J., Li X.Y. \& Yang N. 2009 - Genetic relationships among different breeds of Chinese gamecocks revealed by mtDNA variation. Asian-Aust. J. Anim. Sci. 22 (8) : 1085-1090.

Storey A.A., Ladefoged T. \& Matisoo-Smith E.A. 2008 - Counting Your Chickens: Density and Distribution of Chicken Remains in Archaeological Sites of Oceania. Int. J. Osteoarchaeol. 18 : 240-261.

Storey A.A., Quiroz D., Beavan N. \& Matisoo-Smith E.A. 2011 - Pre-Columbian chickens of the Americas: A critical review of the hypotheses and evidence for their origins. Rapa Nui Journal 25 (2) : 5-19.

Storey A.A., Athens JS, Bryant D, Carson M, Emery K. et al. 2012 - Investigating the Global Dispersal of Chickens in Prehistory Using Ancient Mitochondrial DNA Signatures. PLoS ONE 7 (7) : e39171. doi:10.1371/journal.pone.0039171

Storey A.A., Quiroz D., Beavan N. \& Matisoo-Smith E. A. 2013 - Polynesian chickens in the New World: A detailed application of a commensal approach. Archaeology in Oceania 48 : 101-119 
Trang B.T.N. \& Kim Y.S. 2015 - Reservation and development of Vietnamese Dong Ho folk painting. Int. J. Social Science and Management 2 (2) : 157-164.

Vargas A.D. 1983 - El gallo de combate. Mexico, Diana, 296 p.

\section{NOTES}

1. Les collections d'ethnologie résultent des activités des chercheurs du MNHN à partir de 2002. En effet, on rappellera que les collections non-européennes du laboratoire d'ethnologie antérieures à 2002 ont été transférées au Musée du quai Branly-Jacques Chirac, où elles sont désormais conservées. Les collections européennes ont ensuite été déposées au MUCEM (Musée des civilisations de l'Europe et de la Méditerranée) à Marseille en 2005 (voir Bahuchet et al. 2016).

2. Informations communiquées par Alain Epelboin (CNRS-MNHN).

3. Informations communiquées par Alain Thote (EHESS).

\section{AUTEURS}

\section{PAULINE RAMEAU}

Chercheur associée et assistante de gestion des collections d'ethnobiologie, laboratoire Ecoanthropologie et ethnobiologie (MNHN-CNRS-Paris Diderot)

\section{DELPHINE BRABANT}

Technicienne des collections d'ethnologie, direction des collections (MNHN)

\section{SERGE BAHUCHET}

Professeur d'ethnobiologie du Muséum, laboratoire Eco-anthropologie et ethnobiologie et responsable scientifique des collections d'anthropologie biologiques et culturelles (MNHN-CNRSParis Diderot) 